
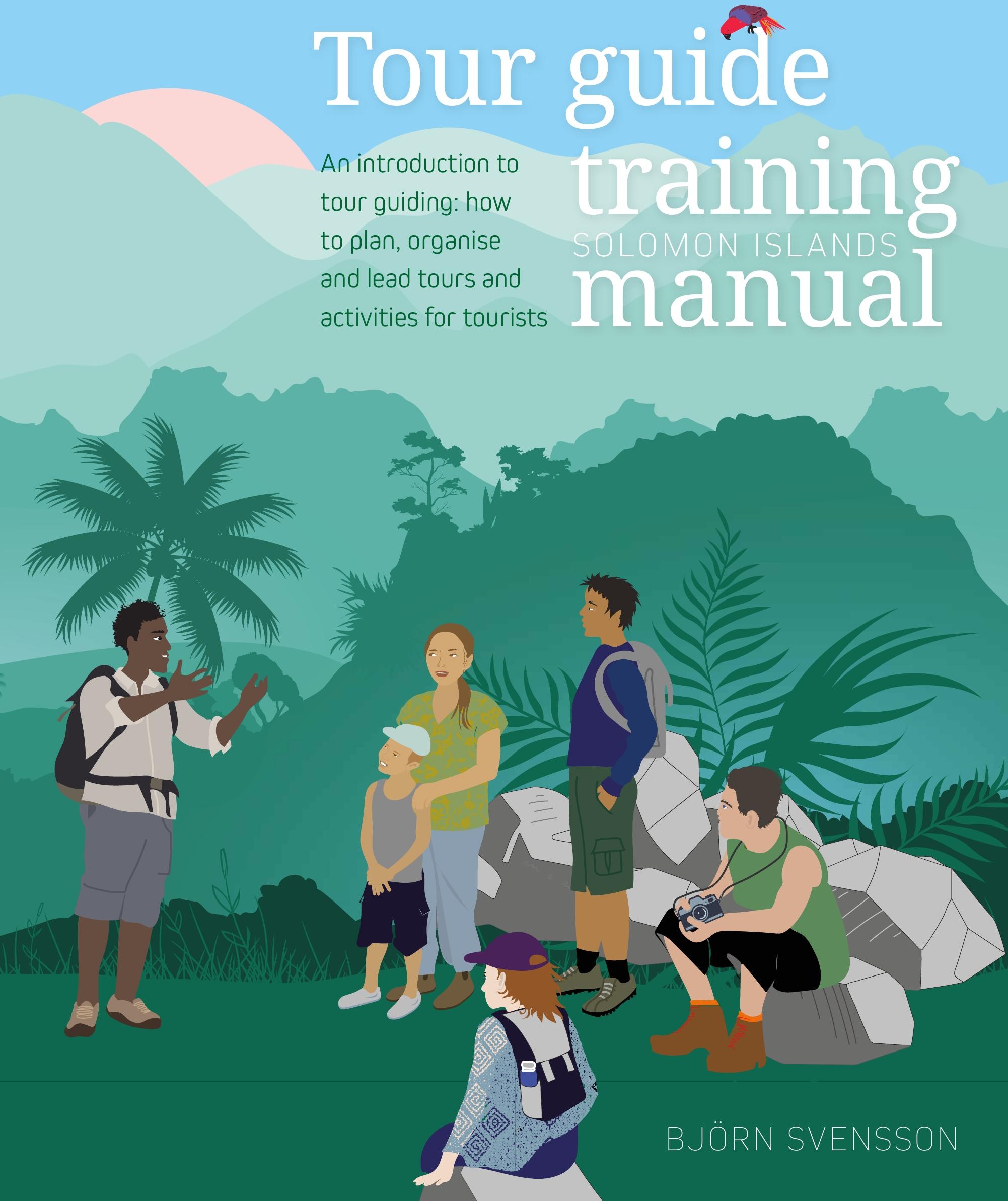



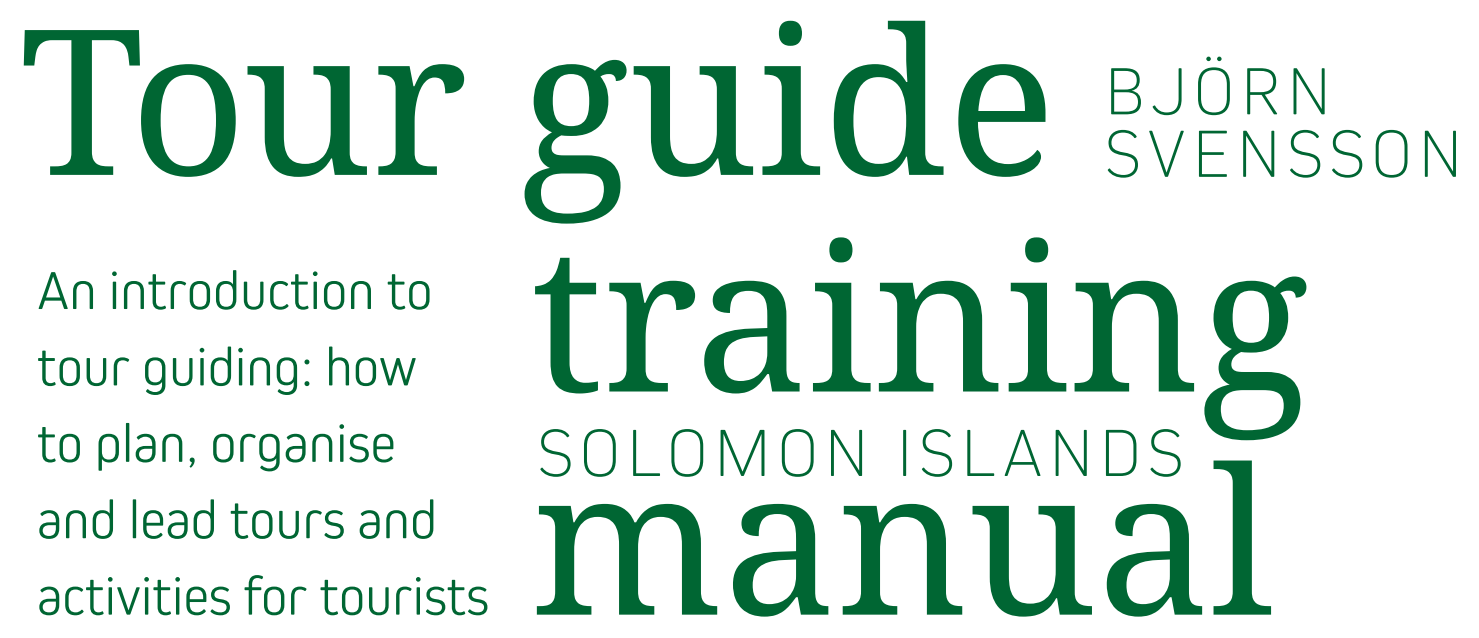



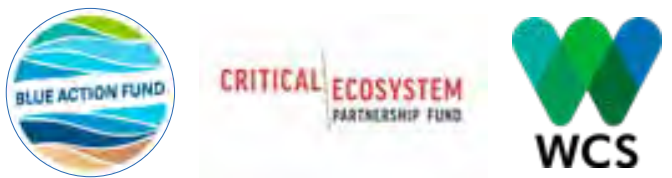

ISBN-13: 978-0-9903852-7-1

This training manual was supported by grant from the Blue Action Fund and Critical Ecosystem Partnership Fund.

The Critical Ecosystem Partnership Fund is a joint initiative of L'Agence Française de Développement, Conservation International, the European Union, the Global Environment Facility, the Government of Japan, the MacArthur Foundation and the World Bank. A fundamental goal is to ensure civil society is engaged in biodiversity conservation.

Copyright (c) 2022 Wildlife Conservation Society

Reproduction of this publication for educational or other non-commercial purposes is authorized without prior written permission from the copyright holder provided that the source is fully acknowledged. Reproduction of this publication for resale or other commercial purposes is prohibited without prior written consent of the copyright owner.

Suggested citation Svensson, B (2022) Tour guide training manual - Solomon Islands. Wildlife Conservation Society, Munda.

https://doi.org/10.19121/2022.Report.43122

Illustrations $@$ Julie Sauerwein, Little by little studio

Layout and design Little by little studio

Author Björn Svensson

Editor Michelle Talemaitoga, Write Right Fiji

Technical edits Robert Howard and Alec Hughes, Wildlife Conservation Society 


\section{m. Acknowledgements}

This training manual is structured in a similar way to tour guide training courses in other countries, such as the Australian Certificate III in Guiding. It is also based on the author's experiences as a tour guide, tourism adviser and a perpetual tourist. To ensure that the training is relevant to a Solomon Islands context, local guides were consulted in a series of in-depth interviews. Some of the most experienced guides in Solomon Islands, with a combined working experience of over 150 years, were interviewed. Without their feedback this training manual would look very different.

Many thanks to Christopher Maelaua, Destination Solomons; Barny Paulsen, Peter Joseph WWII Museum; Billy Kera, Go West Tours; Francis Deve, Pure Solomon Tours; Debbie Lukisi, Suboko Bush Trekking; Tumi Ben, Tetepare Ecolodge; Jeffrey Tafoleh, Travel Solomons; Zenno Entrikin-Hughes, Zipolo Habu Resort; Sunga Boso, Dive Munda; Shona Fafale. Travel Solomons. Two groups of guides working in Tetepare and Kolombangara conservation areas were also interviewed.

Many organisations have developed excellent guide training material that was used as inspiration during the development of this manual. They are listed under sources in the appendix.

The author wished to thank the Wildlife Conservation Society team based in Munda for providing logistical support, inspiration and feedback during the project: Dr Alec Hughes, Tingo Leve, Dolrish Leimah and Dovena Barai. 


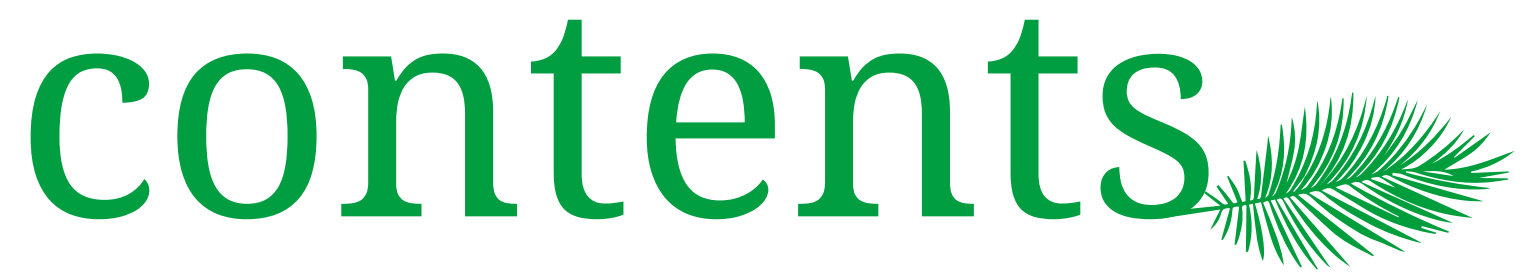

Acknowledgements $\quad 5$

$\begin{array}{ll}\text { Contents } & 6\end{array}$

$\begin{array}{ll}\text { Introduction } & 7\end{array}$

1. INTRODUCTION TO TOURISM 8

Tourism in Solomon Islands 9

$\begin{array}{ll}\text { Tourism niches } & 12\end{array}$

2. INTRODUCTION TO TOUR GUIDING 14

Different types of guides 16

Tour guide roles \& responsibilities $\quad 18$

Tour guide conduct $\quad 22$

3. TOUR GUIDE KNOWLEDGE 24

Local environment 25

Local culture and history $\quad 27$

Contemporary life $\quad 30$

4. TOUR COMMENTARY 34

Interpretation $\quad 35$

Plan and develop tour commentary 36

Guiding tools $\quad 40$

5. TOURS AND ACTIVITIES 42

Tour structure $\quad 43$

Managing activities $\quad 49$

Wildlife viewing $\quad 55$

6. TOUR MANAGEMENT 58

Tour guide leadership $\quad 60$

Facilitating a group $\quad 60$

Kastom fees and access $\quad 64$

7. TOUR SAFETY \& RISK MANAGEMENT 68

Safety planning $\quad 70$

Common injuries and health issues on tour $\quad 74$

$\begin{array}{ll}\text { Dealing with emergencies } & 76\end{array}$

CONCLUSION: WORKING AS A TOUR GUIDE 78

Appendix $\quad 82$

Tourism code of practice $\quad 83$

$\begin{array}{ll}\text { Tour and activity planner } & 85\end{array}$

Resources for tour guide subject knowledge $\quad 86$ 


\section{Introduction}

Tour guides play a crucial role in tourism and are often described as hosts and

ambassadors of the destination. Of all the people working in tourism, local

guides spend the most time interacting with tourists. This means the visitor's

experiences and impressions are largely shaped by the tour guide.

Tourists come to Solomon Islands to experience what is interesting and unique about this country. For some, it may be the underwater world, or the colourful birds. For others, it may be the traditional culture or World War II history. Tourists' experiences can be enhanced by well-trained tour guides. Since the reason tourists come is for the experiences, tour guides are some of the most important people in the tourism sector. If experiences and activities are not interesting or are delivered unprofessionally, tourists would stop coming. Any destination that strives to have a successful tourism sector should focus on developing unique experiences led by well-trained tour guides.

This manual outline basic guiding skills for those starting out as guides, or those who guide tourists as part of their w ork. This may be staff from resorts, or rangers working in conservation areas. It explains the role of the tour guide and the tools and techniques used. It does not include the subject knowledge a guide needs but focuses on how to develop and guide tours.

This manual is based on established guide training from other countries and the experiences of professional tour guides, both overseas and in Solomon Islands. Many great guides have not had formal training, they just happened to have the right personality and passion for the job. This manual, and associated training, combines the key components of formal guide training with real-life experiences from the field. The goal is to prepare new guides with skills that are relevant to tour guiding in Solomon Islands.

This manual can be used as a separate source of reference for tour guides. During workshops, the manual accompanies a Tour guide trainee workbook.

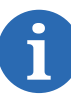

During the development of this training, some of the most experienced tour guides in Solomon Islands were interviewed. Many of them are also senior guides who supervise and train new guides. Their thoughts on tour guiding and examples of situations they have faced can be found throughout this text by following the Guide stories icon. 


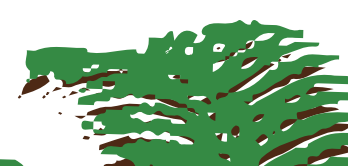

Whym

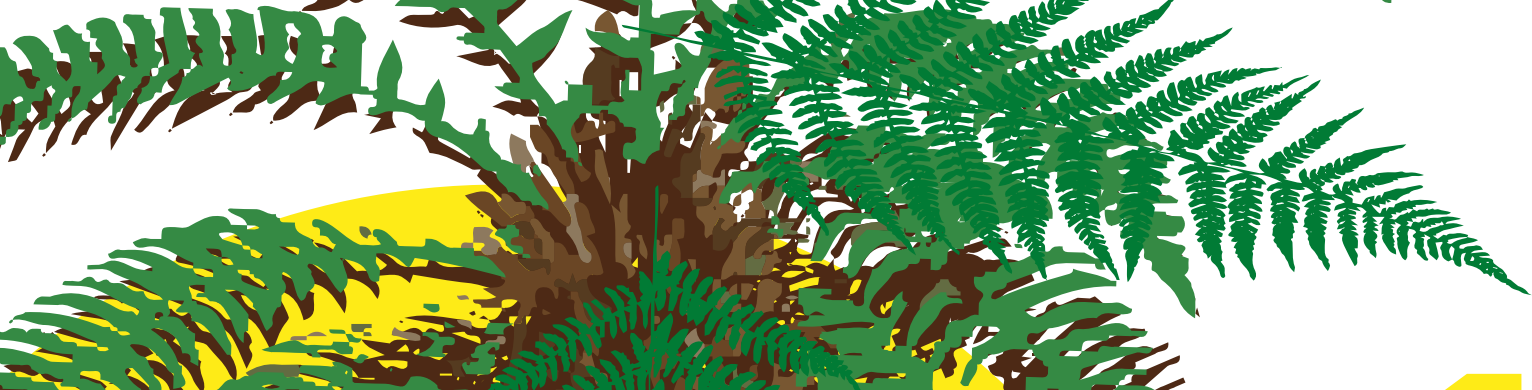
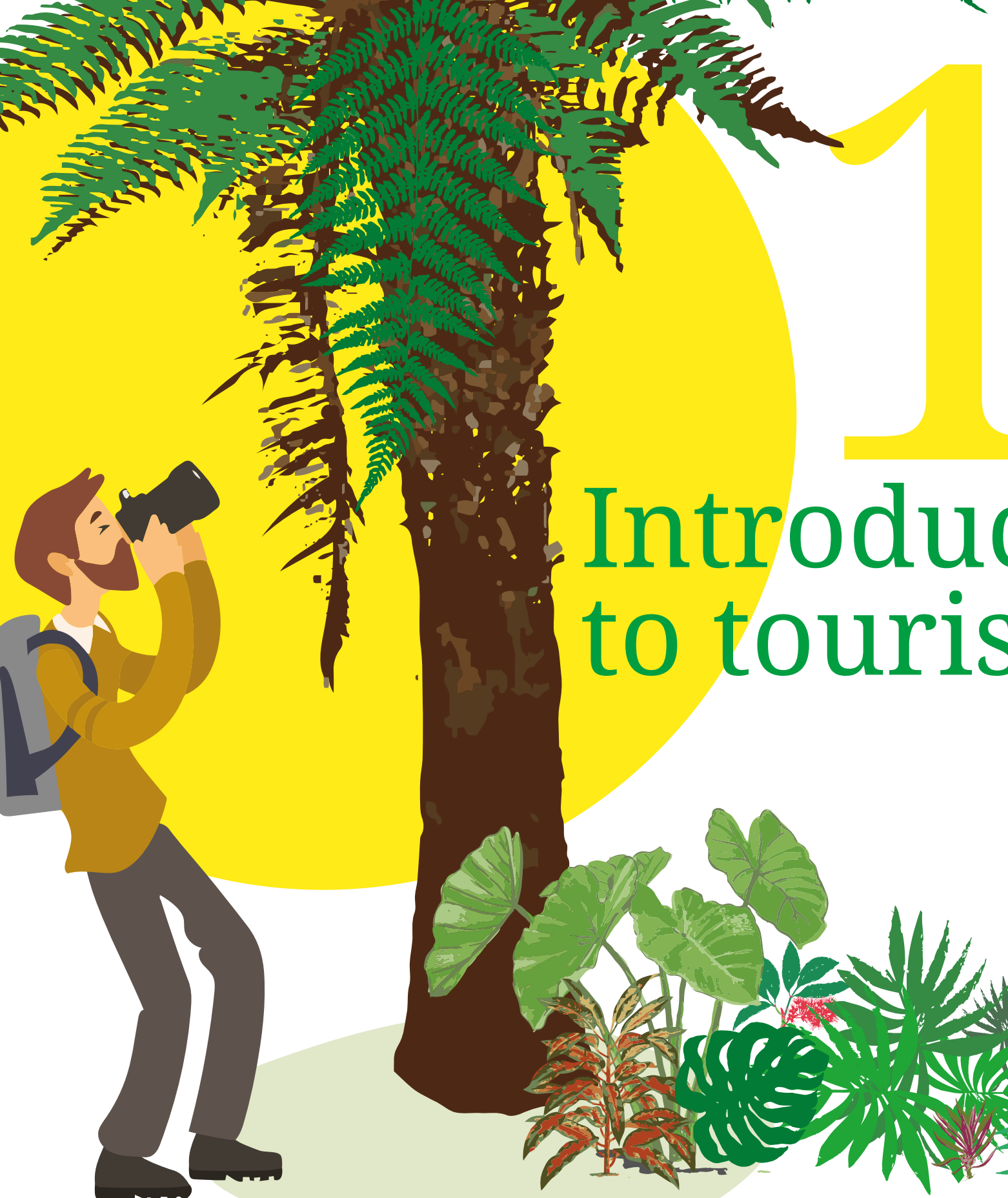
There are many reasons why people travel. It is mainly about getting away from everyday life and experiencing something different. For some people this means relaxing in a hammock on a beach. For others, it might mean hiking in the jungle. Different destinations attract different types of tourists depending on what they have to offer.

Today there are millions of international tourists, and the numbers are growing every year. Tourism is important for the economy of many countries. It is estimated that one in ten jobs worldwide is linked to tourism. In some countries, like Fiji or Maldives, tourism is the largest source of revenue and jobs. This economic sector is the Tourism Industry. There are many different jobs within this industry.

- Hospitality

Jobs at hotels and restaurants - receptionists, cleaners, cooks and waiters.

- Transport

Jobs involving the transportation of tourists - pilots, bus drivers and boat drivers.

- Tours and activities

Jobs that involve taking visitors on tours and activities, for example, tour guides or dive guides.

A healthy tourism sector also creates supporting jobs in construction and agriculture.

Some destinations are known for great hospitality with top hotels and restaurants. Other destinations are popular for their outdoor experiences and wildlife. Some focus on an activity like surfing or diving.

\begin{tabular}{|c|c|c|c|c|}
\hline France & Singapore & Kenya & Austria & Hawaii \\
\hline Food \& Wine & Shopping & Wildlife & Skiing & Surfing \\
\hline
\end{tabular}

Disruptions in international travel caused by events like natural disasters or conflict make the industry vulnerable. The Covid-19 pandemic is the worst challenge that tourism has ever faced. History shows that tourism is resilient and can bounce back quickly. Many places that have faced major disasters or wars have recovered and are now popular tourism destinations.

\section{TOURISM IN SOLOMON ISLANDS}

There is a small yet well-established tourism industry in Solomon Islands. Up until the outbreak of Covid-19, visitor arrivals were increasing each year. Solomon Islands has an abundance of drawcards to attract tourists: our unique culture, friendly people, beautiful tropical islands and amazing marine life. If tourism is developed and managed well, it can grow and offer many benefits for the people of Solomon Islands. The government has high hopes for tourism and sees it as one of the economic activities to replace logging as a source of revenue.

Destinations compete with each other to attract tourists because it brings benefits to a country. Solomon Islands competes with other Pacific countries: mainly Vanuatu, Fiji and Papua New Guinea, but also Samoa, Tonga and New Caledonia. Our tourism sector is small. By comparison, before the outbreak of Covid-19, Fiji had more than 30 times as many visitors as Solomon Islands; Vanuatu had four times more.

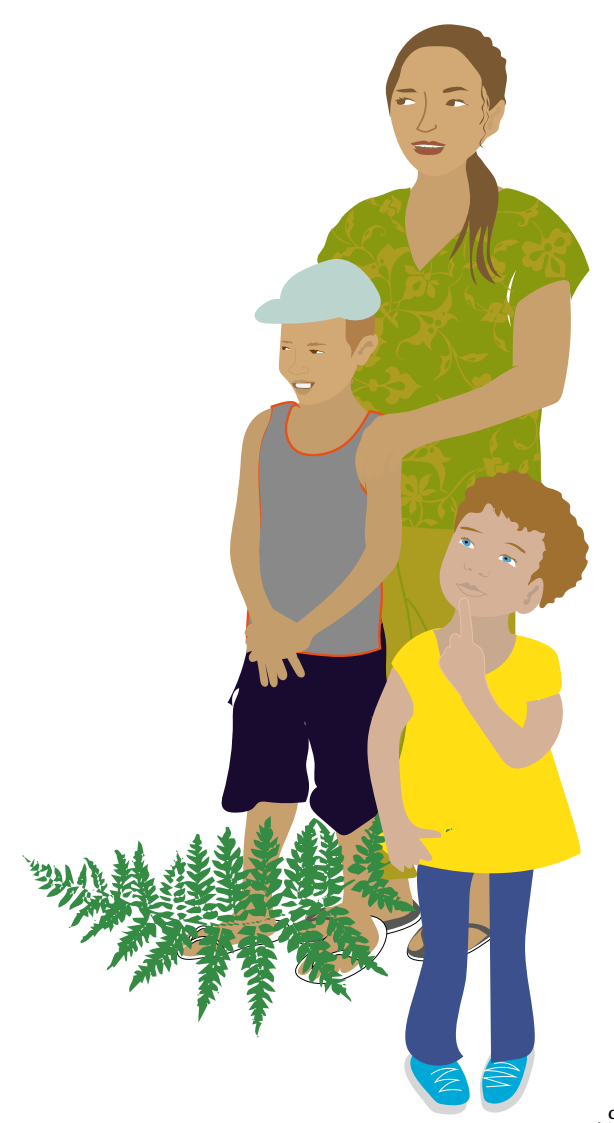


Several experiences and activities on offer here are world-class, which is a great foundation to develop the destination. Without local guides, experiences such as birdwatching, visiting WWII battlefields or scenic waterfalls would not be possible.

Tourists also consider other factors such as the cost or how far away it is. Here are some pros and cons that affect tourism in Solomon Islands.

\section{Pros}

- English - One advantage is that the majority of local people speak English.

- Uncrowded - Many popular tourism destinations have become overcrowded. Tourists look for quieter destinations like Solomon Islands.

\section{Cons}

- Expensive - Solomon Islands is an expensive destination. The cost of transport, accommodation and food is higher than most destinations in the Asia-Pacific region.

- Low standards - Even though prices are high the quality in accommodation, food, and tourist services is often low.
"There are some common likes and dislikes for tourists. all of them like seeing wildlife, and all of them dislike dirty toilets. But guest satisfaction also comes down to their particular interest: birdwatchers who see a rare bird are very happy, but that might not mean anything to other tourists."

\section{Tourists likes and distikes}

This list is based on interviews with professional tour guides in Solomon Islands.

\section{Tourists' like}

- Visiting markets and seeing fresh local produce and seafood.

- Seeing marine life like dugongs and turtles, and especially dolphins next to the boat.

- Visiting beautiful, peaceful and natural places like a beach, a lookout or a waterfall.

- Taking photos of scenery and people. Capturing memories.

- When they have a knowledgeable and friendly guide or driver.

- Exciting activities like turtle tagging or snorkeling.

- When the weather is superb, with calm water and blue sky.

- Seeing or doing what they don't have or can't see at home.

- Meeting smiling, friendly locals.

- Learning about our kastom: visiting sites, traditional villages and hearing stories.

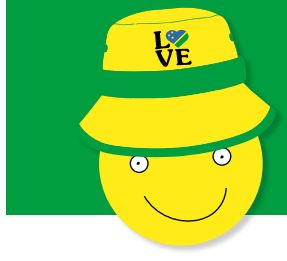

\section{Tourists' dislike}

- If an activity is too hard, like a walk that is longer and harder than they expected.

- The bad state of our infrastructure: public toilets, roads, airports and ferries.

- Bad weather and when tours become uncomfortable, or cancelled.

- When the briefing doesn't match the experience; for example, going fishing and not catching a fish.

- The dust, betel nut spit, garbage and drunkards.

- When tours are delayed, especially if the guide shows up late or is ill-prepared.

- If the guide is passive, not engaging, or lacks knowledge.

- Annoying or dangerous animals - fire ants, mosquitoes, centipedes, crocodiles or sharks.

- Animal cruelty. Seeing sick and skinny stray dogs, or people being cruel to dogs.

- Bad service or low standards (not limited to the tourism sector).

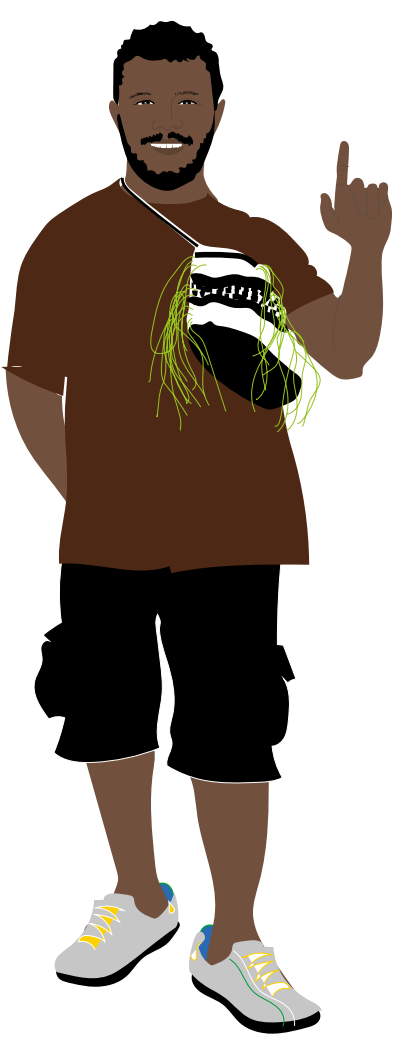




\section{TOURISM NICHES}

One reason people go on holiday is to relax and enjoy themselves, this is leisure tourism. Increasingly people want to be active when they travel, to have different experiences from their daily life. This is the primary type of tourists who come here. Tourism aimed at people with special interests are tourism niches. Diving, surfing and fishing are examples of popular tourism niches that exist here. To pursue their passion, people can spend a lot of time and money, to do so. The tourism niche of scuba diving is in the Western Province where there are several operators catering for divers.

Here is an overview of some of our popular tourism niches:

\section{- Adventure tourism}

Adventure tourists like to explore new places and take part in exciting activities. They don't mind if the activity is physical and has a bit of risk. Common adventure activities include trekking, mountain biking or travelling to remote and undeveloped areas. Comfort is not the most important thing; the experience and the thrill of the adventure is. Some adventure activities require special skills and equipment, like kayaking, scuba diving and mountain climbing. Many organised tours are classified as soft adventure tours that offer a range of activities. They are comfortable but may also include a night in a village stay or camping for a night or two. Soft adventure tours often include bushwalking and snorkeling combined with cultural experiences, like visits to kastom sites or local villages.

\section{- Cultural tourism}

Cultural tourism is for those who want to experience the lifestyle and culture of locals. Culture includes language, music, food, traditions, architecture, art and more. Our kastom sites such as skull shrines or rock carvings are cultural and unique. Demonstrations of canoe building or traditional fishing are also popular. Resorts and lodges organise cultural dances and musical performances for their guests. It could be listening to kastom stories or staying in a village to experience local life.

One niche in cultural tourism focuses on history. Known as heritage tourism it includes war history. In many countries specially trained guides show tourists battlefields and war relics, while telling stories from the war. WWII battlefield touring is a promising tourism niche here since Solomon Islands has some of the most famous battlefield sites in the world.

\section{- Nature tourism}

Nature tourism is a very popular niche. Today many people live in urban areas and don't have the chance to experience nature in their daily life, so they want to experience it on their holidays. Nature-based activities are wildlife-watching, bush walking, jungle tours, snorkeling, etc. When the tourists' motivation is to appreciate and enjoy nature, this is classified as nature tourism. There are sub-niches that are even more specialized.

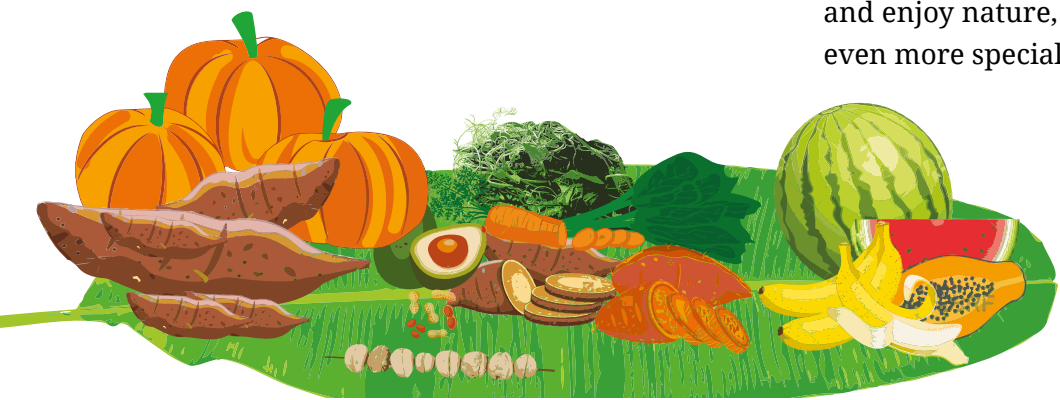

- $\quad$ Bird watching - Birdwatchers travel to see unique birds. Solomon Islands has a lot of endemic birds (species that are found in a specific area and nowhere else) which is very interesting for birdwatchers. Papua New Guinea is one of the best countries in the world for birdwatching. It has a large number of endemic species. 
- Nature photography - This niche is further divided into wildlife photography and landscape photography. Tours can focus on these special interest groups. In Kenya and Tanzania, the wildlife photography niche attracts tens of thousands of visitors every year.

- Species-specific travel - Tourists who travel to view a specific species. Some tour operators have developed special interest tours for:

+ Mountain gorilla tours in Rwanda, Africa.

+ Swimming with Southern humpback whales in Tonga, South Pacific.

+ Wild orchid treks in Peru, South America.

In Solomon Islands, we have the potential to develop leatherback turtle tours.

\section{- Ecotourism}

Ecotourism goes deeper than nature tourism. The International Ecotourism Society (TIES) defines ecotourism as 'responsible travel to natural areas that conserve the environment, sustains the well-being of the local people and involves interpretation and education'. A lot of ecotourism happens in protected areas, such as national parks.

Eco guides have good knowledge about local flora and fauna. It is important that tourism activities are sustainable and don't have negative environmental or social impacts. A portion of the income generated from ecotourism usually goes back to fund conservation or to assist local communities. Some ecotourism destinations here are Tetepare, Arnavons and Kolombangara. Ecotourism is not limited to protected areas. Interesting ecotourism tours can be in any natural area. Eco guides with good knowledge of the natural environment are sometimes called naturalist guides.

\section{- Cruise tourism}

Cruise tourism is a small but growing niche for Solomon Islands. There are different types of cruise ships. The big ships with over 1000 passengers focus on onboard activities and have fewer stops. These big cruise ships usually only stop in Honiara and Gizo. The smaller ships, with around 100 passengers are called expedition cruise ships. They focus on in-depth experiences of the nature and culture of the places they visit. Highly trained guides offer lots of activities such as village visits, cultural shows, birdwatching, etc. These ships do not need a port. They can visit remote places like Marau Sound on Guadalcanal or Marovo lagoon in Western Province. Local tour guides are often hired to assist the onboard guides.

While many tourists focus on a particular activity, it's common for tourists to take part in several activities. Someone who travels mainly to scuba dive may also go surfing or join a cultural tour. A tourism destination needs to cater to a variety of niches and offer a range of activities to be successful. The key to offering successful niche tourism is to have well-trained guides.
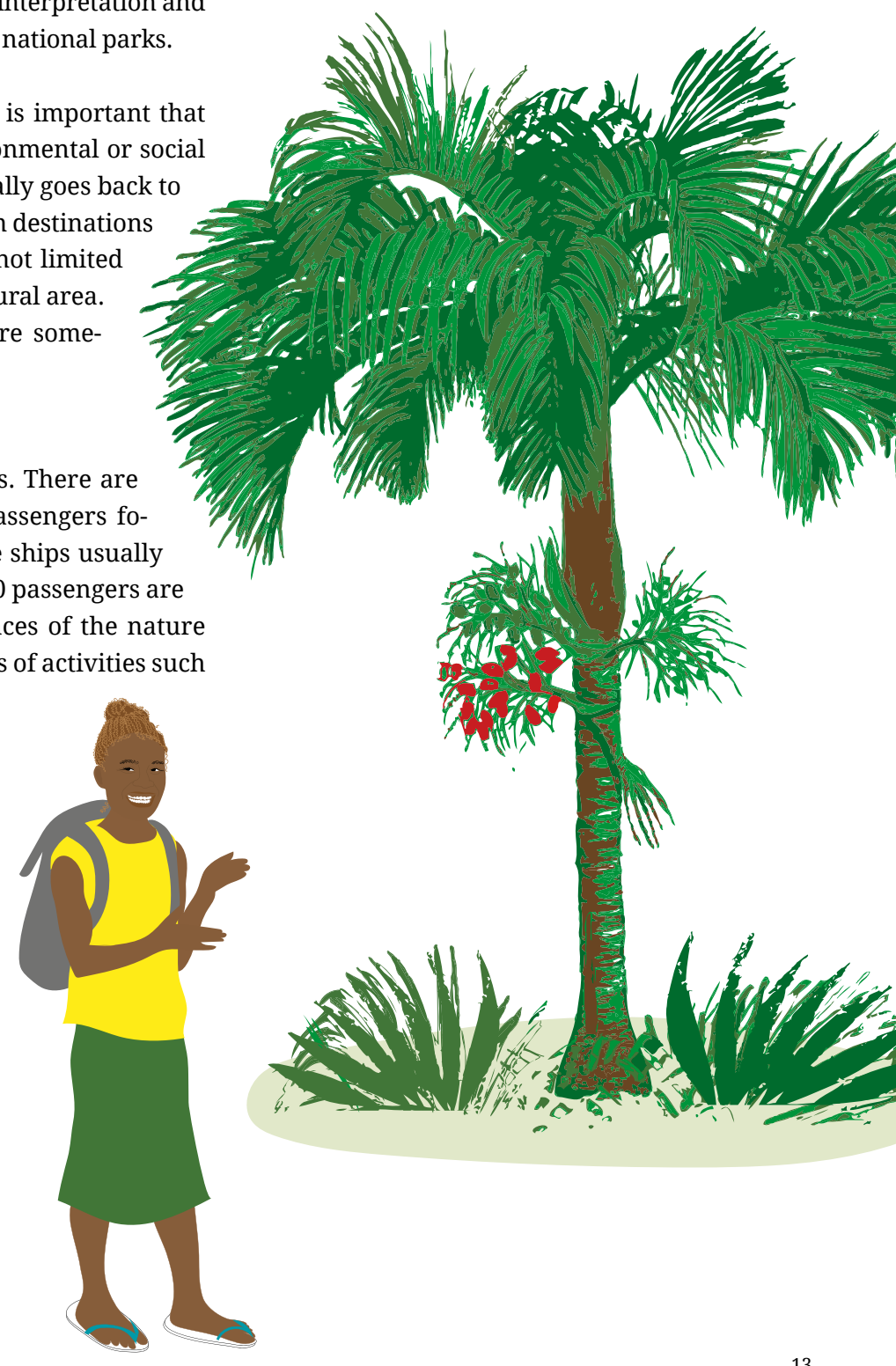


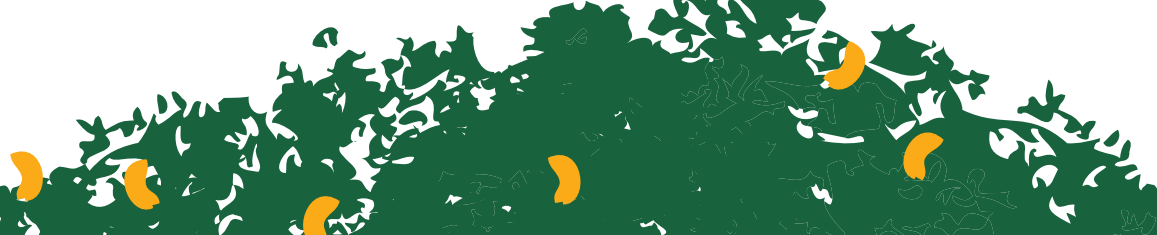

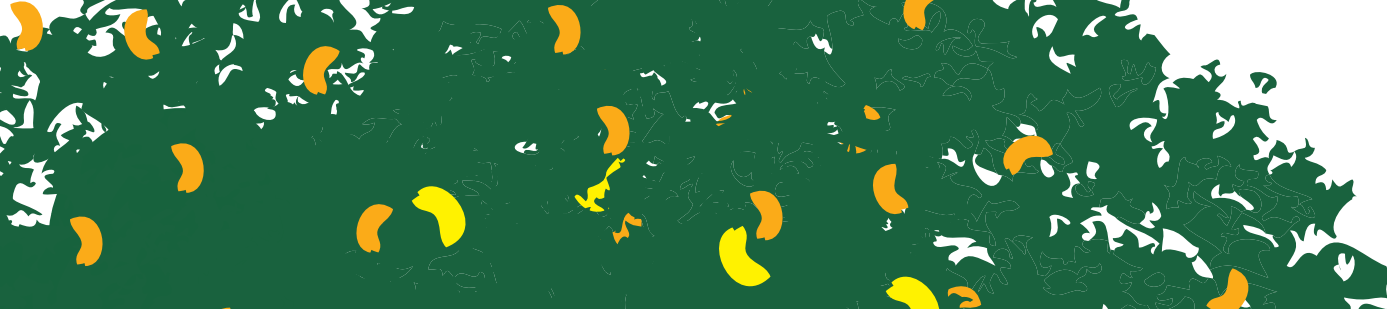

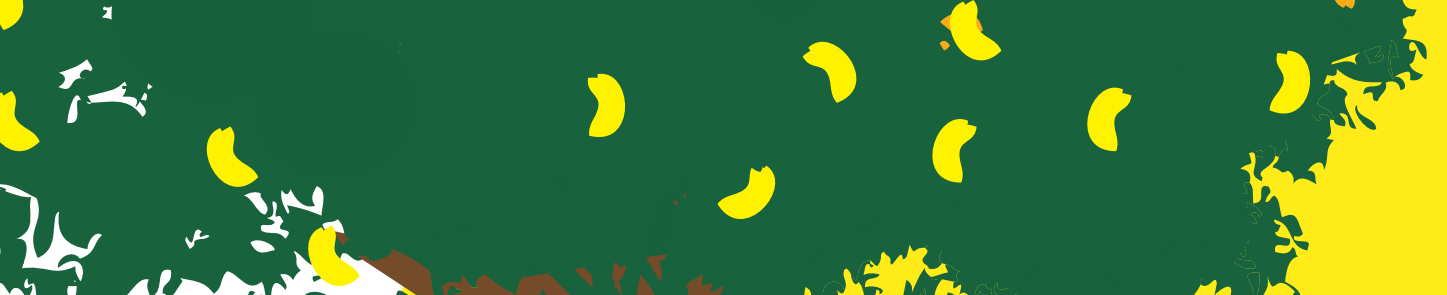

and 


\section{Introduction to tour guiding}

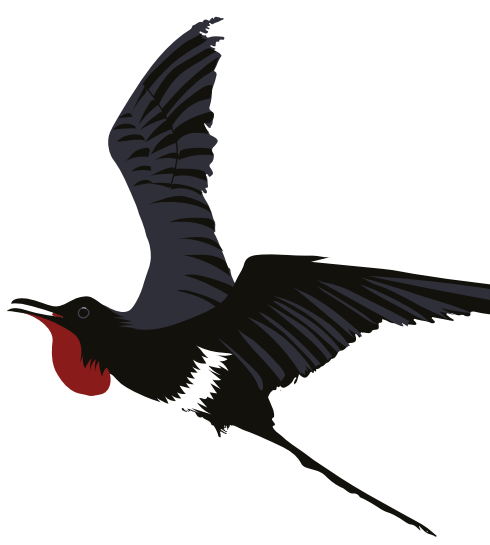

The role of a tour guide is to help visitors experience the best of what the destination has to offer. You will lead tours and activities as well as share stories about your country. As a local guide, you can show tourists a side of Solomon Islands that they wouldn't see or fully understand on their own. Your role is crucial in helping tourists have a good time. A good guide can enhance the tourists' experience and create memories that will last a lifetime.

\section{Why I like working as a tour guide}

Experienced local guides were asked what they like about working as a guide. The most common answer was that they like meeting people from all over the world.

- Guiding is fun, I meet lots of interesting people from all walks of life that I wouldn't have met otherwise.

- I get to meet people from all over the world, and learn things about different cultures.

Many guides also said that working with tourists has increased their pride in their country.

- I like being a host and promoting Solomon Islands.

- I really enjoy showing tourists around and sharing our stories.

- Guiding makes me proud of being a Solomon Islander. The longer I guide the more I appreciate my country and culture.

Tour guiding can be both interesting and well paid.

- This job allows me to pursue things that l'm passionate about.

- Guiding is a better job than other work available for people like myself with a basic education.

- It can be quite good money when there are regular tourist arrivals. 


\section{DIFFERENT TYPES OF GUIDES}

The most common type of guide takes a group of tourists on a local tour for a few hours. Some guides work at attractions and tourists come to them. Other guides lead tours that last for weeks, visiting several countries. There are many different types of guides.

- Local guide - A local guide accompanies tourists during their visit to a site or region. They should have good knowledge of the culture, history, flora and fauna of the area. Local guides can easily find their way around and know where all the points of interest are. This type of guiding is the most common both internationally and in Solomon Islands.

- Attraction guide - A stationary guide who works at a specific site that tourists visit. This is usually a place like a cave, an archaeological site, or where a historic event took place. Many guides work in museums. Famous buildings like churches, sport stadiums and even beer factories have tours led by specially trained guides.

- City guide - Similar to a local guide, but working in cities. They are common in cities like London, Paris or New York. A city tour can be by bus or on foot. Here, tour companies offer tours of Honiara which include visits to the National Museum, National Parliament Building, American Memorial and the Central Market.

- Eco guide - A guide who leads tours that focus on the natural environment. Eco guides have good knowledge about the environment and can name common birds, animals and plants. Eco tours and activities should be educational and low-impact. Eco guides often work in protected areas, where they promote conservation values to visitors.

- Trekking guide - A guide who leads overnight walking tours. A trekking guide should have good knowledge about the natural environment because that is key to the experience. They need to be fitter than other guides and be trained in first aid. Trekking guides not only guide but cook and set up camp as well.

- Tour leader - An experienced guide who leads larger groups or tours that run over several days. The tour leader has a general knowledge of the places visited but often relies on local guides for the guiding. The tour leader's role is focused on the management of the tour, which includes organising transport, accommodation and meals.

- Specialist guide - Guided tours for specific interests like birdwatching or war history. Similar to attraction guides, specialist guides need to have in-depth knowledge about their niche.

- Activities guide - A guide who leads adventurous outdoor activities, like diving, rafting or fishing, that needs special training and equipment. Their role is less about telling stories and more about showing people how to enjoy an activity, in a fun and safe way. Activity guides should have excellent skills in their chosen activities. Diving requires a special licence before the guide can lead tours.

There are more types of tour guides, but most would fit into one or more of the categories mentioned here. For some guides, the different categories overlap and experienced guides can perform multiple roles. 
- Local guides may take visitors on a tour of local attractions, such as museums.

- Trekking guides often have similar skills to an eco guide.

- Tour leaders may conduct city tours during a multi-day tour.

Professional tour guides are often trained in several categories. During their careers, they can move between different types of guide work. This makes them more employable and keeps the job interesting.

In Solomon Islands, guides often get requests to arrange customized tours, which are tailor-made to the clients' interests. To lead customized tours, the guide needs a broad knowledge and experience in different kinds of guiding.

In some countries, some tours and activities are offered seasonally. This can mean guides go back and forth between two different guiding jobs. They might be a trekking guide in the winter, and a diving guide in the summer.

\section{- TOUR GUIDING IN SOLOMON ISLANDS}

Due to low visitor numbers, there are only a few full-time guides here. Most are based in Honiara working for inbound local tour operators. In the provinces, most guides are staff at resorts or lodges. In some places, rangers or community members involved in conservation, work as guides. This is an overview of places where Solomon Islands guides work.

- Inbound tour operators - Honiara-based tour companies arrange tours from Honiara to the provinces. They arrange shore visits for visiting cruise ships. The larger companies employ both full-time and part-time tour guides. They have guides trained for city tours, cultural tours, WWII tours and birdwatching.

- Accommodation providers - Most guides in the provinces work out of hotels, resorts and lodges and work as guides on-demand. Many activity guides for diving, fishing and surfing, work out of resorts.

- Adventure/activity operators - The largest niche, in Solomon Islands is diving. Several dive centres and live-aboard boats employ local dive guides. Fishing and surfing guides work out of a handful of resorts. In Honiara, one operator employs rafting guides part-time.

- Protected areas - Several conservation organisations partially fund their programs through ecotourism. Rangers or community members work part-time as eco guides.

- Self-employed - Some guides work independently running their own tours. This can be more profitable but self-employed guides need to work hard to promote their business. Self-employed guides in Solomon Islands offer bird watching, cultural and historical tours.

- Attractions - The few guides who work at attractions here are at WWII sites and museums.

As tourism develops in Solomon Islands there will be more opportunities for guide work. The established niches are likely to grow, and new ones will develop. Some potential growth niches are trekking tours, soft adventure tours and guiding onboard super yachts and expedition cruise ships.

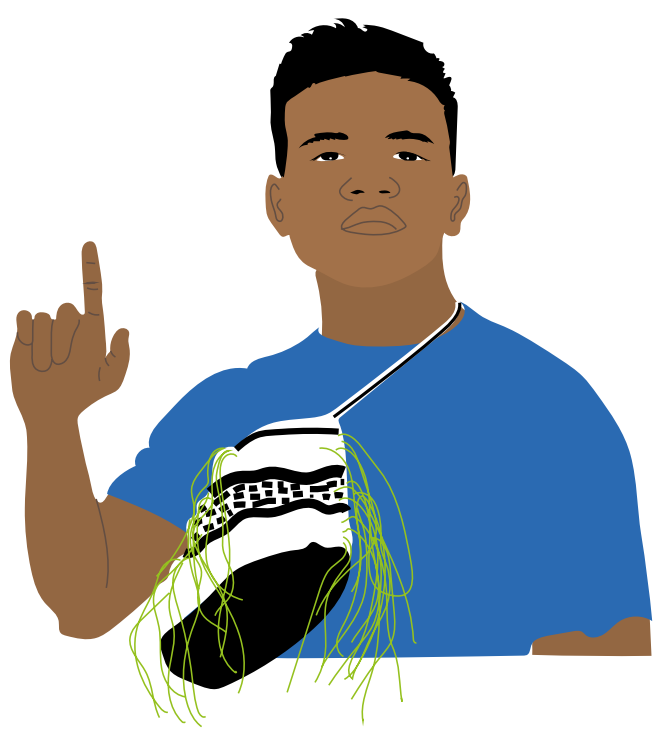




\section{Rude people}

"As a female guide in Honiara, you sometimes get rude comments from local people. I don't know why, maybe it's jealousy. There needs to be more awareness about the benefits of tourism. Compared to other Pacific countries I have visited, the level of awareness and cooperation from the public is low. People should recognize the importance of our work. Tour guides are representing the country. We are the front-line workers of tourism."

\section{Island time}

"One of the things tourists like is the laid-back atmosphere here; that our life is not ruled by time. But at the same time, they get very frustrated when things are not on time. I think us Solomon Islanders have to accept that we live in two worlds now. We can meet halfway without abandoning our culture. While working with tourists, we should respect that being on time is important to them."

\section{TOUR GUIDE ROLES \& RESPONSIBILITIES}

A basic guide is someone who shows the way, like a pathfinder showing tourists the way to a beautiful waterfall. But the work of a guide is more than just being a pathfinder. A professional tour guide doesn't accompany tourists, but leads them. Guides perform a wide variety of roles while leading a tour: informing and entertaining the group, while making sure everyone is safe and comfortable. Sometimes guides drive the tour vehicle and cook for the group. The three sets of skills and qualities that a tour guide needs are professionalism, knowledge and skills, and personal qualities.

\section{- PROFESSIONALISM}

Professionalism is about your attitude towards work, and how you conduct yourself while working. It's also about work ethics and being good at what you do. The tour guide is credible and reliable when professional. This is not unique to the tourism sector; professionalism is needed for every job. It is important for tour guides to be professional as tourists entrust them with their time, money and safety.

\section{- Leadership}

The work of a tour guide is often described as leading a group. Sometimes guides are called tour leaders. A guide's role is to manage and supervise tourists and they should be firmly in charge. Your guests are looking to you for leadership. Part of your role is to explain to the guests how to behave, for example, safety rules during activities. A tour guide needs to be self-confident enough to make decisions that may not be popular, but are necessary. Leadership is maintaining good humour and morale for both guest and staff.

\section{- Organisation \& planning}

Guides who are responsible for organising and leading a group of tourists need to be well organised. There are many parts to a good tour. A lot of planning and organising goes into a longer and complex itinerary. Transport, meals and accommodation have to be arranged and the tour has to run to a schedule. When a tour is wellplanned and organised, the experience feels smooth and enjoyable for the guests.

\section{- Time management}

Being punctual is an essential. Tours run on schedule and your guests expect tours to start on time. Being late for a tour departure is unacceptable! Do not use the excuse of 'Solomon time' as a reason for delays. Clients have paid a lot of money to come here, and even if they are on holiday, they don't want to waste their time waiting for you to get organised. A guide needs to keep in mind meal times, or the start of other activities on the tour. A good guide is time-conscious and knows how much time is needed for each segment of the tour, and when it's time to move on.

\section{- Reliability}

A tour guide needs to be trustworthy and reliable. Tourists trust you to look after them, their families and their belongings. Your employer values you being reliable. It's a given that a guide should be on time for work. Consistent punctuality is what employers need. For you to be responsible enough to come on time every day, even when your boss is not around. A tour guide should be able to work independently without direct supervision and be trusted to handle money and valuable equipment. 


\section{- Appearance}

In your role, you are the face of the tour and represent your organisation. First impressions are important and guides should look neat, clean and tidy. Some companies provide uniforms, but many guides wear their own clothes. The clothes of a tourist guide should be appropriate for the itinerary. For nature tours, many guides dress similar to rangers wearing green, khaki or blue shirts. Avoid bright colours for nature activities and wear closed shoes for bush walks. Whatever clothes you wear they should be in good repair and clean. Personal hygiene is also important.

\section{- Preparedness}

Being well-prepared is essential. Tour preparedness is knowing the itinerary as well and the information that you want to share with the clients. Any logistics for the tour should be arranged in advance. If boats need fuel, the tank should be filled up before the tour starts. Many activities require equipment, such as a first aid kit, life jackets, snorkeling equipment, etc. Before packing your tour equipment, check that it works and you have the right amount of gear. Make sure phones and radios are fully charged. Many guides use a tour preparation checklist so they don't forget anything.

\section{- KNOWLEDGE \& SKILLS}

A tour guide needs to have good knowledge about the topics covered. Topics vary depending on what kind of guide you are. It is common to include information about local wildlife, history and culture. There are also skills, such as first aid, that all guides need. Specialised skills are needed for activities like scuba diving.

\section{- Local knowledge}

The main reason tourists go on tour is to learn about the area they visit. In the past, tour companies sent guides from overseas to accompany tourists. Increasingly, local guides are used due to their local knowledge. Tourists like to hear stories from people who live there. A local guide knows the name of rivers, islands and mountains, the history and culture. They can manage risk better, because of their understanding of local weather patterns and potential risks.

\section{- Subject knowledge}

Tour guides need to know what they are talking about. Many tours focus on specific topics, like WWII history or birdwatching. These guides need to do a lot of research before guiding such tours. It's easy to talk about topics you are interested in. This manual does not include subject knowledge but focuses on how to work as a tour guide. More on subject knowledge in Chapter 3.

\section{- Cultural host}

Tour guides act as cultural hosts. Without someone explaining the story behind cultural sites and practices, it becomes meaningless. A good guide uses examples of local culture, such as art, handicraft or music, as points of interest. As a cultural host, you are a bridge between visitors and locals. This is more than just showcasing local culture. It is explaining cultural protocol to visitors. A common example is to inform guests about appropriate dress during village tours, or areas that may be off-limits.

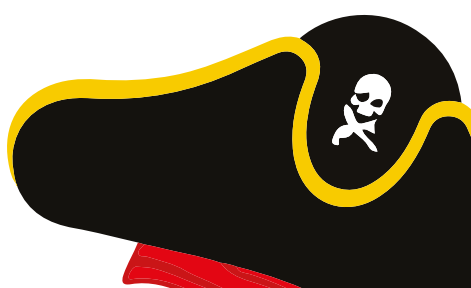

\section{Scary pirates}

"Appearance is very important. I think guides should always wear a uniform, but not every company provides that for their staff. When I wear the uniform, I feel more profession$a l$ and part of a team. When you represent your company, and you should look neat and tidy. If you are provided with a uniform, it's your responsibility to keep it clean. We had to send staff home because they smelled bad. Body odour is a big problem and not acceptable in hospitality and tourism. Drivers also have to be presentable; we had one boat driver that looked like a pirate and the guests got scared when he came to pick them up." 


\section{Tour talk}

"I didn't learn English well in school, but learned it from working with tourists. In the beginning, I was very shy, but not anymore. I tell the new guides, just talk, it doesn't have to be perfect. Foreigners don't mind if you make mistakes and they won't make fun of you. Broken English is better than not speaking at all. In our culture, we are afraid to make mistakes and have people laugh at us."

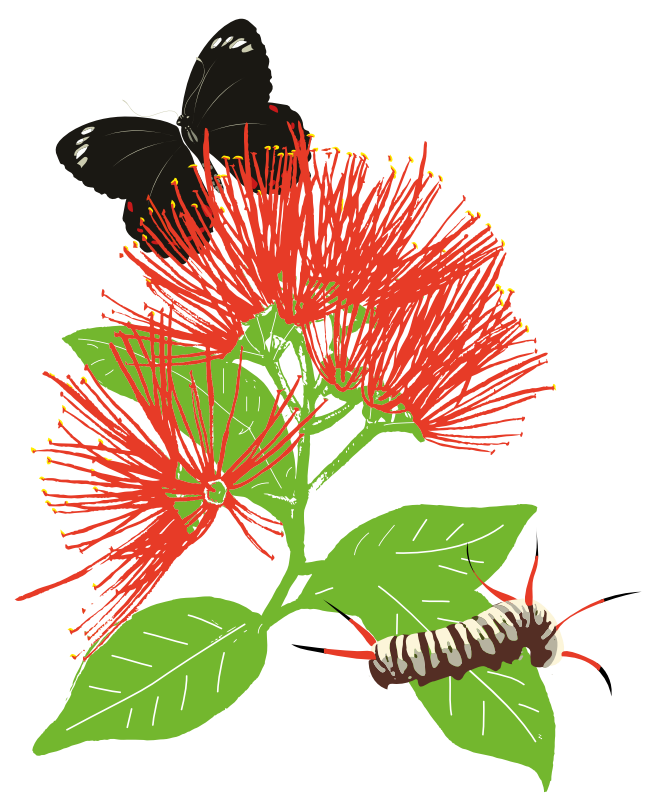

\section{- First aid \& risk management}

Basic first aid skills are essential for tour guides. In many countries, this is a legal requirement and guides need to be certified in first aid to be able to work. Even on a short tour, clients can slip and fall or be bitten by insects. Clients expect guides to carry a first aid kit and know how to provide basic care in case they are injured. For longer tours, such as overnight treks, more in-depth knowledge of first aid is required. An injury in the bush can require an evacuation and guides need to be ready to manage this. You need to know how to prevent risks, to avoid injuries in the first place.

\section{- Technical skills}

Specific tasks require technical skills. For example, if you arrange a snorkeling tour you need to be able to swim and know how to use a mask and snorkel. Examples of technical skills for a tour guide includes first aid, food preparation, map reading and how to put up a tent. Most of these skills can be learned from colleagues on the job. A tour guide also has to demonstrate technical skills to others, for example, showing tourists how to use a mask and snorkel. Specialised skills like diving or rafting require special training.

\section{- Language skills}

Most tourists that come to Solomon Islands speak English, but that may change in the future. In many destinations, tour guides need to speak other languages. Some guides in Honiara have learned foreign languages and specialise in guiding tourists from a specific country. This is common overseas. Guides with language skills can easily find work. In tourism, generally, English is still the most common language. English-speaking guides accompany tourists, who travel in groups, from non-English speaking countries. Some local guides use translation apps on their phone to make themselves understood.

Many new tour guides in Solomon Islands are shy to speak English. Solomon Islanders generally speak better English than what tourists are used to from other countries.

\section{- PERSONAL QUALITIES}

Your personal qualities are the characteristics that you have as an individual. They define how you will apply yourself to the role of a tour guide. Certain qualities are useful when working as a guide. Even if these don’t come naturally for you, you can learn them over time.

\section{- Communicator}

While giving briefings guides need to communicate in a clear and understandable way to make sure people receive the information. This is important when talking to large groups of people. It is not necessary to speak perfect English to be a good communicator, as long as your message comes across. Talking in front of groups can be challenging, but as you gain experience you will become more at ease. Tour guides are essentially storytellers. To tell a good story you need to know how to tell it in a way that captivates your audience.

\section{- People person}

A tour guide's main job is to deal with people. It helps if you are a people person, who enjoys interacting with people. Clients appreciate guides who are friendly and easy-going. It is also helpful if you are a bit of an entertainer with a good sense of humour. If you have a mixed group who don't know each other, you should act as 
a social facilitator by creating a friendly atmosphere so they can get to know each other. Sometimes new guides who are not used to interacting with foreigners are a bit shy, but they overcome this when they realise that most tourists are friendly.

\section{- Problem solver}

Tours don't always go exactly to plan. Guides need to be able to improvise. By being resourceful and able to quickly solve problems that arise. Common issues on tour are equipment failure, transport breakdowns, people not showing up, or bad weather. The guide has to do some quick thinking so that the tour can continue.

\section{- Enthusiasm (Passion)}

You need to show enthusiasm for what you do. People can tell if you are bored or have little interest in the tour. Enthusiasm is contagious, if you are passionate your audience will be more receptive to what you are saying. When guides are enthusiastic about a topic, they want to learn more about it. Beginner guides can make up for their lack of experience and knowledge with their energy and enthusiasm. A good tour guide sets a positive tone for the group.

\section{- Diplomacy}

Tour guides work with people from all over the world with different backgrounds and personalities. Sometimes guides have to deal with difficult people and handle conflict. When that happens, the guide needs to be diplomatic to find a resolution without taking sides. Patience is also required when dealing with some people. A tour guide should never show frustration when dealing with guests. Your diplomatic skills are important if there are misunderstandings between your guests and local people.

\section{- Observation skills}

Tour guides need to have good observation skills and situational awareness. The work of a guide involves pointing out interesting things, for example, wildlife. You need a sharp eye and the ability to spot animals. You need to keep an eye on your guests to make sure everyone is OK. You can spot issues by observing how people behave. If you notice someone lagging behind or who looks unhappy you need to check what is wrong. Situational awareness means that you are aware of what is going on around you, or noticing that someone is missing.

This list is a summary of the important key roles and characteristics, It would be unusual for one person to master them all, especially new guides. With training, practice and experience, guides can incorporate most of these characteristics in their work.

\section{Challenges}

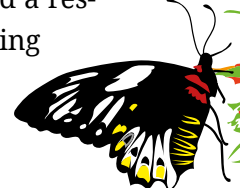

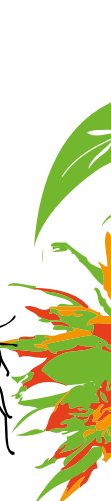

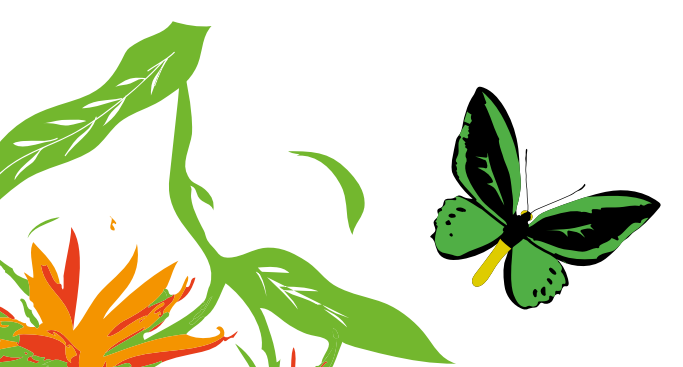

These are some things that local tour guides find challenging about their work:

- When people don't listen to the guide or follow instructions.

- Dealing with difficult and unfriendly people.

- Leading tours during bad weather, like when it's raining for several days.

- When tourists are unfit or tired and get cranky during long walks.

- Being caught between locals and tourists in misunderstandings.

- Dealing with complaints.

- Struggling to remember English names of birds, fish and plants.

- Dealing with tour-related paperwork and payments.

- Not having the right equipment for an activity, or having old and broken equipment.

- Shy to deal with big groups and worried about saying the wrong things. 


\section{TOUR GUIDE CONDUCT}

As a guide you are expected to conduct yourself professionally. Your own behaviour can impact your guest's trust in you. Tourism and hospitality work means looking after people, and your guests should feel comfortable with you. There are no fixed rules for tour guide conduct, but many tour companies include the following advice in their guidelines.

\section{- Follow the law}

Don't do anything illegal in the Solomon Islands. Laws vary between countries and foreigners may not know what is illegal in Solomon Islands. Never allow yourself to be pressured to do anything illegal. Do not accept that foreigners do anything illegal while on tour with you. This can ruin your professional reputation and chances of future work.

\section{- Be present}

You can tell when people are bored with their jobs, for example, a shop assistant sleeping in the store. You want the tourists to believe that you enjoy your work. Focus on the experience and interact with your guests for the whole tour. Don't play with your phone, or take calls that are not relevant to what you are doing.

\section{- Appearance}

In many countries, tour guides wear uniforms. In Solomon Islands dress requirements are casual and most guides don't use a uniform. This doesn't mean that your appearance is not important. Whatever you are wearing when working should be clean and in good condition. Personal hygiene is also important. Don't just roll out of bed and go to work. Wash in the morning before every tour. If you lead overnight tours wash every day and bring clean clothes along.

\section{- Language}

Even if you don't speak perfect English, speak politely to your guests. Never swear, even if your guests do. It quickly becomes a habit, and your next group might be offended by bad language. Some young guides mimic what they see and hear from movies, music, and tourists. This will make them unemployable in the tourism industry.

\section{- Taking advantage of your role}

Don't use your position of trust to take advantage of your guests by overcharging them, asking to borrow money, or asking for fundraising contributions. Tip money is sometimes given voluntarily by guests, if they appreciate the service. This is not the norm in Solomon Islands and you should not ask for it. If you do a good job, you may get tipped anyway, but this is entirely up to the individual tourist.

\section{- Respectful behaviour}

You will spend a lot of time with tourists. However close you get to them, remember that they are paying customers. You should be friendly, but respectful. Female travellers sometimes complain that local guides give them too much attention. A tour guide should never approach guests in this way. If you need to talk to a guest in their room, knock first and wait for them to open the door. Being respectful doesn't mean avoiding them. You need to communicate with your guests, and you shouldn't be shy to approach them about tour related matters. 
- Socialising with guests after the tour

Some guests may invite you for dinner or drinks after the tour as a thank you for a good experience. Getting to know people from all over the world is one of the advantages of working as a tour guide. Just because the tour is over doesn't mean you can let go. If you go out with guests and get drunk, this will be their lasting memory of you, not your qualities as a guide.

These guidelines may not be spelled out to you by your employer, but you are expected to have the common sense to understand this anyway. High expectations of staff conduct is not unique to tourism, but applies to any profession where you interact with people in a position of trust.

\section{Tour guide do's and don'ts}

This is a list of do's and don'ts for tour guides based on interviews with professional guides who supervises other guides.

\section{DO}

- Be outgoing and friendly; a people person.

- Be fit and active, master the activities you lead (e.g., know how to swim)

- Make sure you know what you are talking about.

- Be passionate about tour guiding and the subjects you talk about.

- Be patient and even tempered; know how to deal with difficult clients.

- Be prepared to deal with situations; a problem solver.

- Look after your guest's safety and be prepared to deal with emergencies.

- Be a leader who can organise both logistics and people.

- Know your audience; know how to talk to different people.

- Be able to make unpopular decisions and explain them to guest.

- Be flexible to change plans if the situation calls for it.

- Focus on the work; put in your best effort during each tour.

\section{Don't}

- Don't chew betel nuts in front of guests, or just before the tour.

- Don't smoke during tours (includes drivers and assistants).

- Don't steal or touch the belongings of guests.

- Don't be late and come to work unprepared.

- Don't be shy, it doesn't matter if you speak perfect English.

- Don't come to work hungover or drink on the job.

- Don't cross boundaries with guests, especially women.

- Don't come to work being untidy or smelly.

- Don't leave the guests unattended without explaining what is going on.

- Don't swear or make inappropriate jokes.

- Don't over promise things; for example, what animals you may see.

- Don't ask for money or gifts. 


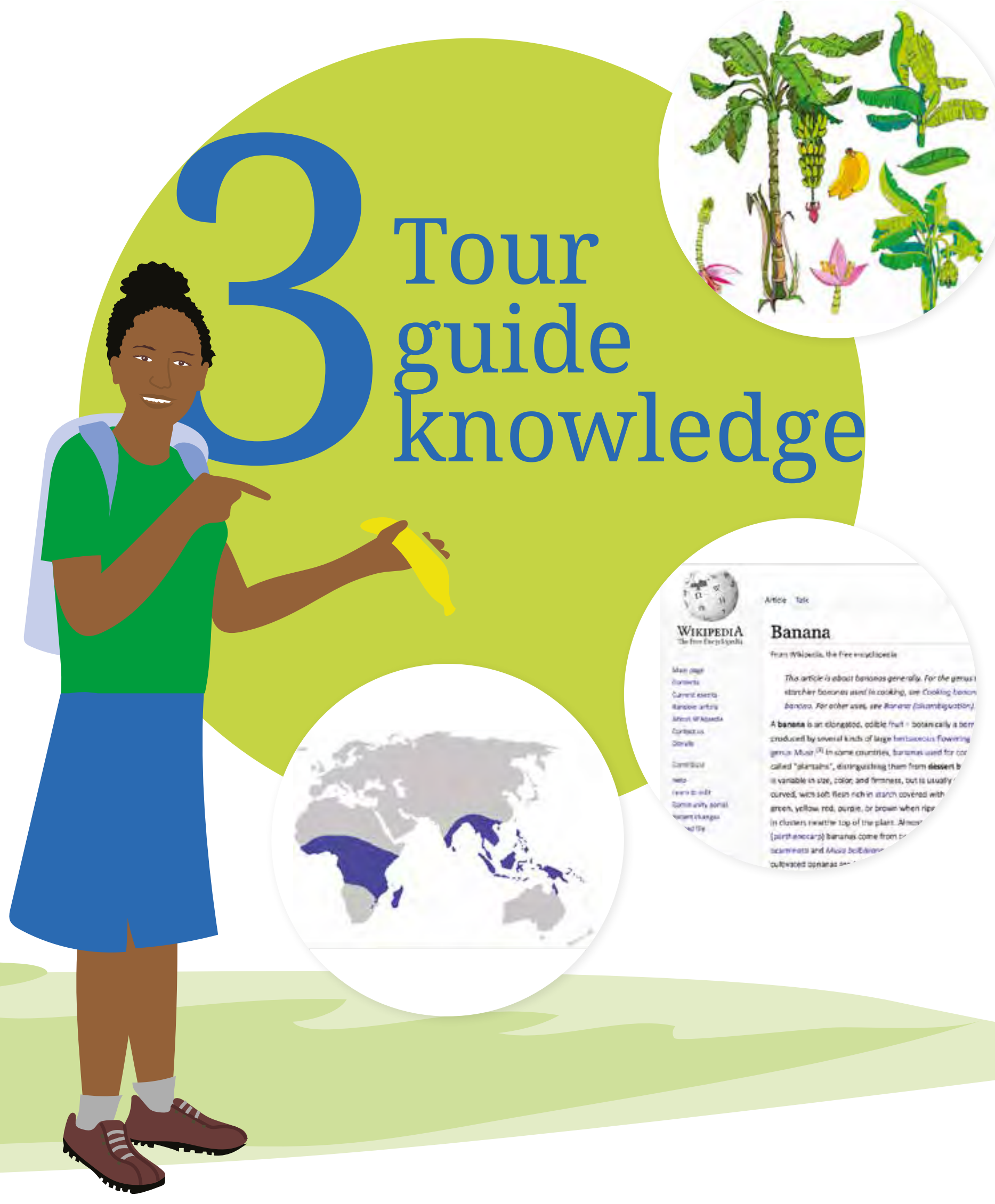


The most important part of a tour guide's job is to share facts and interesting stories about the local area. Tourists will ask many questions and expect you to be able to answer most of them. You need to have good knowledge about the things you talk about. If you lead a birdwatching tour, you need to know how to identify local birds. If you take tourists to visit a battlefield, you need to know the story about that battle. These facts are subject knowledge, and it varies depending on what types of tours you are guiding. Generally speaking, tour guides should have good knowledge of the natural environment, culture and history of the local area. Below is an overview of subjects relevant to Solomon Islands:

\section{LOCAL ENVIRONMENT}

Knowledge about the natural environment is one of the most important skills for tour guides in Solomon Islands since most tours take place in nature. It is important for those guides leading tours in conservation areas.

\section{- SPECIES IDENTIFICATION}

Being able to point out and name wildlife and plants is the most impressive skill of a naturalist guide. Many locals know the species' names in the local language, but tour guides need to learn the English name as well. Start by learning how to identify the most obvious species, such as birds and colourful flowers that you see every day. Over time, you should try to broaden your knowledge to other species as well.

- Terrestrial wildlife: birds, mammals, reptiles, insects

- Marine life: fish, marine mammals, invertebrates, corals

- Vegetation: trees, plants, flowers, fungus

As a naturalist guide, it is good to memorise some basic facts about flora and fauna in Solomon Islands, for example, how many bird species there are, and how many of them are endemic.

Rather than trying to learn as many species as possible focus on species that tourists will be likely to see and those that they find interesting.

- Common - Species that you are likely to encounter on every tour. Example: Cockatoo, dolphin, bamboo, coconut palm.

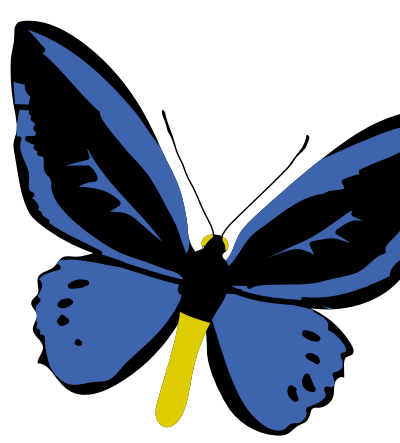

Crazy about butterflies "When I started guiding, I had to learn the names of common birds and fishes. I never really thought about butterflies, they were just like insects to me. as I started guiding people from different countries, I discovered that Japanese tourists love butterflies. They get very happy when they see one, so I started to look for them and point them out to my guests. Most tourists like it, but not like the Japanese, they are crazy about butterflies." 
Naturalist tour guides should be able to explain how life in an ecosystem is connected and also identify which species belong to which ecosystem. An ecosystem consists of non-living things and processes that affects life within it. Experienced naturalist guides can talk about these things as well:

- Geology: rocks, minerals and earth processes.

- Climate: weather and seasons.

- Oceanography: tides and currents.

\section{- SITE KNOWLEDGE}

If you visit a site many times you will notice that the presence of wildlife and how they behave differs a lot depending on the time of day, season and weather. Tour guides should know their sites well - the best time to visit, and what is to see. This is one of the core skills for dive guides. They need to know how different sites can be dived in different seasons and conditions and what marine life can be seen.

Some species, like manta rays, are seasonal and only gather at a few locations when the current flows in a specific direction.

\section{LOCAL CULTURE AND HISTORY}

The local culture is what sets Solomon Islands apart from other destinations. Solomon Islands has an interesting history, which includes headhunting wars and WWII. Even if you work mostly as a nature guide, your guests also like to hear stories about local culture and history.

\section{- WHAT IS CULTURE?}

In tourism, culture often means traditional dances and handicrafts. These are the obvious ways tourists can experience culture. But culture is much more than that. It includes everything that distinguishes a group of people, and links them together. Behaviour, traditions and ideas expressed through art, music, dance, stories and food are all part of culture.

Culture can be divided into things that you can touch (tangible) and things that are expressed through behaviour and ideas (intangible).

- Tangible culture: skull shrines, wood carvings, shell money.

- Intangible culture: dance and song, stories and legends, traditional skills.

Try to include both tangible and intangible culture in your tours, and if possible, combine them. If you show tourists a carving (object: tangible culture) you can explain how it was used traditionally (skills: intangible culture).

The Pidgin word kastom describes many things that are part of traditional culture. When thinking of how to include culture on your tour, think of anything that you can put the word kastom in front of.

- Sites: skull shrines, tabu sites, rock carvings, archaeological sites

- Objects: statues, carvings, weaving, ornaments, shell money

\section{Learning new things}

"One thing I like about guiding

in a protected area is that 1

get to meet researchers and

conservation people who

know a lot about the ani-

mals and the environ-

ment. I never had any

formal training but

over the years I have

learned a lot from

them. When I started,

it was just a job, but

now I'm very interested

in everything about

nature. My work has

become my passion."

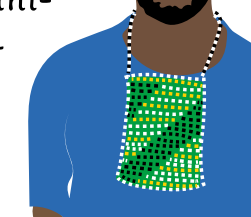

(1)

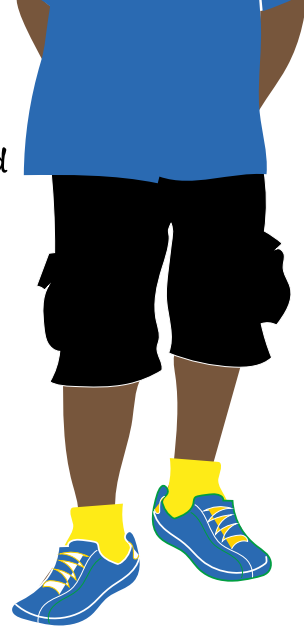


- Performances: traditional dances, warriors welcome, music and song, festivals

- Style: house and boat design, clothing, hairstyle, tattoos

- Skills: fishing, hunting, bush medicine, cooking, canoe building

- Stories: legends, ancestor stories, spirits, black magic

Cultural protocol is how people deal with certain situations, and how they interact with others. It can be for important life events such as funerals, weddings, appointing a chief, or paying compensation to settle disputes.

It can also be about everyday life, how people greet each other and how men and women interact. Some of those things might not be understood by tourists. You need to explain cultural protocols to them, for example, how to dress while visiting a local village.

This also includes local languages. Tour guides can use language to get tourists to engage with the culture by teaching them words like hello and goodbye. When you point out wildlife or plants you can use both the English and local language name to make it more interesting.

Contemporary culture - Culture doesn't have to be old or traditional. Culture is living and evolving all the time. Modern local music and art are examples of living culture. Some tourists may be interested in what people are doing today - what music they listen to, what they eat and what they do in their spare time.

\section{- HISTORY}

Solomon Islands has a fascinating history of interesting stories:

- Headhunting raids and tribal wars

- Famous Chiefs and Big Men

- Mendana and how Solomon Islands got its name

- Interaction between early settlers and locals (includes stories of both love and conflict)

- Blackbirding and labour migration

- Colonisation/British Protectorate period

- How the nation of Solomon Islands was created

\section{Ship stories}

"When I worked on liveaboard dive boats the boss often encouraged me to share stories with the passengers, like kastom stories or stories about everyday life in Solomon Islands. This was very popular with the guests and I realized that our culture is something interesting for them. When I told them that the word for white people in my language means 'ship people' they laughed a lot."
There is a difference between legends and stories and actual history. As there was no written language in Melanesia there are only oral stories from the time before European contact. But there are several archaeological sites that can give clues of life in Solomon Islands before contact with Europeans. From the mid-1800s onwards, when traders and missionaries started settling on the islands, there are historical records and descriptions of traditional life. Tour guides can find inspiration for many stories from these records. Note that most records were written from the settler's perspective.

\section{- WORLD WAR II (WWII)}

The main reason most people in the world know about Solomon Islands is because one of the most famous battles of WWII took place here. Guadalcanal was the turning point of the Pacific war where the Allied forces led by the U.S. turned the tide of the advancing Japanese military. There are several well-known movies and books about WWII in Solomon Islands, and this has created a lot of interest worldwide. Many of the first tourists who came here were war veterans or relatives of veterans. Due to the 
many war relics and battle sites on Guadalcanal, Central and Western Province tour guides can incorporate war history in most tours. Some guides in Honiara, Tulagi and Munda have even developed tours focused only on WWII history. This tourism niche is called war heritage tourism or battlefield tours. Ideas for war-related site visits and stories are:

\section{- Sites}

- War museums: National Museum in Honiara, Vila War Museum on East Guadalcanal and Peter Joseph WWII Museum in Munda.

- Battle sites: Bloody Ridge, Tulagi, American landing site in Munda (and many more).

- War infrastructure: Japanese clinic on Kolombangara, PT 109 base off Rendova.

- Relics: artillery, tanks, plane and shipwrecks.

\section{- Stories}

- Coast Watcher's network

- Life and resistance under Japanese occupation

- Rescue of future U.S. President John F. Kennedy

- Stories of individuals and incidents: local war hero Jacob Vouza and U.S. war hero John Basilone on Guadalcanal, Kennedy’s guerrillas in Seghe.

As you can see, WWII history provides you with endless material for interesting stories. All you have to do is research the war history in your local area. Remember that many overseas visitors are familiar with the main events of the war in the Pacific. There are many hard facts involved in war history (dates, names, equipment and troop movements) so you need to make sure you have the facts right, before you talk about it.

\section{War buffs}

"As a kid, I heard stories about the war from relatives who were in the coast Watchers. When I got older, they took me to the old battle sites. Later on, when I started guiding, I met a lot of war buffs. Those are people who are very interested in war history and travel all over the world to visit battlefields. They often knew more about the battles around here than me, but they gave me some good books and I learned more about different stories from the war."

\section{- Dealing with the history of conflict}

As a tour guide, you will guide both visitors from U.S. and Japan, who were enemies during WWII. Naturally, people from these countries have different feelings about the war. For Americans, the word Guadalcanal is associated with pride and triumph. For Japanese people it evokes great sadness for the many lives lost there. You need to deal with war history sensitively and consider your audience when planning what to talk about and what places to visit. 


\section{CONTEMPORARY LIFE}

How do people live today in Solomon Islands? You will get many questions that are not related to the tour, but rather about how people live their lives today. These may be questions about livelihoods, family life, religion and how the country is governed. Most of those things you don't need to research because as a local you know. You can share your own life experiences to make the stories more personal. For each of the topics below, think of a story you can share with tourists.

\section{Tropical paradise}

"When we visit villages, tourists often tell me that this must be paradise, admiring the carefree lifestyle of the villagers. This is a good cue to talk a bit more about the challenges of village life. It's true that they have enough food and look happy, but some tourists don't understand that even in remote villages people need to find money to pay for things like school fees and medicine."

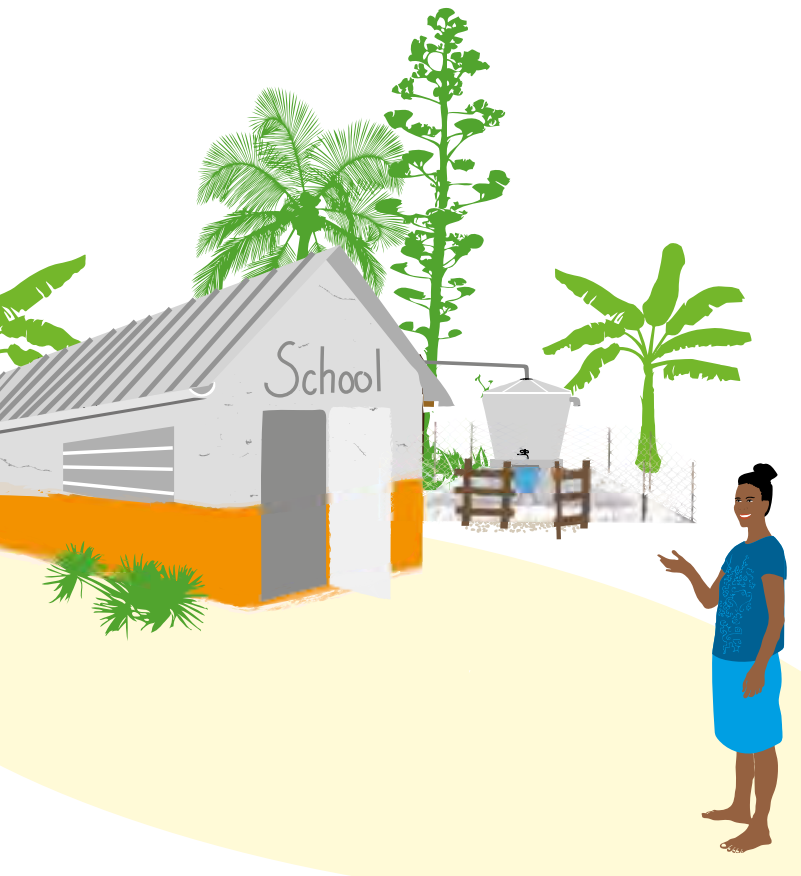

- Livelihoods - For many tourists it's fascinating that most people in Solomon Islands live a subsistence lifestyle and manage to secure the necessities from their environment. Any information about kastom gardening, fishing, hunting and gathering from the bush can be part of a tour.

- Work - Compared to other countries, few Solomon Islanders have a regular fulltime job. It is common to go away to other provinces or overseas to work for a time, and then return to the village. It is also common for people to spend some time in the capital, Honiara. Share your own experiences of work away from the village.

- Life events - Marriages, births and deaths are important milestones all over the world, but they are celebrated in different ways. Sometimes, you may come across events like this during a tour, and this is a great opportunity to talk about how local people celebrate life events.

- Education and health - How can local people access higher learning? What are the main health concerns for local people? Explain that the main expenses for most families in Solomon Islands are school fees and medical bills. In remote areas, education past middle school is usually not available. There may not be any clinics nearby.

- Governance - How is Solomon Islands governed and by whom? What government services exist in the area? What is the role of the government in remote areas and how does politics affect the lives of ordinary citizens?

- Economy - What are the main industries in Solomon Islands? How is most of the revenue generated? How does the government fund its services? You can talk about the logging and fishing sectors, and the role that donor countries play. Tourists are also interested to learn about local products like SolTuna and Solbrew.

- Religion - What is the main religion or church in your area? What is the difference between the different Christian denominations? Does anyone still practice traditional beliefs in Solomon Islands? If it impacts the tour, make sure to explain religious customs such as Sabbath.

Country facts and figures - What is the population of Solomon Islands? How many islands are there? These are questions a tour guide will almost certainly get and should know by heart. Rather than just stating facts, try to weave it into your stories.

- Recent history - This includes events after WWII until today. Some key events in recent history include independence, the ethnic tensions and the 2007 earthquake and tsunami. Sometimes questions about local issues can be sensitive and difficult to discuss. A guide should be able to talk about controversial topics like land disputes and logging in a sensitive way. 


\section{- CHOOSING WHAT TO TALK ABOUT}

What does a tour guide talk about, and what do tourists want to hear about? In this section, we have covered the main topics that are relevant to Solomon Islands. From these topics choose interesting things to talk about from your local area. Most of a tour guide's commentary is based on what the visitors can see. If you see lots of birds, you talk about birds. If you visit the market you talk about local produce. It is impossible to talk about everything you can see during a tour; therefore, you choose the most important or obvious thing and talk about them first. People's attention is drawn to actions and movement: animals hunting or people doing things. If it moves - talk about those things first!

When choosing topics to talk about it is important to remember that people have different interests, likes and dislikes. Some people will want to hear about local wildlife while others are more interested in life in the village. An important rule for storytelling is know your audience. This means adapting your stories and topics to fit the people in your group so you don't bore or insult them.

It's always easier to talk about things you know about or things that interest you. Draw inspiration for stories from your family history and your own experiences. If you talk about the 2007 tsunami, you can explain how your family was affected. This makes your stories more authentic. If you have any particular interests that you already know a lot about you should focus on them. Many guides started out being passionate about something (e.g., birdwatching or surfing) and over time their hobby led them into a career as professional guides.

\section{- DEVELOP SUBJECT KNOWLEDGE}

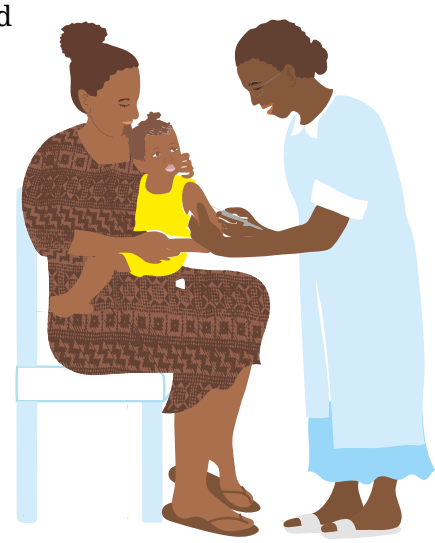

Tour guide training separates the skills of tour guiding and subject knowledge. Most guides acquire their subject knowledge by themselves or from colleagues. In some cases, guides are hired because of their subject knowledge, for example, rangers make good eco guides.

As a beginner guide, it can feel overwhelming to try to answer all the questions from tourists. It would be impossible to remember the name of all the animals, birds and plants you see. But there are some shortcuts that guides can use to quickly develop subject knowledge.

\section{- Shadowing}

Shadowing is when a new guide joins more experienced guides on tours and observe them as they work. The trainee guide should pay attention to what the senior guide is saying and what questions the tourists ask. This is also known as on the job training and it is the most common way for tour guides to learn their jobs.

\section{- Research}

You can prepare by doing some research and memorising some key facts. Many employers have a small library of reference books where you can look up the names of local flora and fauna. You can also gather information from local people with relevant knowledge, such as rangers or elders in your community.

- What, when, why, how

You can anticipate what kind of questions tourists will ask. If you walk past a tall mountain its almost guaranteed that someone will ask: "What's the name of that 
mountain? What does that name mean? How tall is it?" Do a dry run of the tour yourself. Note points of interest along the way and ask yourself the questions, "what, when, why, how?" Find out the answers to these questions and you will be well prepared.

- Most common questions

You will begin to notice that many of the questions tourists ask are the same. Note down the most common ones and find out the answers. Each time you get a new question, add it to your list. After a while you will know the answer by heart. Some common questions are, "What is the population of Solomon Islands?" and "How come some of the kids have blond hair?"

\section{- 5-10-15 method}

When it comes to plants and wildlife it is impossible to memorise the names of them all. Focus on what matters, and learn to identify species that are common or special to your area. Try to memorise five of the most commons birds, animals and plants. Once you can easily identify them, add five more species. Once you are comfortable with ten, add another five. Over time add more categories, such as insects, trees, fish and so on.

Subject knowledge is acquired over time and requires some homework. Don't be embarrassed if you don't know the answer to every single question, but aim to be able to answer most. Tour guides talk about the importance of knowing your product. A guided tour is a product that you sell to tourists. Therefore, to have good knowledge about your tour is the same as having good product knowledge.

\section{- IMPROVE GUIDE KNOWLEDGE}

If you lead a tour regularly you will soon notice that you can answer most questions. Being a tour guide means constantly improving and broadening your knowledge. In this way, the job will never be boring and you will be more employable. Many guides who lost their jobs due to Covid-19 spent the downtime studying or doing their own research to make themselves more employable for when tourists return.

Here are a few things tour guides do to maintain and improve their knowledge:

- If possible, join workshops and training about any topic that is useful to your tours.

- Learn new things - if you are a bird specialist, try to learn the names of butterflies as well. Expand your scope of knowledge.

- In between tours, try to find out more information that you can use on your tours. Keep an eye out for relevant information in books, newspapers, on TV or online.

- Keep a folder for each tour - begin with putting your own notes in the tour folder. Add maps, photos, drawings, articles and anything else that is relevant to that tour. Over time you will have gathered a lot of information. This is helpful if you work on different tours. Before each tour, use the tour folder to refresh your memory.

Finally, try to memorise the information you will talk about, but you don't need to learn it word for word. Your stories should flow easily and not sound rehearsed. 


\section{Different stories}

"Guides should know what they are talking about, and make sure to get the facts straight. The guides working in the same company should tell the same story. We had guests who heard different versions of the same story from our guides. This is embarrassing and makes us look bad. The best thing would be if the company trained everyone in what to say. I only know of a few companies that does that. For the rest of us we have to learn by ourselves, and that's when you get different stories."

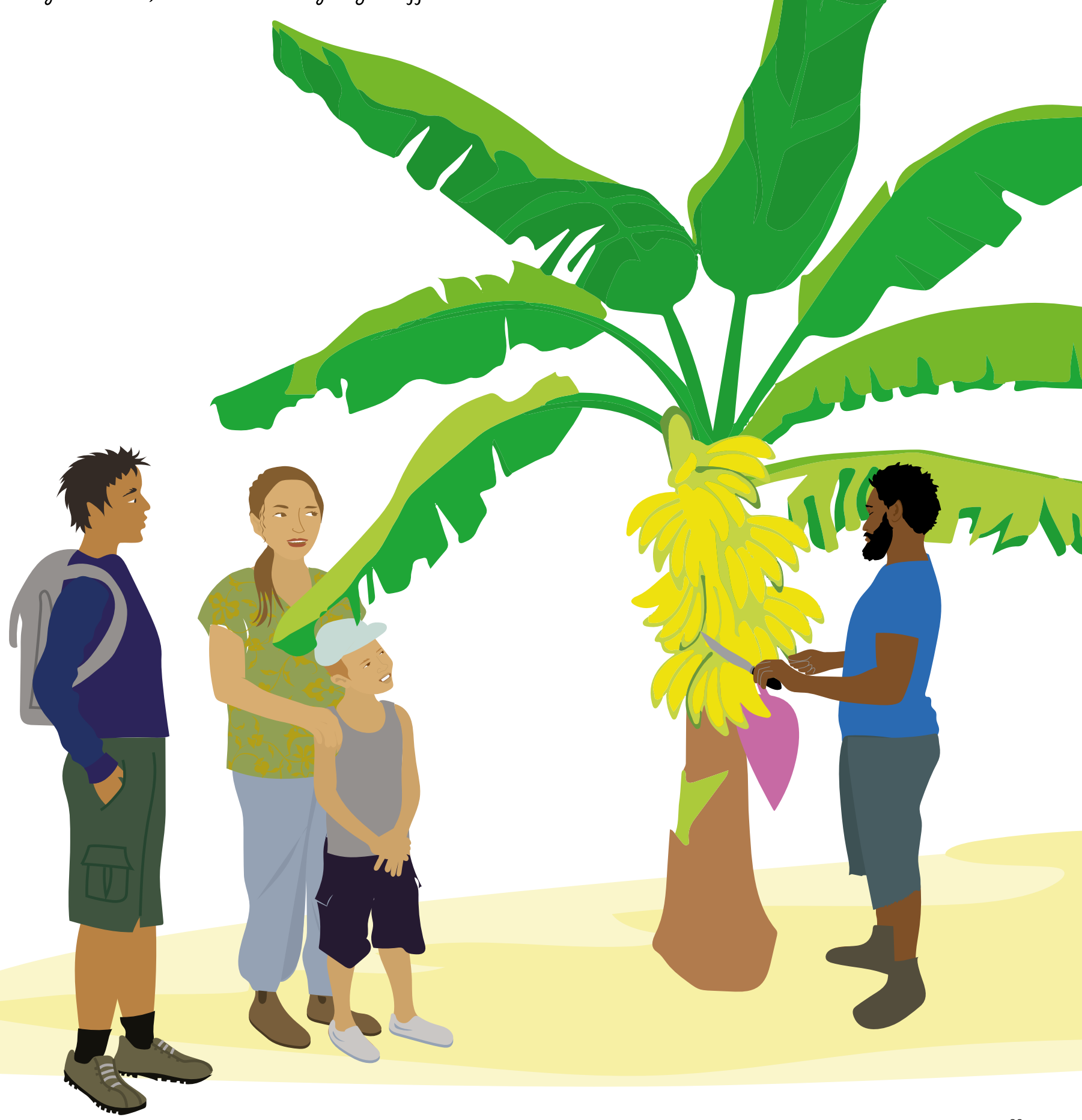




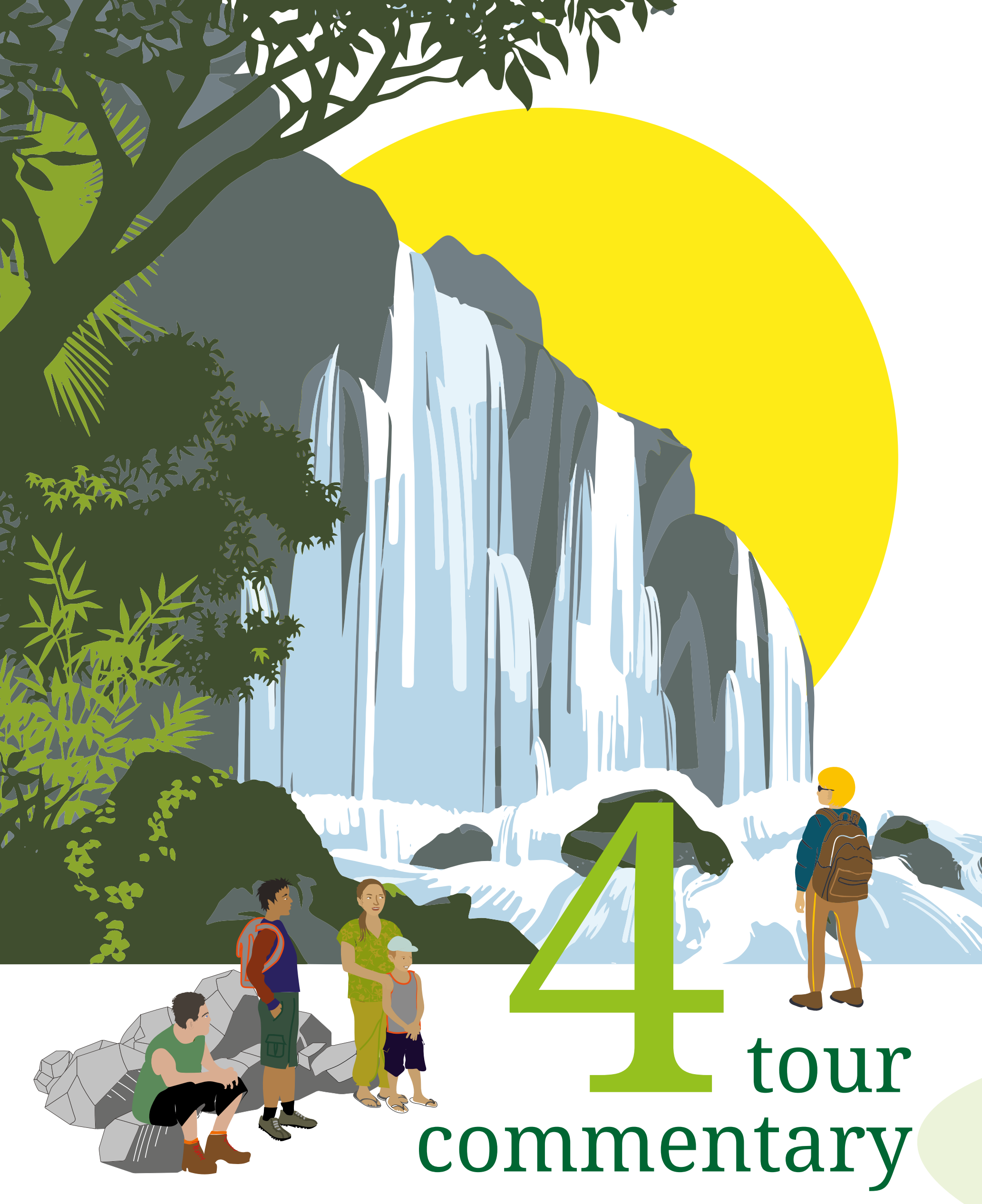


Tour commentary is what you talk about. It is both information and storytelling and should highlight what is interesting and unique. Good commentary can keep your audience entertained and engaged. This is planned and rehearsed in advance. Tour commentary should be:

- Factual: well researched correct information.

- Interesting: something that matters and raises curiosity.

- Revealing: new information not known by the audience before.

- Relevant: something that the guests can relate to.

- Simple: clear and concise, easily understood.

- Entertaining: amusing and thought provoking.

\section{INTERPRETATION}

In tourism, interpretation means the methods used to share information. It is used to explain, inform and educate tourists about what they are seeing. Tour commentary is the most common form of interpretation, but it can also be brochures, signage and activities.

Interpretation is not only sharing facts; it aims to stimulate interest. There is a strong educational component. It is used to help tourists understand the significance of the culture, history or environment.

There are two ways for guides to talk to tourists: a factual style or an interpretive style. The difference is not in what is shared, but how it is shared.

A tourist sees a large bird, and asks what it is.

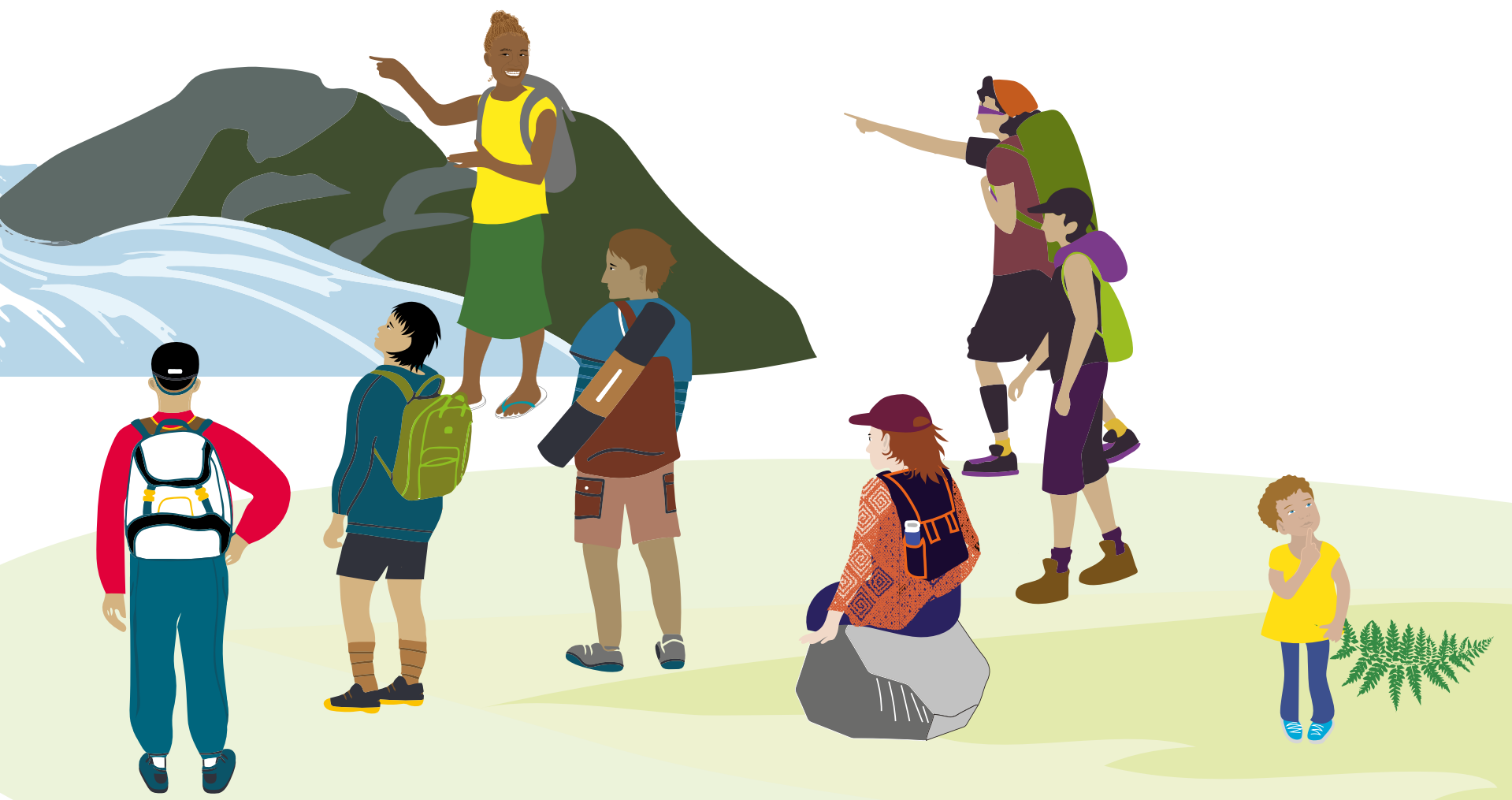


- Factual - That's a frigate bird.

- Interpretive - That's a frigate bird. This bird is an important symbol in the Pacific. It is a symbol of good fortune because it is used by fishermen to guide them at sea. It is on our national coat of arms. You can see it on many cultural artefacts, like shell ornaments and wood carvings. (Later the guide points out a frigate bird designs on a wood carving at the market).

In national parks, interpretation is used to manage behaviour to care for the environment. Rather than telling people what they can't do, the guide uses interpretation to explain what the problem is and how tourists can help. Good interpretation can change attitudes and behaviour.

Interpretation is not always presented by a guide. Many tourist attraction, like museums and parks, are self-guided. Displays, brochures, videos and exhibitions are used. Just like tour commentary, the point is to inform, entertain and stimulate interest.

Interpretation should give visitors a sense of place, so tourists understand and appreciate what is special about where you are.

\section{PLAN AND DEVELOP TOUR COMMENTARY}

Good tour commentary is planned before the tour. It helps to use a simple structure when planning what you are going to talk about. Think of the tour as a story, with a beginning and an end. You tell the story in several shorter talks, as the tour moves along the different points of interests.

- Topic

First of all, think of an interesting topic for your tour. Is the area known for anything special, or has there been any unique events there? Topics can be fairly broad, for example culture, but can also be more focused, like weaving. If the topic is too narrow maybe there isn’t enough to base a tour on. Choose a topic that you are interested in.

\begin{tabular}{|l|l|}
\hline TOPIC & FOCUSED TOPICS \\
\hline Nature & Endemic birds, coral reefs \\
\hline Culture & Weaving, traditional music \\
\hline WWII & The battle of Guadalcanal, Coast Watchers \\
\hline
\end{tabular}

\section{- Theme}

Many tours are planned around a theme. The theme is an important idea or message that you want your guests to understand. It is a sentence stating the message. If your tour is about turtles the theme might be:

\section{"Without community conservation this species could become extinct."}

If you don't have a theme, your tour commentary might just come across as a jumble of unrelated facts. When you plan your tour, try to link the commentary to the theme. Think of the theme as a thread that links the whole tour together. The theme should be like the moral of the story that your guests take away from the tour. 
The tour theme is different from the topic. The theme is the message you want your guests to remember.

\begin{tabular}{|l|l|}
\hline TOPIC & THEME \\
\hline Bees & Life on earth depends on them. \\
\hline WWII & The battle of Bloody Ridge was pivotal to the outcome of WWII. \\
\hline
\end{tabular}

If you lead a special interest tour, it is easy to stick to a theme. But in reality, most tours are a mix of topics sometimes totally unrelated to each other. After all, tourists want to see the most interesting things in the area, regardless of if they are connected to each other, or not. If you can't come up with a theme for the whole tour you can break it up and think of a theme for each topic you talk about.

\section{- Introduction}

At the first stop, tour guides often use a tactic called a contact to make an interesting introduction of the topic. They might start a commentary with a provocative statement or an interesting question. Another effective contact is to use a prop, for example:

A tour guide holds up a piece of shrapnel and asks the guests if they know what it is, (contact) telling them the ground is full of bullets, shrapnel and remnants from the war. This lets the guide introduce the topic and theme:

"This afternoon we will talk about WWII (topic) and visit some famous battlefields. During the tour we will see how the war affects people's life even today (theme)."

A good introduction includes a contact, and a presentation of the topic and the theme.

- Main commentary (body)

The main part of what you talk about is called the body of the tour commentary. Try not to make the main story sound like a boring lecture. Don't overload the guests with facts. Break up the main commentary in several shorter talks. Add some anecdotes; short interesting and amusing true stories about people and places. With small groups, your commentary shouldn't be like a rehearsed speech, more like a conversation. Allow the guests to ask questions during your commentary. With larger groups it's easier to deliver your commentary without interruption, and then answer questions.

\section{- Conclusion}

At the end of the tour the guide finishes up tying it all together with a conclusion. It should refer back to what the guests have seen and what you have talked about. Most importantly it should remind the guests of the theme. You can also end with a short story or anecdote that highlights the main points of the theme. The conclusion can be like the punch line of a joke. You can also make it simple and spell it out.

"I hope that you now understand how important the community's role is in conservation of leatherback turtles."

By the end of the tour, you want the tourists to understand and remember your message/theme. Hopefully you have enthused them about the theme of your tour.

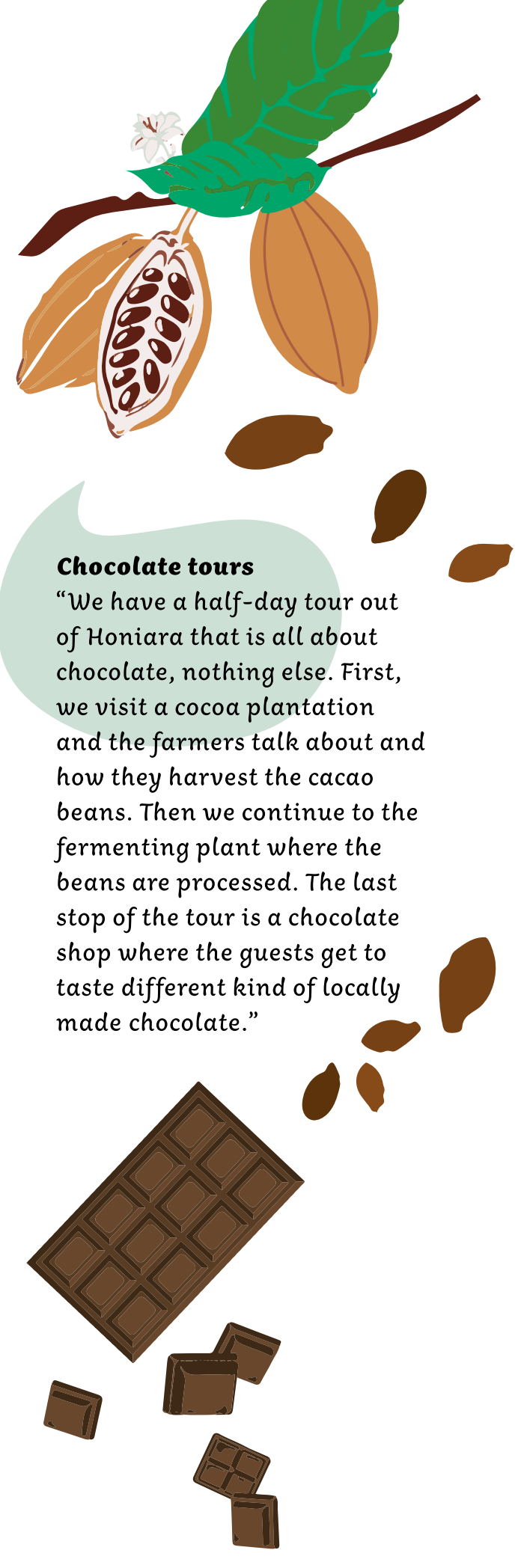

Chocolate tours

"We have a half-day tour out of Honiara that is all about chocolate, nothing else. First, we visit a cocoa plantation and the farmers talk about and how they harvest the cacao beans. Then we continue to the fermenting plant where the beans are processed. The last stop of the tour is a chocolate shop where the guests get to taste different kind of locally made chocolate."

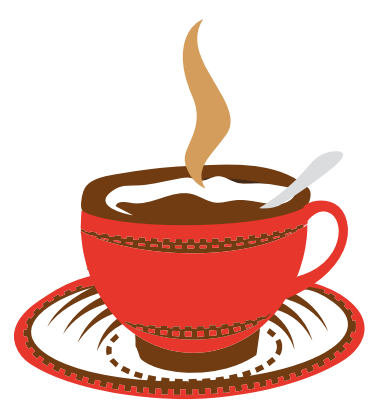




\section{Don't make things up!}

"As tour guides, we should share accurate information. We get a lot of questions and it's impossible to know the answer to all of them. We tell our new guides to answer the questions as good as they can, but never make things up. It's better to admit that you don't know the answer to a question rather than make things up. If you can, try to find out the answer and get back to the guest before the end of the tour."
Try to find a good location for your conclusion. Look for a place that is relevant to the tour theme. A WWII tour may end at a war memorial. You could reflect on the lives that were lost during the war. An emotional but highly effective conclusion.

\section{- FILLER COMMENTARY}

As a new tour guide it helps to stick to the structure described above. As you get more experience you can improvise and be more flexible. During a tour you might get side tracked by random questions from the guest. These questions may not have anything to do with the topic or theme of the tour, and they will vary depending on the guests. This is called filler commentary. It is the spontaneous things you talk about during the tour, usually interesting facts about things you see. You might be leading a bird tour when you walk past a plane wreck. Of course, the guests will expect you to say something about this, even if it's not part of the tour. Don't let the filler talk distract from the theme of the tour.

\section{- PRESENTATION}

Presentation is the act of delivering your talk to a group of people. Your subject knowledge is important but the way you deliver it is just as important as what you say. A good presentation is a mixture of subject knowledge, delivery and knowing your audience.

\section{- DELIVERY}

Delivery is how you present. Just like others that talk in public (teachers, church pastors, politicians), tour guides have different styles of delivery. It would be boring if all guides had the same style. Everyone has different strengths and weaknesses. Here are ten recognised methods to make a delivery more effective:

- Voice - Talk clearly and loud enough for everyone in the group to hear what you are saying. Talk in a conversational way, rather than scripted. Emphasise important parts of your talk with your tone. During walks, avoid talking over your shoulder, especially if the group is spread out.

- Location - Choose good places to stop for tour talks. It should be relevant to what you are talking about, as well as comfortable and safe. Don't let the group stand around in the sun, or on a steep slippery track. Don't stop in the middle of a busy market where the group might be blocking the way, or be distracted by the activities around them.

- Positioning - Face the group while talking and stand so that the group can hear you well. They also need to see you in case you point things out or use props. Make sure you don't block their view. Position yourself so that the sun is not directly in the eyes of the group. Avoid where guests encircle you or stand behind you.

- Body language - When you talk, people look at you so your body language is important. Use friendly and open body language. Don't slouch or keep your hand in your pockets while talking. Use hand gestures a lot to emphasise what you are saying, or point things out. When dealing with non-English speaking guests, gestures or hand-talk, may be the only way to make yourself understood.

- Attention - What do you want the tourists to do while you talk? Mainly pay attention, but also understand what you are saying and participate by asking questions. Observe your guests and get everyone engaged. For people who seem disinterested talk directly to them. Remember that tourists are paying guests and you can't scold them for not paying attention like a school teacher might.

- Length of talk - Don't talk for too long. Your tour commentary should be broken 
up in several smaller talks or activities during the tour. If a talk goes on for too long people start to get restless. You don't need to talk constantly during a tour. There is a time for sharing information and a time for the guests to just enjoy the experience.

- Interruptions - Unexpected questions might come in the middle of your tour commentary. This can be annoying as it disrupts your flow. Calmly respond to the question and pick up your story where you left off. Random outside events might also cause distractions, like rain, or wildlife sightings. Experienced guides are used to dealing with this and don't get flustered.

- Passion - Get excited! Show you are interested in what you are doing. If you seem bored about the tour, your guests will pick up on that. If the guest feels that you enjoy what you are doing it will make a big difference to their experience. A passionate guide can hide other weaknesses, for example, poor subject knowledge, by being enthusiastic about the topic.

- Entertainment - Tourists want to have fun on their holiday. While the focus on most tours is about learning and new experiences, it should be entertaining. Information and entertainment are of equal importance for the tourists. Use humour in your talks, joke with the guest and add fun and enjoyable activities on your tours.

- Planning - Plan your tour commentary before the tour. Plan where you will talk. Have a dry-run of the tour by yourself looking for good shaded places to stop for talks. Look for good view points, and places where you can see things relevant to your talks. Once you have led a tour several times you will know the perfect places to talk, rest and stop for activities.

\section{- KNOW YOUR AUDIENCE}

Tourists have different backgrounds. What is interesting for some people can be boring and repetitive for others. What is funny to some, may be insulting to others. A good guide knows how to adapt tour commentary for different groups.

A group travelling in the Pacific for the first time may find everything new and interesting. If the guide shows them how to open a coconut or chew betel nuts, they may never have seen that before. But a group of expats working in Honiara will know about coconuts and betel nuts. For this group the guide needs to go deeper by telling stories unique to that particular area.

To understand more about your group, get to know them a bit. Ask where they are from and why they chose here. Other information that is helpful is nationality, age, profession and where they have been already in Solomon Islands. Find out if they have any special interests. If they carry binoculars, assume they are interested in birds or wildlife. Use casual conversation and observation rather than direct questions.

Assessing your group is to find out what their interests and knowledge are, so you can adapt to suit them. Just like you talk differently to children than you do to adults, you need to adapt your commentary to different groups of tourists.

\section{- ADAPTATION}

Just as you adapt the level of your commentary to suit the tour participants, you may need to adapt it due to events outside your control. If you are a new guide this can be stressful, but experienced tour guides learn to adapt to changing situations and to think on their feet.

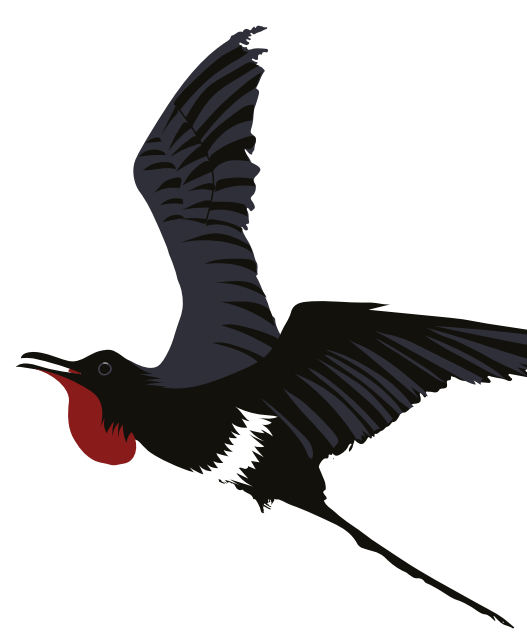

\section{Different levels}

"On the way to our first stop on the tour the guests usually chat to each other. Sometimes I can learn a lot about them by just listening. This is useful because I need to know how to talk to them. It would be stupid to talk to a group of war veterans like they don't know anything about the war. You can't talk in the same way to every tourist, because every tourist is different." 
Here are some common situations where a guide needs to adapt the tour commentary to the situation.

- Running late - Most tours run to specific times. Your guests need to be back in time for dinner, or to be ready for transport. Sometimes, a tour is delayed. Maybe the group walked slow, or asked a lot of questions. If you feel that you won't make it back in time, you need to speed things up. Rather than skipping tour commentary you can shorten it and focus on the important bits.

- Changed route - Sometimes, part of the tour may become unavailable. This may be because of landslides or roadwork. Some sections might depend on local guides who don't show up as agreed. Every tour guide needs to have a back-up plan for events like this. When planning the tour think of what you could do if a place or activity is not available.

- Weather - A common disruption is the weather. You often have to take shelter during sudden downpours. Rather than just sitting around waiting for the rain to stop, use this time to talk about things you were going to talk about during the tour. It's good to bring some props with you, so that you can deliver your tour talk anywhere. You can adapt your commentary to your location. As an example, if you take shelter in a school, you can talk about stories from your own school days.

- Delays - You may have to unexpectedly wait somewhere because of delayed transport. Anyone travelling in Solomon Islands is familiar with delays due to problems with boats. Use the waiting time in the same way you would if stuck somewhere because of the weather. If the delay is long, improvise and add things to talk about and come up with new activities to do while waiting.

A tour guide should be flexible and expect that no tour will go exactly as planned. You should be able to deliver good tour commentary in less-than-perfect circumstances. Plan for back-up activities for each section of the tour.

\section{GUIDING TOOLS}

Interpretation is about making your tour interesting. Tour commentary is the most common form of interpretation, but tour guides also use tools to support their commentary.

\section{- VISUAL AIDS}

It's always helpful when people see things with their own eyes. The most common visual aid is pointing things out and explaining what it is you are looking at. Show people where to look with your hands and give directions "on your left" "behind the boat" etc. You can also use props to make the commentary more effective.

If you pass a tree that was used to build war canoes, stop and explain how war canoes were built. If you see turtle tracks on a beach, use that as a cue to talk about turtles. There are visual aids all around you and every story becomes more interesting if you can look at something related to your topic. The local market is a great source of inspiration. You can talk about where and how the produce is grown or caught, harvested or transported to the market.

Sometimes guides prepare their own props. If you want to talk about crocodiles, you can show a crocodile skull, or bring a photo. In this way, you can talk about crocodiles even if you don't see one. Other examples of props are: 
- Things found in nature - Collect interesting items you find in nature (feathers, eggs, bird nests, shells, bones) and use them while talking about local wildlife and environment.

- Handicraft - Paintings, wood carvings and weaving often have motifs linked to local culture and stories.

- War relics - Old equipment and guns from WWII are great props for stories. Many locals near old battle sites have small relic collections in their homes.

- Maps - Use a map to show where you are and where certain events took place. If you didn't bring one, you can draw a mud map on the ground. This is helpful to explain the big picture of an event which might be hard to understand.

- Reference books - Many guides bring ID guidebooks with them to help identify birds, animals, plants and marine life.

- Tools - Some things are hard to see with your eyes. Guides often bring binoculars to view things in the distance, or a magnifying glass to show tiny details. For wildlife spotting at night, a powerful torch is useful.

\section{- INTERACTION}

Another way to make your tour commentary more engaging is to include interactive activities. This is where people do something, rather than just listen. Visual aids can be used as interactive tools, by letting people touch and feel them.

Example:

- Visual aid - Use a conch shell as a prop for a story.

- Interaction - Show how to use the conch shell as a horn and let people try.

Most museums today include interactive displays where visitors can touch and handle objects. This is more interesting than just looking at things in a display case.

A tour guide can engage all five senses during a tour. Looking and listening to the guide are two. By using interactive interpretation, the remaining three senses are also engaged:

- Touch: bones, feathers, shells

- Taste: food, betel nuts, kava

- Smell: fruits, flowers, herbs

The best interactive tool is for people to do something (experiential interpretation). This is more than just touching something; you want them to try something they haven’t done before. Tourists learn about it by experiencing it.

- Paddle a traditional canoe

- Open a coconut

- Throw a spear

These kinds of activities are much more engaging because the participants are active. This is often the highlight of the tour. When you see tourists laughing and taking lots of photos you know they are having a good time. Some tours are focused entirely on interactive experiences.

- Traditional cooking. Learn about local food and cooking methods.

Activity: Visit a market and kastom garden to source produce and cook using traditional methods.

- Wood carving. Learn about the meaning of cultural symbols in traditional art and try wood carving.

Activity: Watch a wood carver work and take part in a wood carving class.

- Turtle tagging. Learn about turtles and conservation methods. Activity: Interact with turtles in the wild and participate in conservation work.

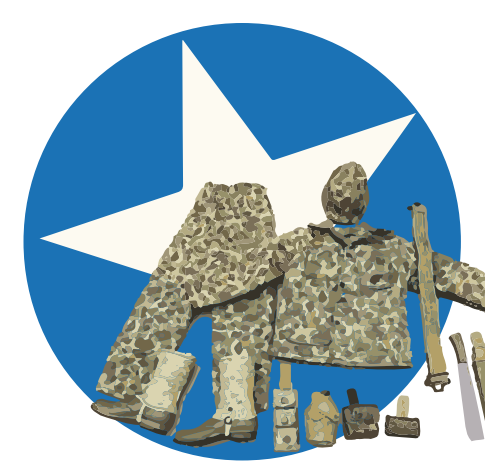

\section{Barny's museum}

"I run my tours out of a small museum which houses my collection of WWII relics. Many people ask me why I don't put labels on the relics which explains what it is. I want people to touch the relics and try to guess what it is. They usually ask me; what is this, what is that, and then I tell them. Then we talk about how it was used and where I found it. I think they learn more this way."

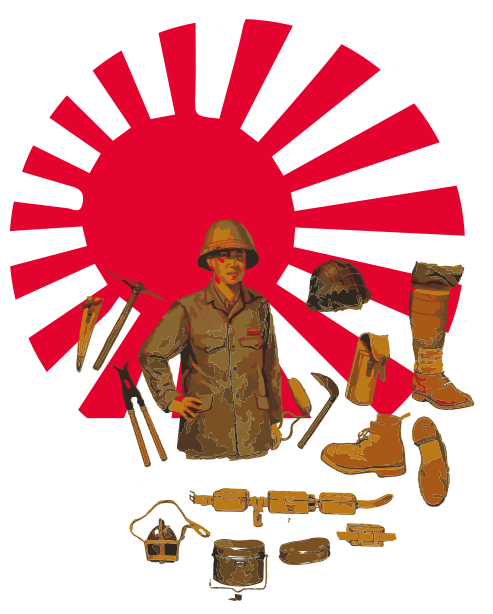




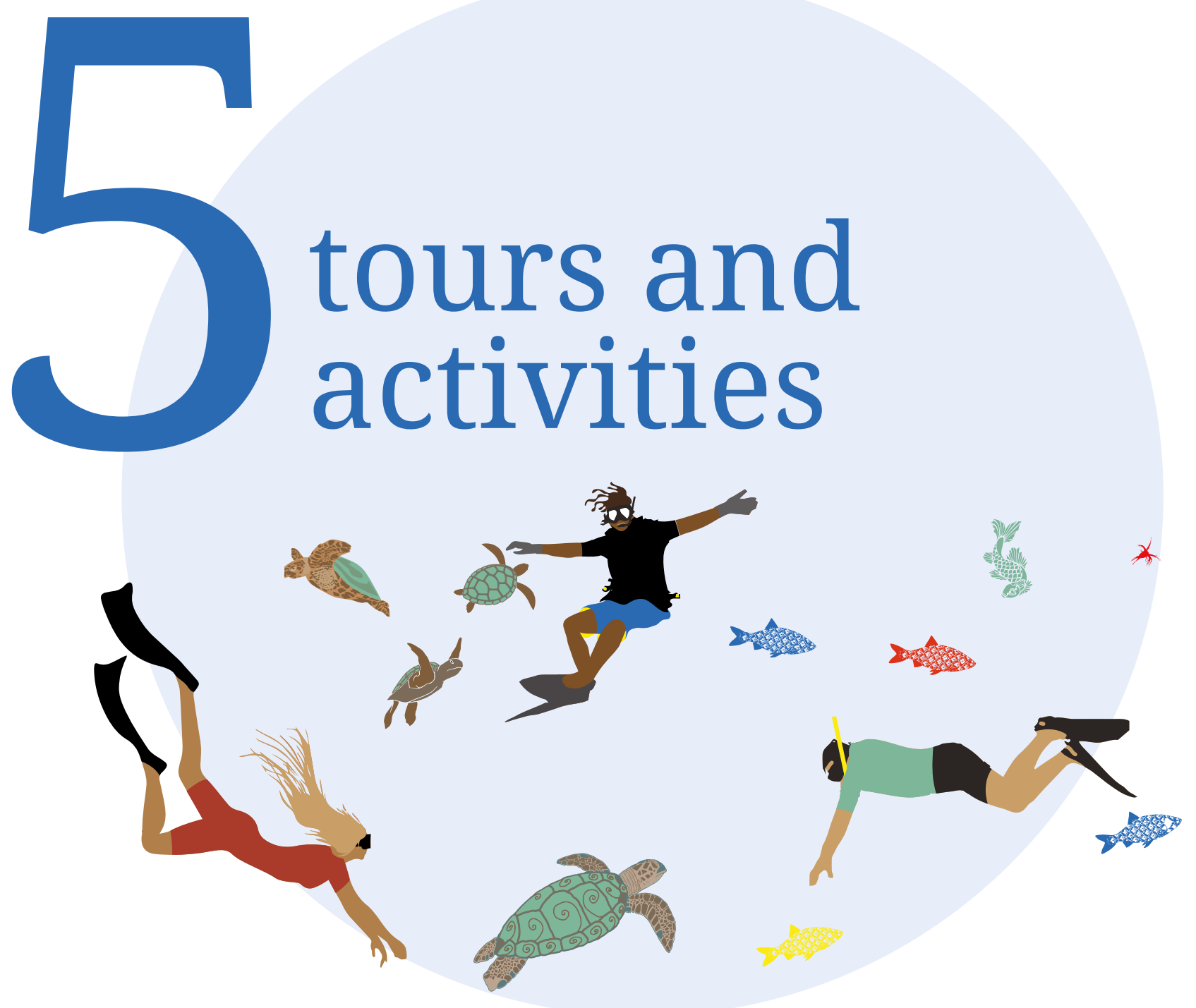

$\because-\infty$
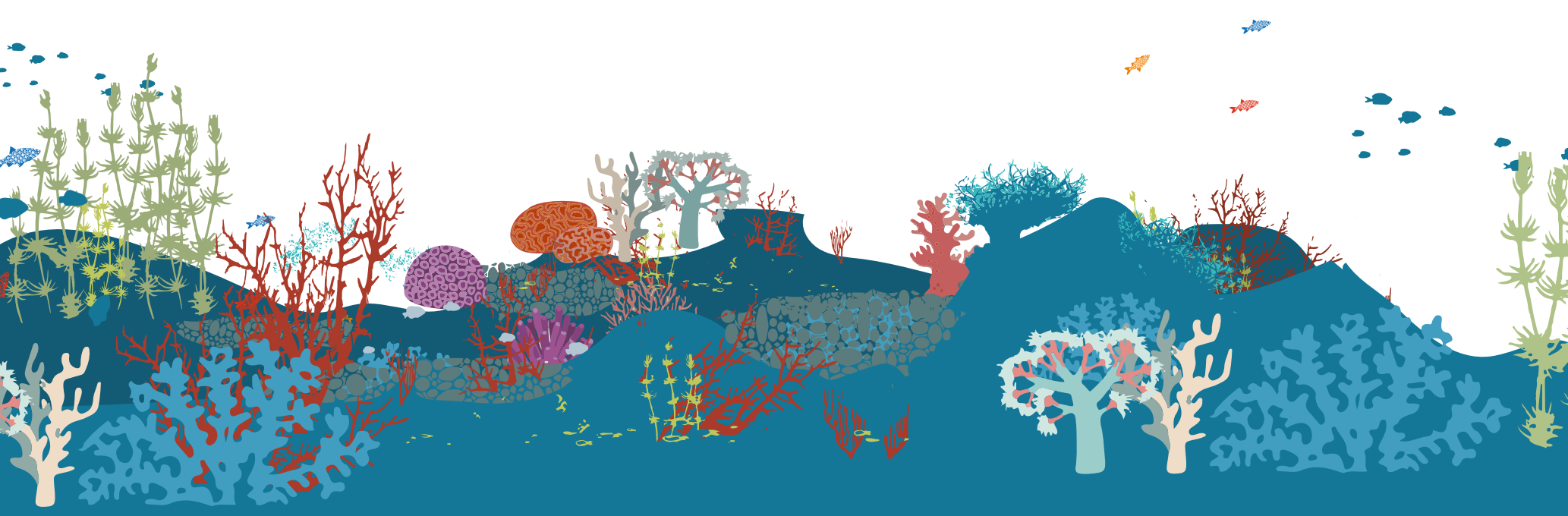
What is the difference between a tour and an activity? A tour is about seeing or learning something new, while an activity is about doing something.

Tour - Visiting several places by foot, boat or car. The tour is often focused on a topic. The guide points out interesting things and provides tour commentary. Tour guides should be good at sharing information and telling stories.

Activity - Focus on doing something like fishing, snorkeling or hiking. The person leading the activity may or may not provide tour commentary. The focus is on the experience and that it is enjoyable and safe. Activity guides should be good at organising the logistics and safety involved in activities.

Tours and activities can be similar. A tour guide may include activities in a tour (e.g., snorkeling) to make it more fun, and an activity guide may add tour commentary to make an activity interesting. Many guides started out by taking tourists on activities. Over time as they learned what interested tourists, they developed their own tour commentary and added to the activity to make it more interesting.

Because tours and activities have so many similarities, and are often blended, you can use the same methods when it comes to planning, organising and leading a tour or activity.

\section{TOUR STRUCTURE}

Tours and activities have the same basic structure.

- Meet and greet - Participants meet their guide at the beginning of the tour.

- Tour briefing - The guide briefs the participants about the tour and safety measures relevant to the activity.

- Tour/activity - The tour starts and runs according to a pre-planned itinerary. It is a mixture of site visits, activities and tour commentary.

- End of tour - The guide delivers tour participants to the end destination. If required, the guide sorts out payments, onward transport and equipment return.

All of the above apply to activities as well. In addition, is the tour logistics, the organisation and delivery of the tour. These are the things you do before, during and after the tour that are necessary for the tour to run smoothly. Let's look closer at the basic structure of a tour.

\section{i}

\section{Excursions}

Shorter tours, like a quick visit to an island by a group of tourists based in a resort, are excursions. When passengers from a cruise ship disembark for a few hours, they are offered a range of excursions. Excursions are outings, or side trips made during a larger journey, such as a multi-day tour, a resort stay or a cruise.

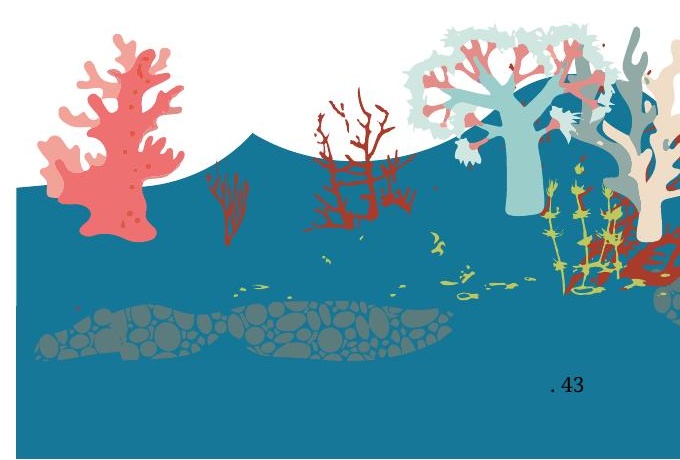




\section{- ITINERARY}

An itinerary is a travel plan, or program. It is an ordered list of things to do and see during a tour. Tour companies and resorts often advertise their tours with itineraries, so that visitors have an idea of what the tour is about. Here is a simple example of an itinerary for a half-day tour:

\section{Vona Vona Eagoon Tour (half-day)}

- Departure: Munda Jetty (9:00am)

- Skull Island: visit famous skull shrine and kastom site in Vona Vona lagoon.

- Kolohite Island: enjoy the beach and snorkel the reefs of an uninhabited island.

- Kuri Point battle: hear the story about a WWII battle and see war relics on site.

- Return: to Munda (12:30pm).

*Price includes boat, kastom fee and morning tea/coffee. Bring your own snorkel equipment.

Itineraries list what the price includes and what people should bring. Some Itineraries have times for activities.

For simple tours with only 2-3 activities the guide should memorise the itinerary. For longer tours with lots of activities the guide should keep a copy of the itinerary. Ensure nothing is forgotten and that time and order are followed.

It's important that the tour guide sticks to the itinerary. Skipping parts of the itinerary is not acceptable, and should only happen if something goes wrong. If you cancel an activity you need to explain the reasons for this to your guests. Acceptable reasons might be bad weather, or if someone gets injured. If people feel that you have tried your best to deliver the itinerary, they will be OK with it. But if you don't explain why the tour was cut short, they will complain and possibly ask for their money back.

Before each tour read through the itinerary to remind yourself of the program.

\section{- TOUR PREPARATIONS}

Most tours and activities require some preparation. Arrange transport, equipment and food beforehand. It is part of a tour guide's job to ensure everything is ready when the guests arrive.

An example of bad preparation is starting a tour by getting fuel at the petrol station. Do this before the tour starts, either the day before or early that morning. The guests shouldn't really be involved in the logistics of the tour. The tour logistics should run smoothly so the guests don't notice it. For complex tours prepare a checklist, listing everything you need to prepare. This may include:

- Transport - The day before, make sure transport and driver is ready, and that you have plans for back-up transport if needed. The most common reason for cancelled or delayed tours in Solomon Islands is boat problems. Work only with reliable transport providers and drivers.

- Equipment - If you use equipment on the tour, make sure it is in working order. There is nothing worse than being halfway into a tour and discovering important gear is broken. If possible, check and pack it down the day before or early in the morning before departure. Tour equipment may include snorkeling, fishing, camping gear and life jackets. 
- Food - If you provide food during the tour, this requires quite a bit of preparation. Unlike equipment, you cannot pack the food a day before the trip. Tour guides have to get up early to go to the market and/or cook before the tours starts. Some tour companies outsource the food preparation to make the logistics simpler. But the guide needs to check that the right kind and right amount of food is packed.

- Pre-departure administration - Your employer briefs you about the logistics of the tour. This includes telling you what falls under your responsibility and what other staff will organise. Before the tour the guide needs to find out the following information:

+ Meeting place/pick up point

+ Tour plan/Itinerary

+ Manifest/number of guests

+ Logistics-transport/equipment/food

+ Other staff-guides/rangers/drivers/cooks

+ Cash for trip expenses-kastom fees, etc.

+ Any special instructions-e.g., vegetarian food, food allergies

+ End of tour/drop off point

If you work for yourself, you need to think of these things as well.

\section{- MEET AND GREET}

The moment you first meet your guests is important because first impressions set the tone of the tour. If you appear well-organised and friendly, it's a good start of the tour. If you show up late looking dishevelled without apologising, it's a bad start of the tour. By starting on a good note, you can minimise problems that may come up later. Show up on time for the meet and greet and welcome guests with a smile.

The meeting point can be the start of the tour, usually, at the guest's accommodation. In Honiara, the participants may be in several hotels across town.

If you pick up people at different locations quickly introduce yourself but wait for the proper meet and greet until everyone is together at the starting point of the tour.

\section{- MANIFEST}

As guests start to arrive at the meeting point you can start to check them off against the list of tour participants. This list of names is a manifest, and is used on tours, particularly on multi-day tours or on tours where there is a certain risk involved, like scuba diving. A manifest is very helpful for the guide, as you have all the names and other details of your guests on one document. A manifest includes:

- Names and nationality of passengers

- Passport number (for longer/adventurous tours)

- Hotel and room number

- Pick up times and drop-off location

- Special needs and food allergies

This is the most common information, but the tour company can add whatever they want. If the guide also collects payments, there is a column to note who has paid.
want. If the guide also collects payments, there is a column to note who has paid.

\section{First impression}

"First impression really matters! I know some very good guides who have crazy hair and lots of tattoos. They have to work harder than other guides to get the tourists to trust them, even if they are better guides. That's OK for longer tours, because over time they have a chance to prove themselves. But for short halfday tours, it's not enough time for the tourists to get over their first impression." 


\section{i}

\section{Head count}

The manifest and the pre-tour check-in is the basis of the all-important headcount that tour guides use to make sure they don't lose anyone. Before starting the tour, you look at the manifest and see how many people have checked in to make sure you know how many people you have. Every time you stop somewhere, you should do a headcount before moving on. This is important for big groups travelling by boat or bus where there is a real risk of guests being left behind if the guide doesn't do a proper headcount.
The person who handles tour bookings puts together the manifest. The guide gets the list the day before, or on the morning of the tour. For some activities where people just show up before the tour without booking, the guide can create a manifest by writing down the names of the participants as they arrive. Before starting the tour, the guide checks the names on the list to make sure it's the same people and number of participants as listed in the manifest.

Guides who work at small lodges and resorts in Solomon Islands often have very small groups with only 2-4 participants. A manifest may not be needed if the accommodation already has the details of the guests. The guide should know the exact number of people. It's preferable that guides get used to using manifests, because as tourism in Solomon Islands grows, the groups will get larger.

\section{- INTRODUCTION}

Once you have checked everyone in against the manifest you should introduce yourself and any other staff on the tour. Use the same presentation technique that was discussed earlier in the Tour commentary section.

- Choose a good locating for the meet and greet.

- Stand so that everyone can see you.

- Speak loud enough so that everyone can hear you.

- Smile and look people in the eye while introducing yourself.

A guide introduction is more than just stating your name. Usually it includes your name, where you come from, and your experience in this kind of work.

"Welcome everybody, my name is ..., but you can call me ... I am from .... village which is on the other side of this island. I have been working at ... tours as a guide for five years. I like this work because I really like showing visitors what is special about Solomon Islands."

If you have a small group, ask the guests to introduce themselves during the meet and greet. Repeat the guests name and ask where they are from. If you can memorise their names, its good, but it can be hard if you have a big group. During multi-day tours you can save the guest introduction for the first dinner. Then you will have more time to let everyone introduce themselves. This works well with mixed groups who don't know each other beforehand.

\section{- TOUR BRIEFING}

After the initial introduction it's time for the tour briefing. This talk is also called a welcome briefing. A tour briefing is an overview of the tour and the places you will visit. You don't need to be detailed since the guest know the overall itinerary from when they booked the tour. You should include things like travel times, rest stops and lunch time. A key part of the briefing is to explain how you want the guests to behave during the tour. This can be related to safety, or cultural protocol.

Don't let the tour briefing take too long. The guests are eager to get going with the tour, and easily get restless. If you have a lot to say, it's better to break it up and brief in segments as the tour gets started. For multi-day tours with lots of activities, you make tour briefings each day or before each new activity. 
- Overview: we will visit three islands/we will look for leatherback turtles.

- Location/direction: in Vona Vona Lagoon/along the beach south of the village.

- Time/transport: travel by boat for 30 minutes/walk from here for one kilometre to the beach.

- Advice: don't forget to put on sun-cream /wear long pants in the jungle if you are sensitive to mosquitoes.

- Rest stop: there is a toilet on the second island/there is no toilet in the bush.

- Participant's behaviour: don't swim alone/don't touch the turtles.

- Lunch/rest: we will have lunch at the second island/when walking uphill we will have frequent rests. We will eat around 12:00.

- Safety: keep life jackets on during boat travel/don't go too close to the water if waves are big.

- Equipment check: snorkel equipment/torch

For adventure activities, where there is an element of risk involved, the briefing is more about safety and participant's behaviour than during a normal tour. Adventure activity briefings are stricter because there are certain rules that have to be followed for the guest's safety. Safety briefings are not suggestions from the guide, but rules to be followed.

It's common for guides to check if the participants are prepared. This can be checking the guest's footwear before a walk. Guides can remind the group before departure, "Did everyone bring a bottle of water and sunscreen?"

\section{- TRANSPORT}

After the tour briefing the tour gets underway, travelling to the first attraction. In Solomon Islands this is usually on foot or by boat. In Honiara and overseas most tours travel by bus. You can organise tours with any vehicle: bike tours, canoe tours, helicopter tours and so on. Before the first trip make a short briefing about the safety features of the transport, for example, the use of life jackets, seatbelts and toilets on board. Help people get settled and if necessary, assign seats. While boarding the vehicle the guide and driver should be on standby to help passengers. This is important when boarding unstable boats in bad weather. During the tour the group will get on and off the transport many times. The guide must make a headcount after every stop to make sure that no one is left behind.

\section{- ON TOUR}

A tour can run for a couple of hours, several days or even weeks. In Solomon Islands most tours are half-day and full-day tours. The logistics of short tours is not complicated. The guide can focus on providing interesting tour commentary and that the guests are safe and enjoying themselves.

Once the tour starts, follow the itinerary while providing commentary, along the way. While you are doing your main job of commentary, there are a few things to think about during the tour.

- Engage - If you show the guests early on that you are friendly and approachable, they will relax and enjoy the experience. Your focus should be the tour commentary, but in between talks, you can engage in casual conversation with your guests.

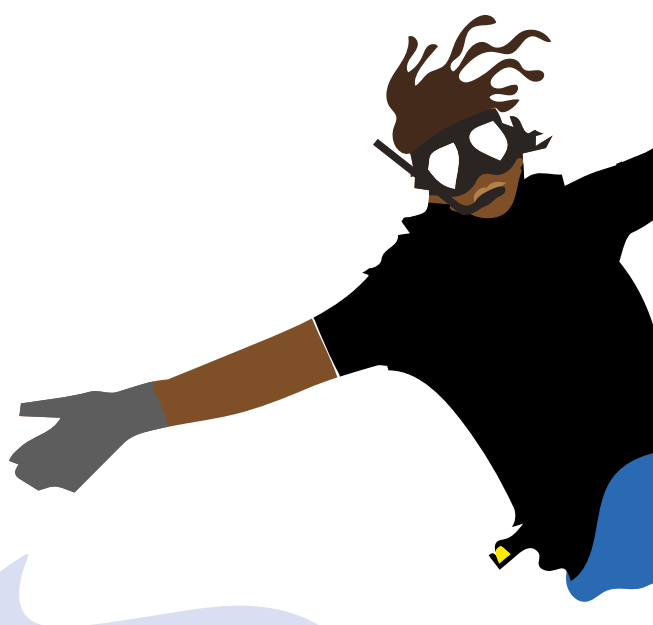

\section{Dive briefing}

"When we are diving it's very important that the guests do as I say. The briefing is not a joke; it can be dangerous if they don't follow my instructions. If they swim in the wrong direction they can get caught in a current and swept out to sea. I always try to be easygoing but if tourists ignore what I say I have to be strict. We even banned some people from diving for not following the rules. Some people think because they paid a lot of money, they can do whatever they want." 


\section{re}

Eye contact

"The tour guides should take off their sunglasses when talking to guests. It's better if they can see your eyes. With a small group look people in the eye when you talk. We tell our guides, if they work on the boat on a very sunny day, they can have sunglasses on. But in the bush or village it's not necessary. If you wear them, it's rude if you don't take them off when you talk to the guests."
- Observe - As a guide you are always on the lookout for interesting things to point out. You should also keep an eye on how your guests are doing. Does someone look unhappy about something? Be proactive and handle problems at an early stage.

- Time management - Keep an eye on the time throughout the tour. Depending on how many questions you get the time spent at each stop will vary. You don't have to stick to exact times for each stop, but try to move the tour along. If you spend longer than planned in one place, you need to pick up the pace later.

- Comfort - Remember to think of water stops, rest and toilet breaks throughout the tour. Observe the guests to see if they look tired, and also ask them if they need a break. Some tourists are shy to ask for toilet breaks, so you need to tell them where this is available without being asked.

- Personalise - Adapt the tour to the participants. Remember any particular requests and try to fulfil them. If they are a small group of birdwatchers you can focus on finding birds, even if the tour is not strictly about birdwatching. Your goal is to make your guests happy.

- Energy - Throughout the tour remain enthusiastic and friendly. This is easy if everything goes to plan, but some tours can be challenging. By the end of a long rainy day, you may be tired and cold, and fed up with answering questions. Don't let this show, but stay professional throughout the tour.

There are many additional things to think about while leading a tour, which will be discussed in more detail in the next chapter Tour management.

\section{- END OF TOUR}

Tours usually end where they start, back at the guest's accommodation or the tour office. To wrap up the tour, guides have a small end-of-tour talk. If the tour has a strong theme this final talk might take place at the last stop of the tour, preferably a place that is relevant to the theme. During this talk you should emphasise and repeat the theme and remind the guest what they have seen and done, to reinforce the highlights of the tour and end on a positive note. Finally thank the guests for joining the tour and wish them safe travels.

Before the guest leave there are a few more tasks to complete. Tour companies ask guests to fill out feedback forms or guest books at the end of tours, and these are handed out by the guide. Sometimes the guide also needs to collect payments, or make sure equipment is returned. Check inside the tour boat/vehicle if anything has been left behind before the guests leave.

If anyone has asked you for additional information (for example, the names of birds seen) or want to make arrangements for additional tours, help those people once the rest of the group have left.

\section{- POST-TOUR LOGISTICS AND ADMINISTRATION}

Just like before the tour, there is some logistic and administrative tasks to take care of before your work is over. If the tour is a half-day tour this will be minimal, but for longer multi-day tours there can be quite a lot of work at the end of a tour.

- Equipment care - Any equipment used, such as snorkeling gear or tents, need to be cleaned and dried in preparation for the next tour. The guide is the only 
one who knows if something broke during the tour, so it's your responsibility to report this to your employer. For a 3-day camping tour it may take a whole day to sort out all the gear afterwards. If your company uses its own transport, the guide usually helps to clean it after each tour and makes sure equipment such as life jackets are stored properly.

- Trip expenses - On many tours there will be some expenses that are paid by the guide. To cover this, guides are given some petty cash by their employer. In some cases, the guides also collect tour payments from the guest. After the tour, the guide needs to hand in the cash together with all the receipts. If there are a lot of expenses, use an expense sheet which lists everything paid during the tour.

- Trip report - It's important to let your employer know how the tour went. If there were any incidents, they want to hear about it. It is difficult for them to handle a complaint if they haven't heard your version of the story first. For smaller tours and companies, it might be enough to check in at the office after the tour and tell them everything went well. For longer tours the company sometimes ask for a trip report, which is a written summary of how the trip went. If something happened on tour that led to injury, or something that may result in serious complaints, you should write an incident report which describes what happened and how you handled it.

- Prepare for next tour - Many tour operators in busy destinations run tours back to back. This means if you do a tour in the morning, you may have another one in the afternoon. During busy times guides leading multi-day tours may not have any time off in between tours, and the guide needs to start preparing for the next tour immediately. Apart from the normal tour preparations you need to think about if any tour equipment needs to be replaced or repaired.

In this section we have covered the different components of a tour. You may not go on to work exactly as described here, but the majority of tours around the world are structured in this way.

\section{MANAGING ACTIVITIES}

Often tours and activities are combined, and it is common to break up a tour with a fun activity. Guides need to be able to switch from being interpretive guides to activity leaders. As mentioned, activities are about doing something, for example, snorkeling or fishing. You can add some interpretation as well, but the focus is to arrange an activity in an enjoyable and safe way.

You already briefed the group at the beginning of the tour. The activity briefing is focused on demonstrating how to do something, the use of equipment and safety rules. If the activity requires equipment, always make sure it is ready before the tour. Don't use broken, ill-fitting or dirty equipment. This is particularly important for activities like scuba diving or rock climbing where equipment failure can be fatal. Remember that the guest may not have used this equipment before. The guide should explain to everyone how it works and how to put it on. Before the activity you should check that all the gear is being worn correctly.

During activities there are three roles for the tour guide:

- Lead the activity

- Participate in the activity

- Monitor the activity
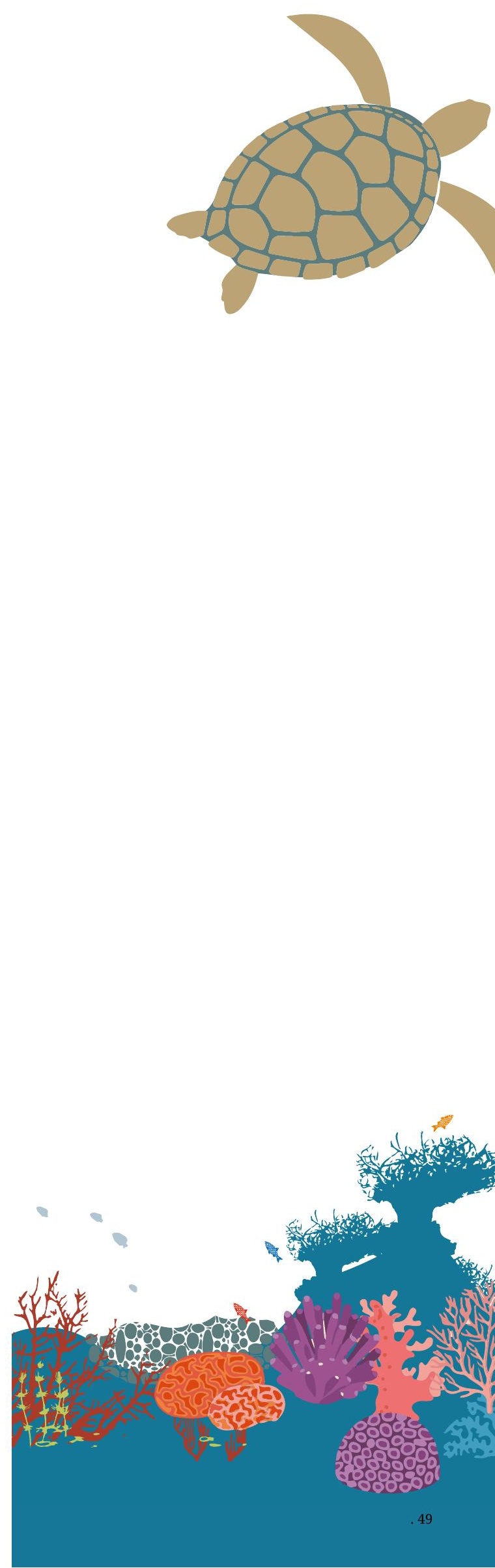


\section{not enough clothing}

"most of the tourists behave very well when we visit local villages, we rarely have

any problems. Maybe the tourists that come to Solomon Islands are more experienced travellers than in other

places. The most common problem is young women who wear too little clothes, or stay too close to their boyfriends. another issue is people taking pictures without asking, or walking away in the middle of a welcome ceremony. This is very rude in our culture."
It is never allowed for tour guides to leave the group, sleep, or get distracted while guests engage in an activity. Even if there is another person doing something relatively safe like a weaving demonstration, the guide should be present to make sure everything runs smoothly. Even if your direct participation is not required you should remain with the group and observe from the background. If you choose to join the activity it's appreciated by the guests. It shows that you think it's fun as well. For activities where risk is involved, for example, snorkeling, the guide should stay close and constantly keep an eye on everyone. Preferably such an activity should have two guides, one in the water leading the activity, and one in the boat monitoring the participants. Never, ever, lose sight of your guests while they are in the water. Do frequent head counts to make sure you are not missing anyone.

A tour doesn't have to be jam-packed with activities and tour commentary from start to finish. Give space for quiet time, and also a chance for the guests to do their own thing, especially on longer tours. This can be time to enjoy the view, or take photographs. Give set times for the free time to avoid people wandering off. A common example in Solomon Islands is a visit to an uninhabited island where the guide tells the guests that they can do their own thing for half an hour before the tour continues.

When managing cultural activities or visits to local communities the tour guide needs to explain about cultural protocol, for example, dress code or certain behaviour that is frowned upon. A common issue is tourists wearing inappropriate clothing for village visits. You need to monitor this and advise your group if necessary. Also stand by to deal with any misunderstandings between locals and your guests.

\section{- LEADING WALKS}

In Solomon Islands a common tour activity is walking. It might be walking to get to an attraction, or just to enjoy the scenery along the way. Walking for recreational purposes is popular and is referred to as bushwalking (Australia), tramping (New Zealand) or hiking (America). Bushwalking is considered a soft adventure activity and the guide needs to apply basic outdoor leadership skills while leading a walk.

\section{Before the walk}

- Check the weather forecast - Guides should always keep an eye on the weather. Many guides access weather forecasts on their phone before each tour. It's hard to walk along wet and slippery trails in steep terrain. If part of your walk can't be done in heavy rain, you have to plan for an alternative route. It's acceptable to cancel an activity because of weather, but you should have a back-up plan for something you can do instead.

- Bring the right equipment - A guide should always carry a backpack, even on a short walk. There is no situation where a guide doesn't need to carry anything on a tour. At the bare minimum you should have a first aid kit, extra water and other tour related equipment. More on this in Chapter 7 under Guide kit.

- Toilet kit - If you walk in the bush the whole day, eventually someone will need to use the bathroom. A toilet kit should include a roll of toilet paper, a small shovel and hand sanitiser. Mention that you carry a toilet kit in the briefing. If someone asks for it, explain that they should go at least 20 metres from the track and dig a shallow hole, which should be covered up after use.

- Use proper footwear - Flip flop sandals are the most common footwear, both for locals and tourists. This is not suitable for a bushwalking as many trails are slippery and can be difficult to walk on without proper closed shoes. Remember that the most common tourist injury is from slips and falls. 
If you are going on a longer walk, you should insist that the guest wear proper shoes, and you should act as a role model by also wearing shoes. It's not necessary to wear heavy trekking boots, normal trainers with a good grip is enough.

- Bring an assistant - If possible, bring someone with you on longer or more difficult walks. This doesn't have to be a fully trained guide; any reliable person will do. The assistant should walk in the back of the group as a sweep to make sure there are no stragglers. The assistant can also help carry stuff, help guests on difficult parts and prepare lunch. In an emergency, the assistant can run for help while the main guide stays with the group.

- Briefing before walk - If the walk is longer than 30 minutes always give a briefing before you start. Mentioned how long the walk is (both distance and time) and give an idea of the terrain and trail conditions. Also mention rests, any hazards or highlights along the way and how you want the group to behave during the walk. For example:

"The walk to the waterfall is 4 kilometres. It takes 1.5 to 2 hours to get there. There are some hills along the way, and some places may be a bit slippery. We will have a break halfway at a nice view point. During the walk please don't go ahead of me. My assistant is walking last to make sure no one falls too far behind. If you lose sight of me, and come to a section where you are not sure which way to go, wait for the guide in the back to catch up with you. Don't stray off the track without telling anyone. During the walk keep an eye out for bird life, we usually see some beautiful endemic birds on this walk."

As part of a walk briefing, tell the group that you have extra water, first aid and a toilet kit with you. This shows that you are well prepared and will make the group feel more comfortable with your leadership.

Options - On some walks you may have several options, if you think the group might struggle with a certain walk, you can suggest an option where they walk one way and take a boat back. It's important to explain the options in detail during the briefing. If they decline to go back by boat it may not be possible to change, even if they get tired later. Tourists often underestimate how draining the heat and humidity in Solomon Islands can be.

\section{- During the walk}

- Don't let stragglers out of sight - Keep a steady pace, but don't walk so fast that you get ahead of the group. If you lose sight of anyone, wait until you see them again before continuing the walk. Preferably the slowest walkers should be in front just behind the lead guide. If the trail is so narrow that you need to walk in single file, try to mix up the order from time to time. As mentioned, it's good to bring an assistant as a sweep in the back of the group.

- Assist through difficult sections - If you see people struggling always give a hand, especially on slippery or steep parts of the trail. On difficult river crossings, the guides should form a line and help the guests, or take them across one by one. Observe how people are coping to assess how much help you need to give. People react differently to assistance. Some people are embarrassed to ask for help, while others really appreciate a helping hand.

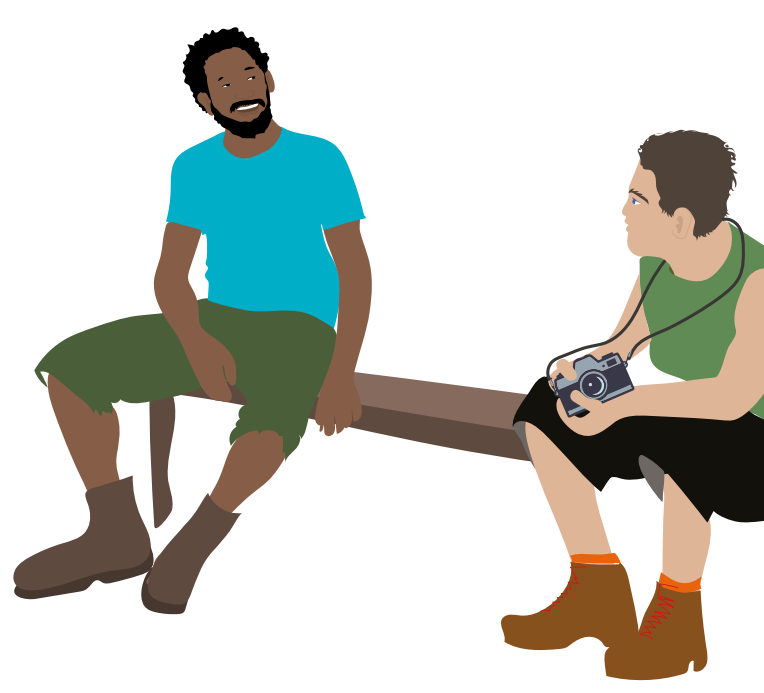



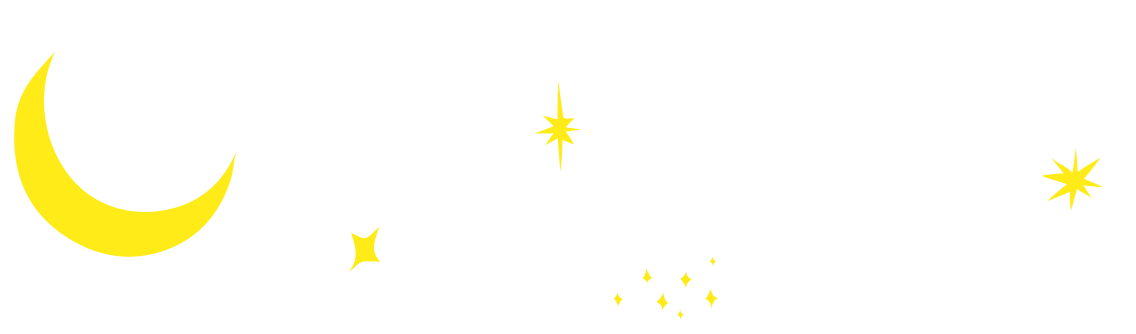

breaks. By keeping the same pace it's also easier to estimate how long it will take to cover a certain distance. The most important thing is to plan the distance for each day, so that each day is a comfortable walk; not too short and not too long.

- Always two guides - Overnight treks have at least two guides. While there is always a leader, there can be one or more assistants. For larger groups there are porters and cooks as well. Since a guide should never leave the group alone, it's almost impossible for one person to lead an overnight trek safely. Sometimes one guide needs to go ahead of the group to prepare camp, other times one guide stays behind to help stragglers. Working as an assistant on treks is a good way to learn how to lead and organise overnight tours. If there are several female guests in the group, it's a good idea if at least one guide or assistant is a woman.

- Start early - You want to do most of the walking early in the morning before the sun gets too hot. Check how long it takes to make breakfast and break camp. If it takes two hours and you want to leave at seven, you need to wake up at five. Trekking guides rise early each morning to start preparing for the day's walk. The first morning, breaking camp will take a long time. It is quicker each day as staff and guests become more organised.

- Don't walk too late - You should arrive at your destination early to mid-afternoon. Walking the whole day in tropical heat is tiring. If you arrive to your camp early, the guests have time to explore the surroundings for a couple of hours. Never walk past $5 \mathrm{pm}$ otherwise you may have to set up camp and cook in the dark. When you are tired, setting up camp always takes longer than you think so plan ahead and start early. Practice setting up and breaking camp so that it becomes routine.

- Water - You can survive without food, but not without water. Because of the heat and the hard work, trekkers will sweat a lot and need several litres of water each day. Add to that water for cooking and cleaning and a trekking group will need a lot of water each day. You can’t carry that much water with you, so you need to be sure that there are accessible water sources along the trail. Once you have the water, you need to boil or filter it. Stomach problems due to dirty water is common during trekking.

- Communication - Trekking usually takes place in remote areas, where it is rare to have phone coverage. Mountainous terrain can also block signals, even if a tower is nearby. Trekking guides often carry short wave radios to communicate with each other. While leading a big group, walkers can become spread out over several kilometres. The lead guide and the group sweep (person in the back) can use radio to talk about the group's progress. Trekking guides often carry satellite phones for emergencies. If you don't have radios or a satellite phone you need to bring an assistant who can act as a runner in case of emergencies.

- Camp sites - On overnight treks there may not be accommodation available, and the tour guide has to find a camp site in the bush. It's best to scout out a good camp site before the trek, or ask locals if they know a suitable place. The camp site should be a flat dry area with sufficient room for all the tents. Make sure the site in not prone to flooding in heavy rain. There should be a water source nearby where trekkers can wash and collect water.

- Bush toilet - An important part of the camp is the
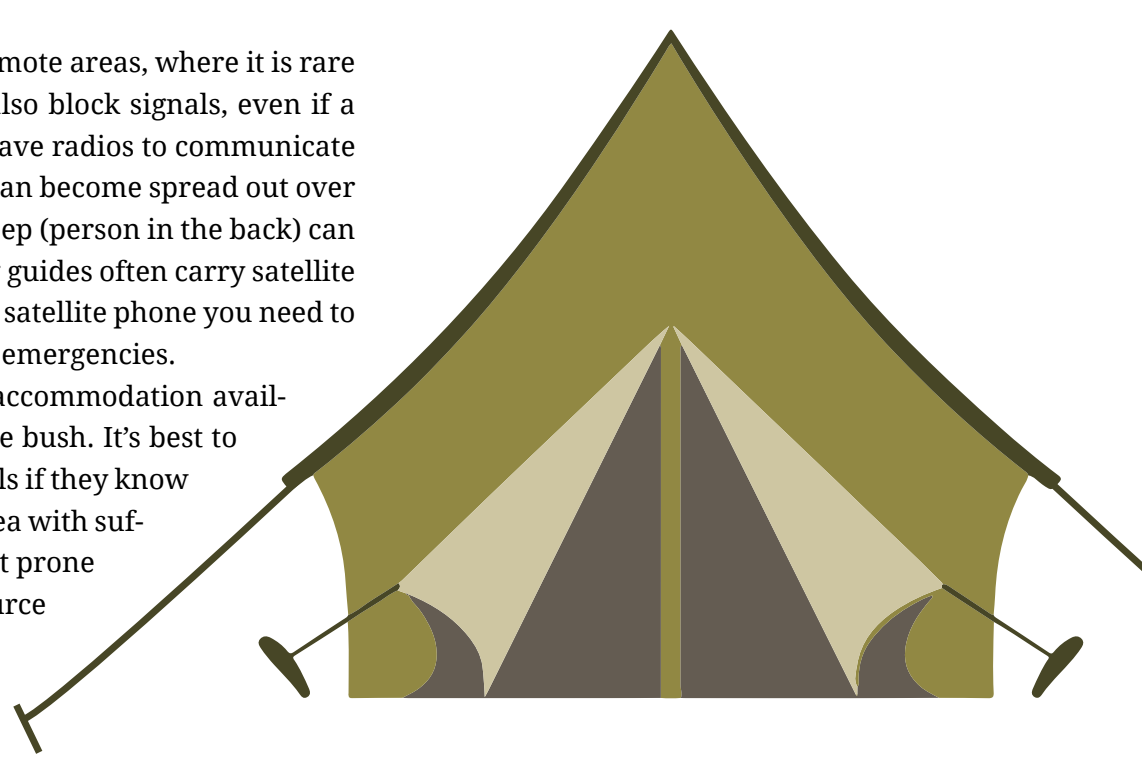
toilet. It should be sufficiently secluded that everyone feels comfortable using it, but not too far away so that people can get lost in the dark. A bush toilet may just be a shallow hole in the ground with a raised tarp for privacy. Trekkers sometimes get stomach problems (gastro) because of bad camp hygiene. Make sure to use separate locations for washing, drinking water and toilet. Drinking water should be collected upstream, and washing should be done downstream. Don't place toilets near water sources.

\section{Tour talk while trekking}

"During trekking tours, we have a lot of time to talk the guests in the evenings when we have dinner in camp. This is when we get to know them and tell our stories. During the walks it's sometimes too hard to do tour commentary, but we try a bit during the breaks. But the main priority is to manage the walk and get the group to the camp safely and in time."
- Leave no trace - Overnight tours produce a lot of rubbish, mainly from food packaging. If you trek through a pristine forest, you should never leave anything behind. This is known as a leave no trace policy. Once you leave a camp site there should be no trace of the group other than flattened grass and some broken branches. Always bring a rubbish bag and place it in the middle of the camp. Remind the guests to place all rubbish in this bag. Also make sure that staff don't litter. Before leaving the camp site make a sweep through the area to make sure no litter or cigarette butts are left behind. If you have used an open fire, make sure the fire pit is extinguished and covered. Bush toilets should be covered up with stones or soil.

- Contact person - Never leave on a walk or overnight trek without telling anyone. There has to be someone who can raise the alarm if you don't return on time. This person should be someone who is familiar with the walk and understands where you might be, or what has caused the delay. This person should be able to make a judgement call if its best to wait, or initiate a search right away. The contact person has to be reliable and able to set a rescue mission in motion. Porters - Increasingly local people are hired as porters in trekking destinations around the world. This is a good way to share the economic benefits of tourism with locals, and it also makes the trek more enjoyable for the tourists. Some tourists insist on carrying their own pack as a matter of pride, or to challenge themselves. Try to explain the benefits of using a porter. If you use porters, they must be advised on how to interact with tourists as well. One important rule for porters who carry guests' personal packs is to always stay with the tourists. If the porters walk ahead an unforeseen incident might mean that the guest and porters become separated, and the guests don't have access to their luggage. Manifest - Use a proper manifest for overnight walks, where participant's names, nationality, hotel and passport numbers are recorded. If there is an accident that requires evacuation the police, hospitals and consular staff from the tourist's embassy will need this information.

Organising overnight treks is considered advanced tour guiding due to all the logistics and equipment involved. Before considering leading a trek, get more experience as a tour guide, and join more experienced guides as an assistant. Managing trekking tours is best learned by handson experience. 


\section{WILDLIFE VIEWING}

Seeing animals in their natural environment is one of the main reasons people travel. Something as simple as seeing dolphins playing around the boat may be the highlight of a tour for some people. If possible, try to include wildlife encounters in every tour. Solomon Islands is best known for its rich bird and marine life. On land there are few animals to see, mainly reptiles.

\section{- WHILE LOOKING FOR WILDLIFE}

- Tell everyone to be alert and look around for animals. Encourage the guests to point out anything you may not have spotted.

- Tell the guests to be quiet before entering areas where you think there may be wildlife. Once you move past that area, indicate that it's OK to talk again.

- Even if you're not seeing wildlife, point out other things of interest to limit the disappointment of the guests.

- Keep your integrity as a guide. Resist pressure by guests to get too close to animals, or feed them if it's not allowed. Your professional reputation is more important that the guest's satisfaction.

Remember to manage expectations, don't promise to see wildlife if you are not $100 \%$ sure you will. Guides should remind tourists that there are no guarantees in the wild, it's not like a zoo. Interactions with wildlife should be conducted in a way that doesn't harm or stress the animals, while at the same time being safe and enjoyable for the guests. Stress on wildlife is hard to measure. Some parrot species can happily sit in a tree in the middle of a village, while other parrot species can become extremely stressed seeing humans. If tourists regularly disturb wildlife, it can change their natural behaviour, or displace them. Guidelines for how to interact with wildlife vary somewhat from area to area, but there is some basic advice that applies in most places.

- Keep your distance when viewing wildlife. Different species have different limits that they are comfortable with. Don't get so close that the animals get stressed and leave.

- Don't feed wild animals. This encourages unnatural behaviour. Some animals that get fed regularly can become aggressive.

- Keep groups small. It's hard to stay quiet and spot wildlife with large groups.

- Don't encourage keeping wildlife captive by visiting places where animals are kept in cages for no reason (a properly managed zoo or conservation centre is different).

- Don't touch a wild animal. If you do, wash your hands as soon as possible. Many diseases start from human contact with wildlife. It does not benefit the animal. The scent of humans can lead to young animals being abandoned by their mothers.

- Explain the rules for wildlife interactions before the tour and make sure they are followed. People can get excited when they encounter wild animals and may need to be reminded.

- Wildlife trade is illegal. Don't encourage trade in wild animals or parts of dead animals. Locals may try to sell turtle shells, shark jaws or crocodile skins. Tourists seeing items like this being sold, may assume it is legal. Explain that these items cannot be exported and that they risk huge fines both in Solomon Islands and overseas.

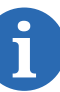

\section{Conflicting views on wildlife interaction} wildlife tourism guidelines advice is that you shouldn't disturb, or touch wildlife, or keep them in cages. But what about zoos and activities like animal tagging? Rangers and scientists might need to manhandle animals during research. This is a necessary part of protecting the species. Keeping some animals in cages in zoos might be the only way to avoid extinction. Well managed zoos are also good at educating people about wild life and raising awareness about threats to wildlife. There is a big difference between tourists and trained personnel like rangers, and this is why different, sometimes conflicting rules seem to apply. 


\section{- MARINE WILDLIFE}

Whale and dolphin viewing from boats is a popular activity in many destinations around the world. There are a lot of opportunities to see amazing marine life in Solomon Islands. Many iconic species like dolphins and turtles are regularly seen. Recommendations for:

\section{- Marine mammal viewing}

- If following a group of animals with a boat, drive parallel to the group.

- Do not stay with a group of animals for too long (maximum one hour).

- Don't drive into a group so that they get scattered. This can separate mothers from calves.

- Never use the boat to herd a group into a particular direction.

- If using two boats don't approach the group from different sides.

- If following a group don't get too close (recommended 30 metres).

- Slow down when getting close to whales or dolphins. Never drive full speed in the vicinity of groups of animals.

- If animals approach the boat to play in the bow wave, slow down and keep a steady course.

\section{- On turtle nesting beaches}

- Avoid bright lights and camera flashes. Some operators insist on red lights only.

- Avoid making too much noise.

- Take care to not disturb or touch the mother turtles laying eggs. Do NOT walk or stand in front of the nesting turtle.

- Look around for hatchlings so you don't step on them by mistake. Never pick up a hatchling unless with a trained professional.

- In the water never grab a turtle or chase after it.

\section{Stakka crocodiles!}

"Some guests have too high expectations, thinking that they will see wildlife very easy. I always tell the guides to not promise too much. This is a protected area with lots of wildlife, but it's not a zoo. When tourists arrive, they always ask what they can see here. One of our tours is a walk to a lake and the guests asked if they would see crocodiles. 'Stakka' the guides responded, but then they never saw any and the guest were very disappointed."

How strict these guidelines are enforced varies from place to place. If there are a lot of tourists, there needs to be strict rules to limit the stress for the animals. This is often enforced by rangers. In Solomon Islands, which has low tourist numbers, it's still rare to encounter another tour group in the field, but that might change in the future.

Remember that marine life is not only about the large creatures you see, it involves all the living things in the sea. The corals that make up the reefs are living organisms as well. One negative impact of large numbers of tourists is damaged reefs. Always brief tourists to be careful when snorkeling so that they don't damage the reef. Snorkellers should never walk on the reef, or break off corals, or collect living shells. Tourist boats should not throw anchors on fragile coral reefs.

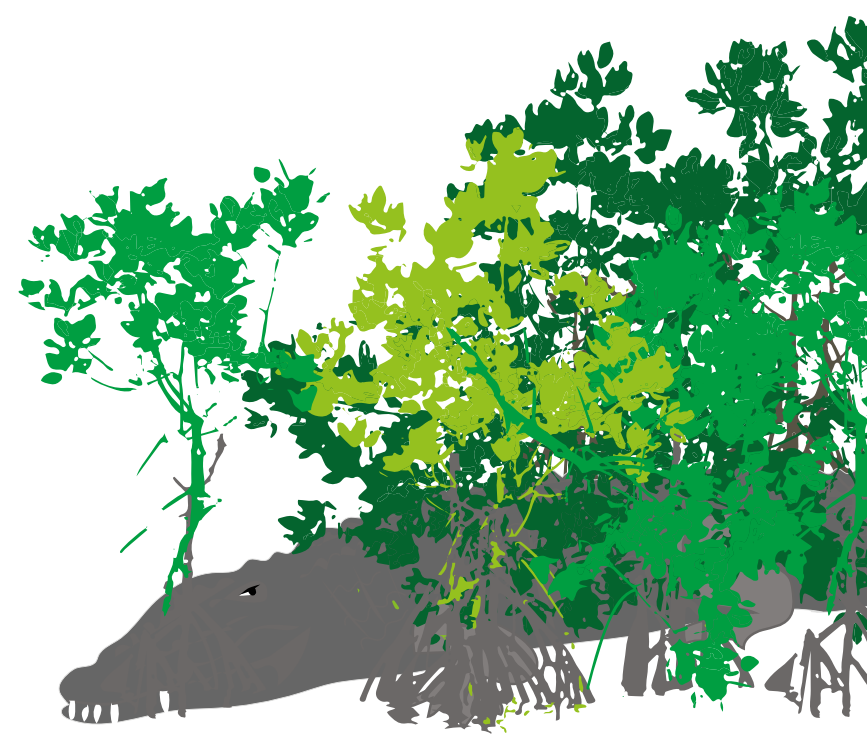




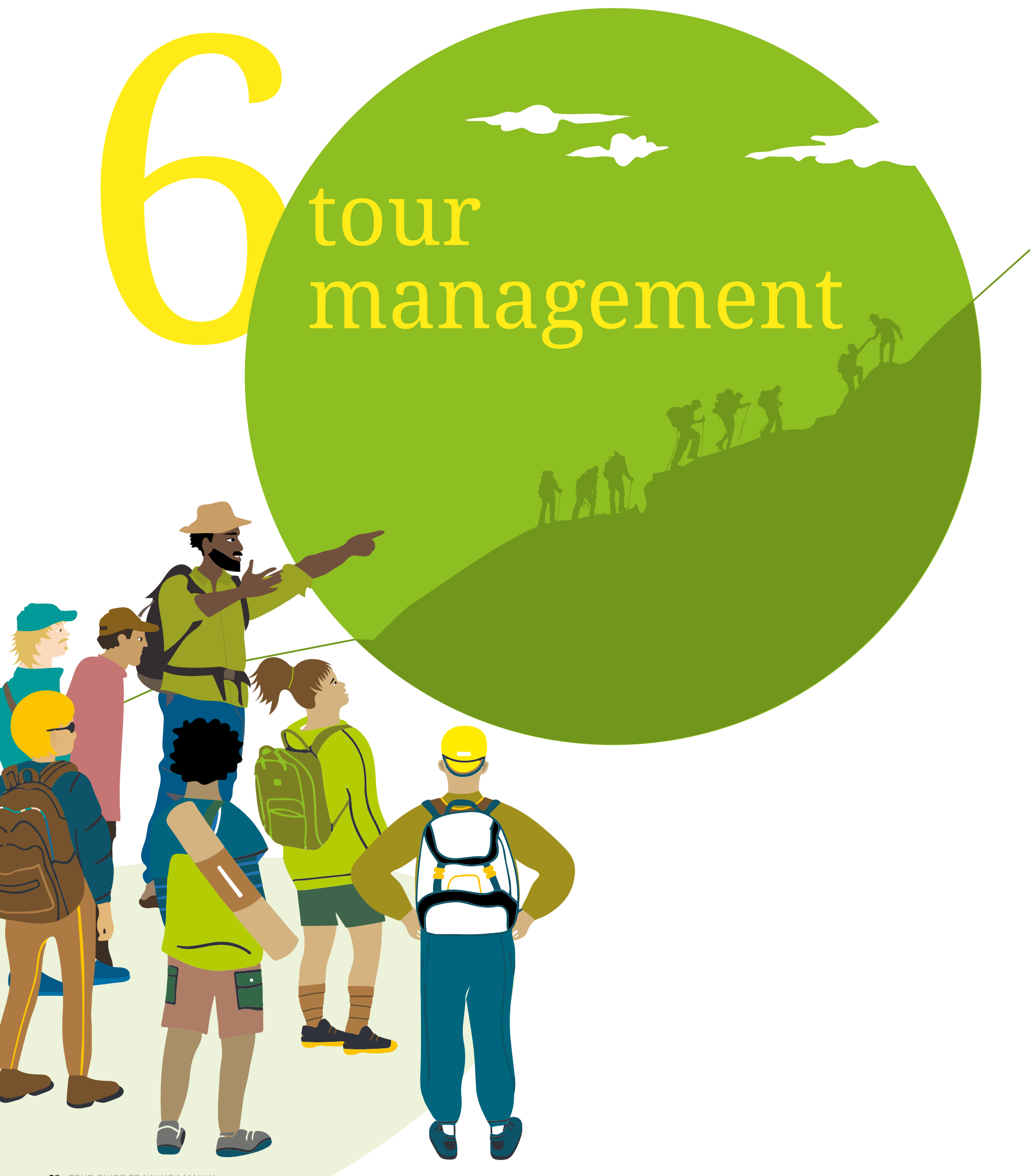




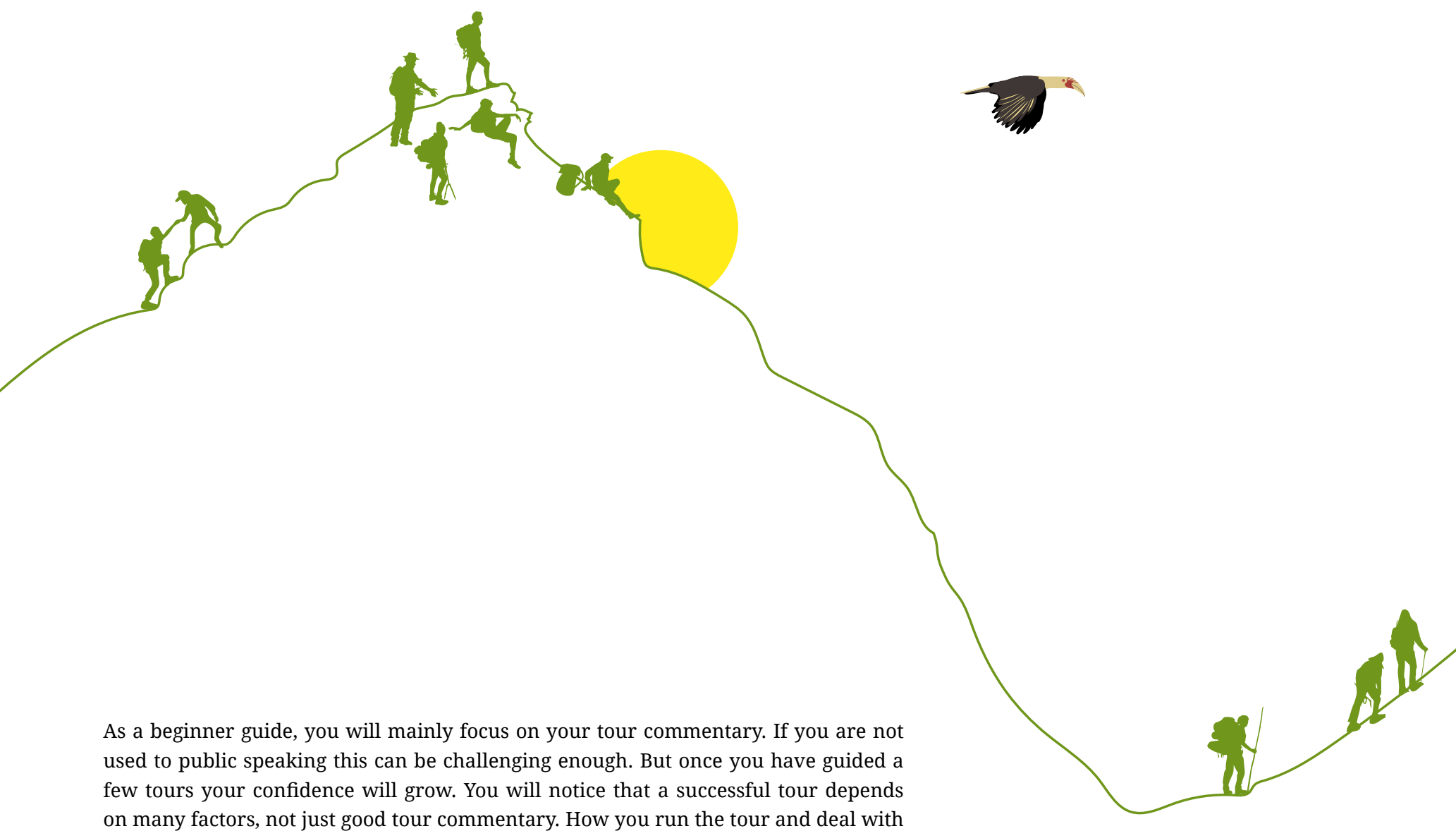
different situations is also important. This part of a tour guides job is referred to as Tour management.

\section{- TOUR GUIDE VS TOUR LEADER}

The person who leads a tour is often called a tour guide or tour leader. There is actually a difference between those two roles.

Tour guide: focuses on providing tour commentary or leading an activity. A tour guide often works in a particular area, or specialises in a certain activity. The main role of a tour guide is to provide tour commentary.

Tour leader: also work as a guide, but the main responsibility of the tour leader is to manage all aspects of a tour. This includes making sure that tour logistics runs smoothly. Tour leaders have additional tasks such as dealing with payments and reporting to the office. The tour leader stays with the group for the entire duration of the tour, while guides may only lead parts of it.

Large tour groups may have one tour leader and several guides as assistants. To become a tour leader, you need to work as a guide for a while and show that you are organised and responsible enough to take on this role. Tour leaders often lead complex multi-day tours that cover a large area.

In Solomon Islands most tours are day-trips and not that complex. The tour guides often have to fill the role of the tour leader as well. The exception is when big cruise ships make shore calls. Experienced tour leaders can be in charge of groups with over 100 guests, but they use several assistant guides to help them manage the tours.

\section{Working with translators} "Sometimes we have asian tour groups coming to Honiara. They usually have their own tour leader who speaks English, and our role is to be the local tour guide. If they don't have a tour leader, we have local translators who speak Chinese or Japanese who help us. It's important that the translators work well with you, otherwise the tourists can try to take control of the translator and use them to push for changes to the itinerary or extra services." 


\section{TOUR GUIDE LEADERSHIP}

As a tour guide, you are not just following tourists around, you are leading them. If anything happens during the tour, you are responsible. In many countries, guides are also legally responsible for the safety of tour participants. The group will look to you for leadership if any issues come up. You need to establish your role to be accepted as a leader by your guests. If you appear shy, disorganised and don't take charge of the group, they won't listen to you. Leadership has a lot do with experience, but also with personality. You don't need to act like a bully to be a leader, there are other ways to establish this role.

Confidence - Act like you are in charge and you know what you are doing. Speak loud enough for everyone to hear and look people in the eyes while talking. Engage with the group and be confident in yourself as a leader of the tour.

- Even tempered - Throughout the tour be enthusiastic and positive. Even if it rains the whole time, don't show the guests that you are cold and miserable. It's important to remain calm and don't show stress or fear if faced with problems. Your mood is contagious to your guests. Never lose your temper with guests or colleagues, even if you are frustrated.

- Lead by example - Be the first to cross a river or climb a steep section of a trail. Help both guests and staff when needed. Be a role model and others will follow your lead. If you tell your guests to wear a life jacket, you should be wearing one.

Mutual respect - Be respectful to your guests. They should respect you as well. There are times where you give the group instructions that have to be followed. If you have established yourself as a leader this is not a problem, but you need to be firm if the situation calls for it.

- Manage - You are in charge of the whole tour, including other staff. You need to show leadership towards the people under your supervision. Don't undermine or embarrass other staff in front of guests or colleagues, but make sure all staff are performing to the standards set by your employer.

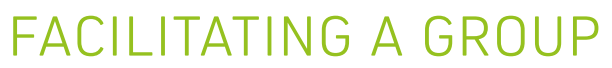

When leading a group of people, the main focus of most guides is delivering the tour according to the itinerary. For the tourists the tour might be as much about meeting other people and having fun. The tour guide should think beyond the itinerary and make sure that the whole experience is enjoyable. A tour guide acts as a group facilitator to ensure that everyone is comfortable and having a good time. This is important on multi-day tours where people spend a lot of time together.

Establish rapport - Try to establish a rapport with everyone in the group as soon as possible. This will make your guests comfortable with you. Give equal attention to all participants regardless of their age, wealth or attractiveness. While it's good to be friendly, your clients are paying guests. Remember, if you get too close to them, it can be difficult to maintain your role as a leader.

Social facilitator - If you have a group of different people who don't know each other you may need to help break the ice between them. Try to bring people together, and avoid anyone being left out of conversations. If there are disagreements between people in the group, you need to mediate even if its awkward for you. Meal times are great for social interaction and on longer tours people get to know each other well. Special needs - Some guests need special consideration due to their health 
or religion. This can be things they can't eat, can't do or don't want to do. The guests should tell the tour company about their needs when they are booking, but sometimes you won't know about it until the tour has started. If possible, try to accommodate these needs to make the guest feel comfortable. If a guest has requested vegetarian meals, and then don't get it, they will most likely be upset. Be respectful - People respond in different ways to certain topics. Some things that are funny to some might be deeply insulting to others. Being called fat in some countries can be a compliment, while in Australia it's an insult. Avoid asking personal questions, like how much money people make, what their weight is or why they don't have children. These are things most people only discuss with close friends.

Managing expectations - Be clear with guests what to expect. If you are honest about potentially negative aspects of an activity, your guests are prepared for it and are less likely to complain. A common complaint is when a tour focused on something (for example, seeing crocodiles) and the tour guide fails to deliver. One way to avoid this is to explain in the briefing that it's not guaranteed to see them on each tour. There will always be things that are out of your control, such as weather and wildlife. It's OK to be honest about that from the start.

Different cultures - People working in tourism can usually tell where people are from based on their behaviour, likes and dislikes. Without stereotyping too much, tour guides should use this knowledge to adapt their tours to cater for the guests they have on tour. In some parts of the world resorts adapt their food, activities and entertainment to suit tourists from certain countries. Of course, this is only possible if the whole group is from one country. Try not to express negative views about particular people or countries.

The dynamics of every group differs depending on the people, and there is no set way to manage groups. It helps if you are a people person with well-developed social skills. As you gain more experience interacting with tourists you will become better at facilitating groups.

\section{- PROBLEMS ON TOUR}

It's rare that a tour goes exactly as planned. The longer and more adventurous a tour is, the more likely it is that something will go wrong. Experienced tour guides are good at thinking on their feet and come up with quick solutions. Sometimes external factors that are out of your control can cause delays, or force you to change the itinerary. A good way to deal with problems on tour is to have a back-up plan (plan B). It's also good to have more than one back-up plan, in case the first one doesn't work.

Guides can prevent the most common problems already at the planning stage.

Vehicle breakdown - Only use reliable boats/cars and perform regular maintenance. Keep spare parts with you and learn how to quickly fix common problems. If you hire transport, only use reliable providers.

Staff not showing up - Only work with reliable people (drivers, guides, cooks, etc.) who you can contact at any time. Keep a list of back-up contacts that can jump in at short notice.

If there are unexpected delays for any reason, have a cut-off point when you will cancel the activity and continue with alternative plans. If you are stuck and waiting somewhere, it's important to keep the group occupied. Don't just leave them without information as this will make them feel abandoned. Engage with them and keep them busy during the wait.

\section{Left behind}

"Once I had a big group of tourists on a walk. One of the guests was walking very slow, which made us late to get back to our pick-up point. When we didn't show up on the agreed time the bus driver just left. We had no accommodation or food and it was getting dark. I had to ask the villagers to help $u s$, and they let us sleep in the school. I borrowed money from the tourists to buy food. The next day we had to hitch hike back to town on trucks." 


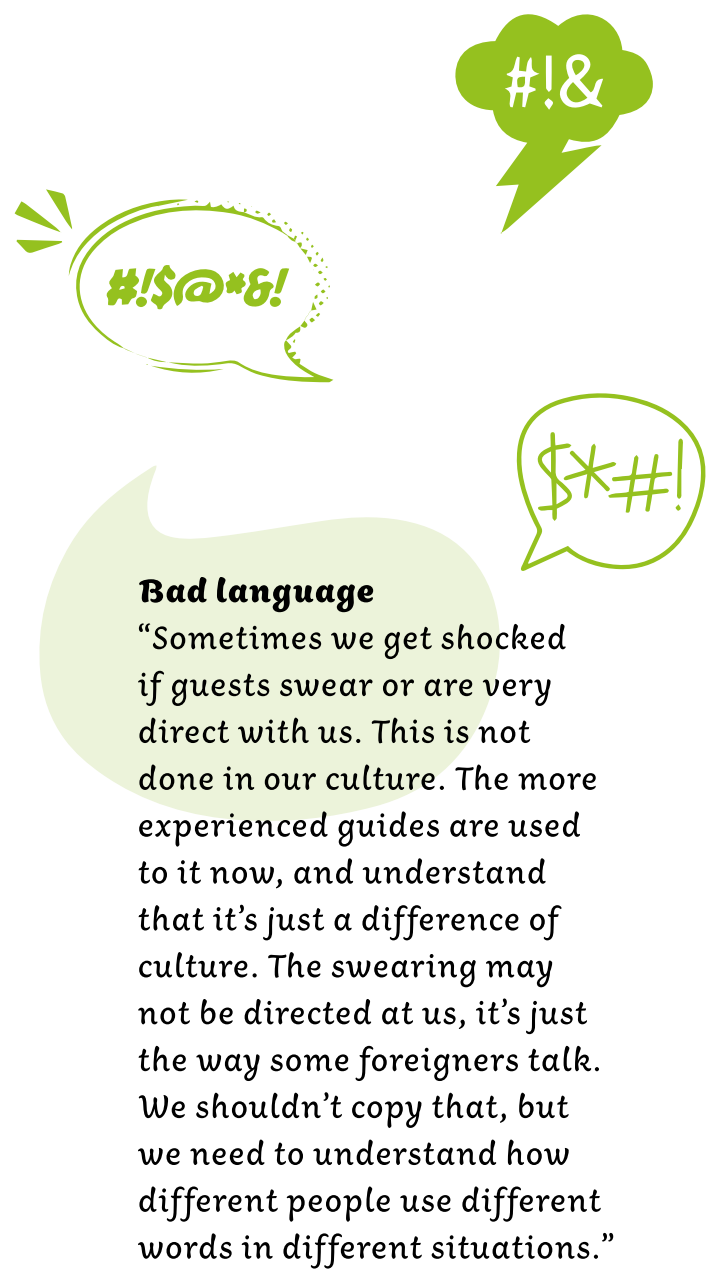

Problems on tour can also come from within the group. These issues might not force you to change the itinerary, but it can be challenging to deal with. This is where your leadership and people skills come in handy.

Difficult guests - The majority of tourists are friendly and easy to work with. But tour guides also have to deal with the occasional difficult guest. This may be someone who is always late for activities, or constantly complaining. Try to deal with this professionally and don't lose your temper. Remember that many of the tourists are out of their comfort zones, and this causes them stress and anxiety.

Deal with issues - If something serious happens on tour (accident, theft or assault) you need to assist and support the victim in whatever way they need. Failure to do so, will almost certainly lead to complaints. After an incident the guests will be very upset, and possibly blame you for failing to prevent the incident. This is why it's so important to show that you are doing your best to support them. Dealing with issues between locals and tourists can put you in a difficult position, but it is your responsibility to protect your guests.

Conflict within the group - Sometimes there are disagreements within the group. If left unresolved it can ruin the overall experience for your guests. The guide may have to step in and act as a mediator if the situation calls for it. As a mediator you shouldn't take sides. Try to stay impartial if guests complain to you about other guests. However, if the complaint is serious, for example, if someone is harassed by another guest, you have to do something about it.

Alcohol - A lot of issues on tour revolve around alcohol. Some people become aggressive or emotional when drunk. If you have guests who can't handle their alcohol you need to keep an eye on them and try to limit their alcohol consumption. You may also have to tell someone who has become drunk and obnoxious that they are not allowed to drink any more.

Theft - Petty theft is an issue everywhere, including Solomon Islands. The best way to deal with this is to not give anyone the opportunity to steal from your guests. Make sure that the tour boat or vehicle is never left unsecured with guest's belongings inside when you go off on activities. On overnight stays make sure that rooms can be locked and that nothing is left outside. Remind guests that that there is a lot of poverty in Solomon Islands, and leaving cash or valuables lying around is an unnecessary temptation.

Integrity - There is a saying in hospitality that the customer is always right. It means that you should always try to give the tourists what they want. Of course, there are situations when this doesn't apply. Don’t feel pressured by tourists to agree to activities that are inappropriate or unethical. Never compromise on safety rules to please guests.

Injury - The most serious issue you can have on a tour is an accident when someone is injured. For this reason, tour safety and risk management is covered in detail in Chapter 7.

Many Solomon Islanders feel awkward dealing with conflict, especially when involving foreigners. This is the challenging part of being a tour guide, but it is part of the job. Fortunately, these situations don't happen that often but everyone who has been guiding for a while will have experienced some of the situations mentioned here. 


\section{- MULTI-DAY TOURS}

Tours that last several days are unusual in Solomon Islands, and it is typically only trekking, birdwatching and diving live-aboard tours that offer overnight tours. In other countries, multi-day tours are common, and many companies offer adventure tours lasting from a few days or several weeks. Just like trekking tours, the planning and logistics for multi-day tours is complex. The difference between overnight treks and multi-day tours is that you don't need to bring camping equipment and food along. Instead, tour operators use existing accommodation and eat at local restaurants along the way.

Multi-day tours are led by tour leaders, who have a lot of experience as tour guides and have demonstrated that they are reliable and well organised. The tour leader's main role is the smooth operation of the overall tour. During a multi-day tour the guide must always think one step ahead. At lunch you need to call the accommodation to make sure the rooms will be ready for the group's arrival. In the evening you must check that the breakfast is ordered for the next day and transport is ready. Tour leaders need to be trustworthy because they handle money and important documents, like receipts, tickets and passports.

During multi-day tours the tour leader will interact with other people who works at resorts, restaurants and attractions. It's important to develop a good working relationship with all of those people whose services you rely on. If you really need help one day, these relationships will be useful. It's likely that you will come across tour guides from other companies. Try not to see them as competitors, but as colleagues, because one day you may need their help. Experienced tour leaders have a wide network throughout the tourism industry.

The great thing about multi-day tours is that you have time to show the best of Solomon Islands. If you lose one day due to bad weather, you can make up for it later. When it comes to interpretation, you can plan an interesting theme that runs like a thread throughout the tour. Compared to other tours you will spend a lot of time with your guests which is a great opportunity to get to know them.

In a resort, it is similar to multi-day tours in many ways because you spend a lot of time with your guests. This means you can plan for tours and activities over a number of days. Even if you come back to the resort after each activity, the whole experience can be tied together like a multi-day tour. You have more flexibility to move things around if the weather is bad. As you learn more about the guests and their particular interests you can adapt the program you offer them.

\section{Rainy days}

"If the weather is bad, we try to adapt activities and ask the guests if they want to postpone something or swap activities around. If they have planned a boat tour and it's raining, it's better to offer another option. The guide shouldn't wait for the guest to say something, they should offer different options. If it rains a lot, we have prepared indoor activities, like weaving or cooking classes, and sing-a-longs in the evenings. Guests spend a lot to come here so we have to try to make them happy."

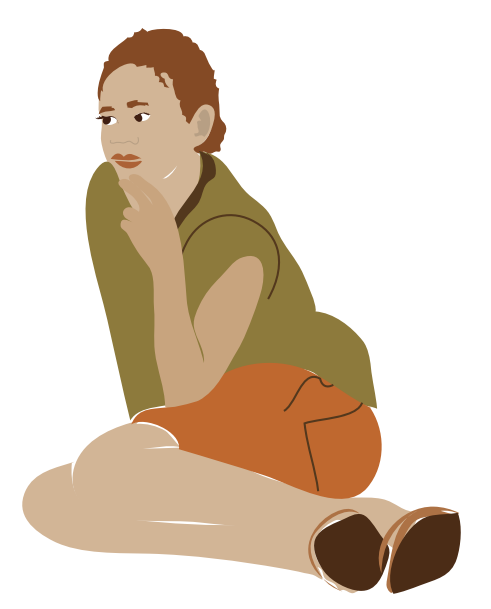




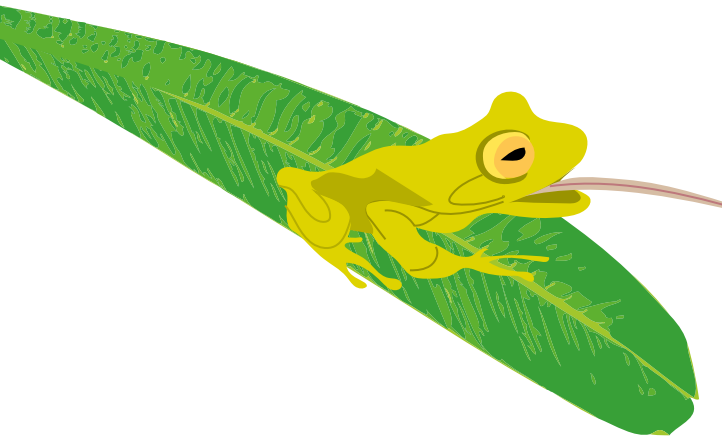

\section{KASTOM FEES AND ACCESS}

In Melanesian culture, customary landowners control access to their land. This is still the case today, and tourists have to pay a kastom fee to access certain sites or areas. In places where tourism is well established tour guides know who the owners are and how much to pay. In rarely visited areas, it can be difficult to know who the actual land owner is. There may even be more than one group that claims ownership. For new tours, always visit the area to meet the landowners before bringing tourists there, avoiding confrontations with angry land owners in front of your guests.

Some tour operators have an agreement with land owners about kastom fees, which are collected at the tour office. This is easier for the guide who doesn't have to deal with cash, and argue over who should be paid. Other guides pay cash directly to the landowners, but do it away from the tourists. The situation with kastom fees is constantly changing as landowners die or new people settle in an area. You need to constantly stay on top of this in the areas you work in.

\section{Disputes}

"It's good to share the tourist money with local people. They are happy when we visit and they get some income. But it can be difficult too, when families have internal disputes about money, or when they ask us for too much. Sometimes when I arrive, they say we didn't pay last time. a few times people have threatened me with bush knives. I think it's mainly for show, but the guest doesn't like it. I tell the landowners, we can solve this back at the office, please don't frighten my guests."

If there are already tourism activities in the area, make sure that your guest pays the going rate, not undercut or inflate prices. Kastom fees can be a good way to share benefits, but some locals have unrealistic expectations as to how much foreigners are willing to pay. Solomon Islands is already an expensive destination compared to other countries, and if kastom fees keep going up it might become an unaffordable destination.

Most foreigners are not familiar with the concept of kastom fees. A good way to explain it is to compare it with an entrance fee for an attraction, or someone's private property. It's also important to explain beforehand if guests need to pay a kastom fee on top of the tour price. If the fee is paid directly by the guests, remind them to bring the correct amount, as landowners usually don't have any change. Most tour operators include the kastom fee in the price, and pay the landowners in bulk.

Apart from paying the kastom fee, anyone wanting to access someone else's land needs permission. This might not be about money but for cultural reasons. In some areas, the cultural protocol dictates that a landowner has to introduce the group to their ancestors in the local language before safe passage can be guaranteed. For this reason, local assistants should accompany guides when visiting other provinces, particularly in remote areas not familiar to them. It is common for guides to pay local people a small fee to accompany them to ensure access, even in their own provinces.

Even if you have permission to enter a village try to not show up unannounced. A group of tourists running around taking photos can be disruptive. If it happens too often local people may turn against tourists. This in not generally a problem in Solomon Islands due to low tourist numbers. Overseas, mass tourism is a big problem, and some villages have turned into human zoos. It is your job to make sure this doesn't happen in Solomon Islands. Both you and your guests should behave respectfully towards people in the villages you visit. Most tourists mean well but their actions can have unintended consequences. It is common that tourists ask to visit the local school but this can be disruptive for the teachers. Even just walking past the school will get the kids excited and distracted. Some tourists bring gifts like pens or lollies which they hand out to kids. This can create a beggar mentality among children in villages that have a lot of tourists coming through. 
Scientists regularly come to Solomon Islands to conduct research. They hire guides to help them. The kastom fee for projects is often a lump sum which covers access for a specific period. Some scientists collect samples of animals and plants, and take them back to their own countries to do further research. This is common practice all over the world, but the scientists need a permit from the government for this. If the scientists you work for are planning to collect any samples, you need to inform the land owners and get their permission. Conservation areas sometimes have limits on how many samples can be collected, and from what species. You need to make sure that any agreed limits are respected. There have been several incidents where miscommunication between landowners and scientists resulted in the guides being caught in between.

\section{- TOUR PRICE}

Most guides work for a tour company, or a resort. The tour price is already set and the payment does not go directly to the guide. Your work is a lot easier if it doesn't involve dealing with payments. But some guides are self-employed and set their own tour prices. The price should be based on your expenses and what you think your time is worth. A simple walking tour can be cheap because the only thing the guest pay for is your time. If boat travel is involved, prices go up due to the cost of boat hire and fuel. When you set the price for a tour consider that Solomon Islands is a very expensive place compared to other destinations in Asia-Pacific. Don’t assume that every foreigner has unlimited wealth.

When you do regular tours, you know exactly the costs involved. But many tours in Solomon Islands are customized, and itineraries are made up of things that your guests want to do. You should be able to quickly calculate the price for various tours if people ask for it. One of the most annoying experiences as a tourist is the feeling of being taken advantage of or being overcharged. To avoid this, be crystal clear when explaining the cost of a tour, and what is included. Add everything together and state one price for the tour. Sometimes, it can help if you write down the costs that makes up the total tour price and show it to the guests. If they think it is too expensive you can explain in detail what each expense is made up of:

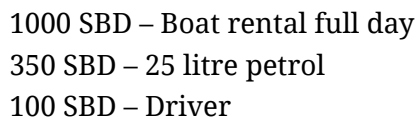

Some drivers and guides in Solomon Islands don't give a straight answer when asked for a price. Instead, they start talking about fuel prices, distances, engine horsepower, etc. Of course, this is all part of the calculation, but not something you need to explain to the guests. Just state the overall price, but be prepared to explain the details (the different rates of fuel consumption of different sized engines) if asked. If you eat at a restaurant, you don't care about the price of the individual ingredients but the total cost of the meal. If you are not straight about the price from the beginning the tourists will get suspicious. They shouldn't have to ask how much the total tour price is, you should start by telling them that straight away.

Once you have explained all the cost included in the price you can't add things afterwards, even if they are expenses you had. If you expect any extra charges on the tour, such as kastom fees, include this in the tour price, or explain that this cost will come on top of the tour fee. Once you have agreed on the length of the tour (half-day or full-day) you have to deliver on that. Half day is four hours, not three. If the tour is only three hours, don't call it a half-day tour. A full-day tour is between 7-9 hours, not 6 or less. Unless the guest tells you that they want to return early you have to deliver what you have promised.

\section{not welcome}

"We stopped offering some tours due to problems with access. We first assumed that it was due to misunderstanding about the payment of kastom fees. But when we talked to the landowners, they told us that some visiting scientists had collected frogs which were sacred to local people. This made them very angry and they told us to not bring any more foreigners onto their land."

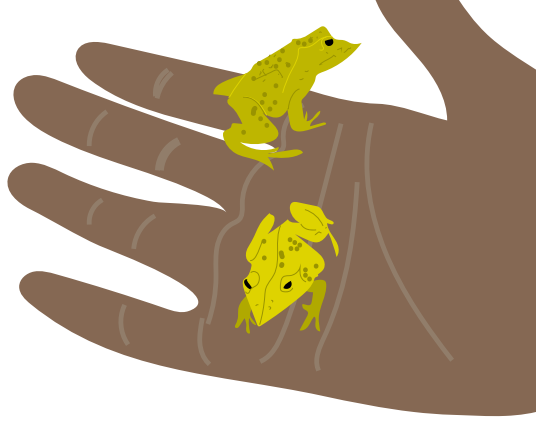


Many guides also arrange tours for people working in Solomon Islands. This may be advisers for development projects or researchers. Project work is good, extra income for guides and drivers, especially when tourist numbers are low. Sometimes a project trip can be several weeks long. These projects are funded by international organisations and the project staff don't pay anything out of their own pocket. It's important to understand the difference between tourists on holiday and project staff on assignment.

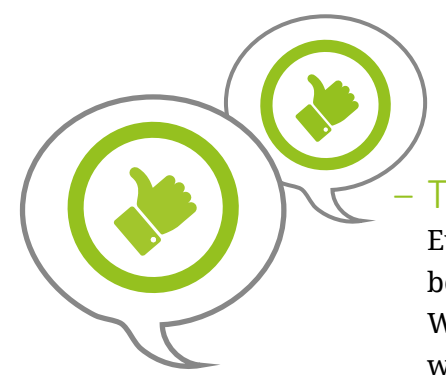

Why is Solomon Islands so expensive for tourists?

Compared to other similar destinations, it is very expensive for tourist to visit Solomon Islands. The price of flights, accommodation, food, tours and activities are considerably higher than most other countries in the asia-Pacific region. High prices are common in small island economies because most things have to be imported. This makes fuel in particular expensive. Since energy is mainly produced by fuel, Solomon Islands has one of the highest costs of power (per kilowatt) in the world. As a result, transport and accommodation operations are expensive. During the tension, the early RamsI era and currently due to Covid-19, domestic tourists (mainly expats) make up the majority of tourist. They are well paid and able to pay more than normal tourists. This has added to further increase prices, and many locals now have unrealistic expectations on what tourists are willing to pay. This is the reason there is no backpacker tourism in Solomon Islands, as young people simply cannot afford to travel here. Prices need to come down for Solomon Islands to become a competitive tourism destination.

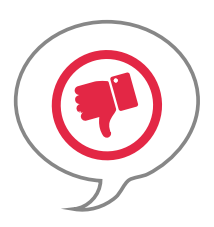

Every tour is evaluated in some way. Guest talk about their experience with you, your boss or their friends. This is feedback, and is an important tool for tourism operators. Without feedback, operators don't know if they are doing things right or not. While working, you first and foremost represent your company or organisation, but also yourself. If you run a good tour, it makes your organisation look good. If you are a popular guide, it can lead to more work or better jobs. Your performance is evaluated both by guests and your employer.

Verbal - The most direct feedback you can get is the guest telling you what they think about the tour. It's personally satisfying when a guest thanks you for a wonderful experience.

Feedlback form - Many operators use a form where guests are asked to rate and comment on various aspects of the tour, such as guide performance, customer service, food, etc. This is a good way for your employer to monitor performance. Guest book - Lodges use guest books where visitors can write about their experience. This helps other guests, so that they can find out about the various activities on offer.

Social media - Many people post photos and stories about their travel expe- 
riences on social media. If the feedback is positive, it's great, especially if they share it in groups or blogs. But if they share negative comments, it can damage the tour operator's reputation. Due to social media it's harder to get away with providing bad service these days.

If there are problems on a tour, don't try to ignore it, even if it makes you look bad. It's likely that the guests will mention it in their feedback or post something about it on social media. If you haven't told your employer about the incident before, it will make it worse. A professional tour guide must be able to deal with complaints, whether they are justified or not.

Tour management is complex and as a new guide it can be hard to do everything right. Everyone gets the odd complaint so don't get discouraged by this. But do take it seriously, especially if the same complaints are repeated. If a tour gets a lot of negative feedback about the food, then clearly there needs to be improvement. Look at the feedback as useful advice on how to become a better tour guide.

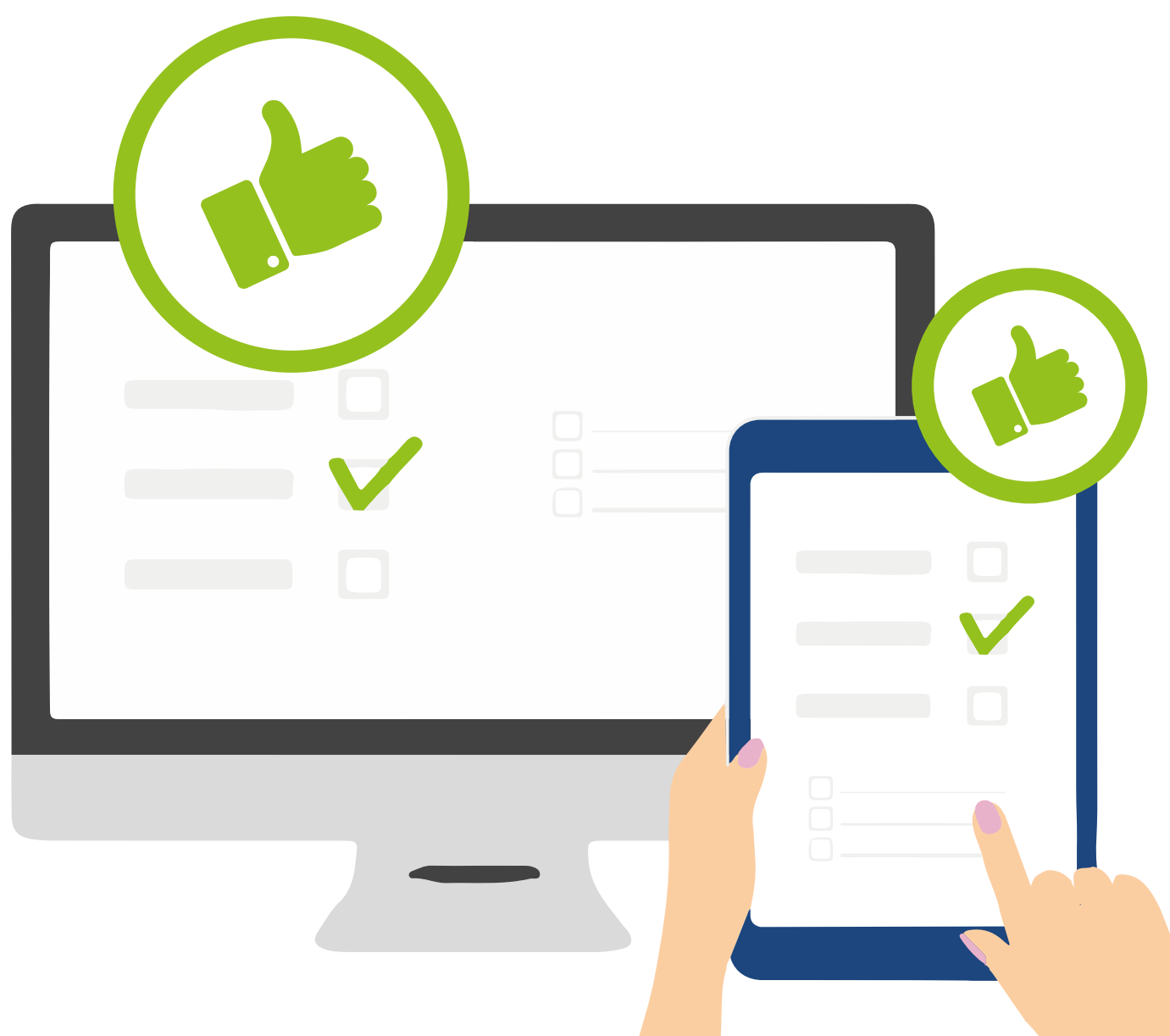




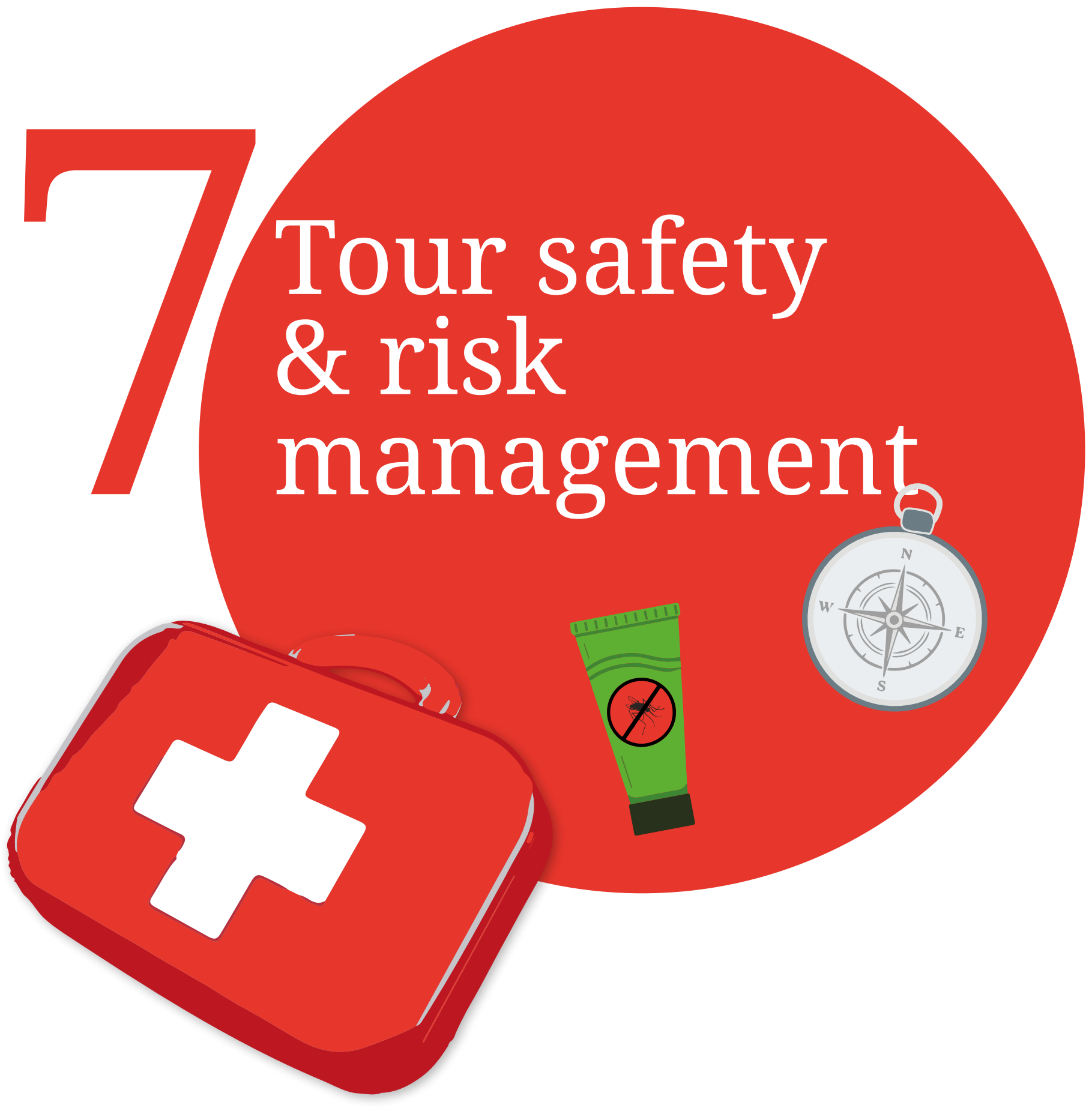




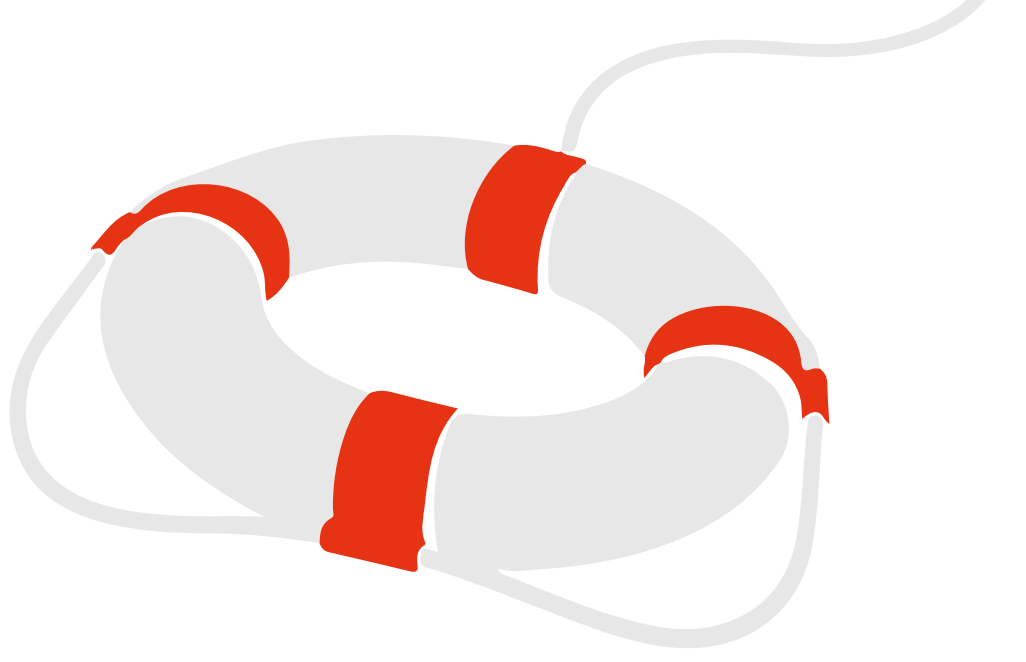

A successful tourism destination needs a reputation as a safe place. If visitors regularly get injured or sick while visiting, it will impact the image of the country. Tour safety and risk management are an important part of your work. Since many tourism activities involve a degree of risk, take extra care to make sure that your tours are as safe as they can be.

Most tourists come from countries where safety is taken seriously. Tourism operators are regularly checked by government inspectors to make sure they follow safety regulations. Guides must carry a first aid kit and have current certification in first aid. If there is an accident there is a thorough investigation. If a tourism operation is found to have caused it by not following the required safety standards it can have serious consequences. Foreign tourists expect tours to be conducted in a safe way, with guides properly trained and equipped. This is unfortunately not the case in Solomon Islands, and there needs to be improvement in this area.

Another reason safety is taken seriously in developed countries is the legal system which allows people who have been injured to sue. This is similar to compensation payments in Solomon Islands and it is handled by civil courts. If it's clear that an accident was caused by the actions or neglect of a tour guide or driver, the company can be sued for a lot of money. In cases of serious injury or death the compensation could be high and the responsible person might go to jail.

Tour companies pay a lot of money every year for insurance, in case they have to pay compensation, or pay for costly emergency evacuations. In many countries, it's illegal for tour companies to operate without third party or public liability insurance. This is not the case in Solomon Islands yet, but in the future it's likely that the legal system will be aligned with other countries. This is another reason for tour guides to start taking safety seriously. 


\section{SAFETY PLANNING}

You can manage safety issues by planning ahead and being prepared. There are two sayings that are useful when planning tours:

+ Hope for the best, plan for the worst. You should have plans for incidents that may occur and have the right training and equipment to deal with them.

Stuck in the bush

"Once we had a tour guide stuck in the bush with two guests for several days. During a walk it started raining very heavily and the rivers became impassable. In the evening when they didn't return, we sent out a search party, but could not reach them because of the rivers. The guide kept the tourists alive with food he collected in the bush until a helicopter came and airlifted them out."
+ The best way to solve a problem is to solve it before it becomes a problem. Be aware of which situations can cause problems and avoid them or deal with them, before there is an incident.

\section{- SAFETY PRECAUTIONS BEFORE A TOUR}

- Check weather forecast - The weather is a factor on every tour, in particular for boat travel and bushwalking. Some passages are notoriously dangerous in bad weather and there are regularly fatal accidents at sea. In Solomon Islands there have been several serious bushwalking incidents, including fatalities, due to heavy rain and flash floods. In one incident, a group was stuck in the bush without shelter, food or water for days. For this reason, the guide always has to keep an eye on the weather.

- Safety briefing - Every briefing should include information about potential hazards on the tour. The point isn't to highlight dangers, but to tell guests how to avoid things that might cause injury. Many lodges and resorts have a welcome briefing where guests are told about potential risks and what to avoid.

- Equipment - Make sure to bring the right safety equipment with you. Most important is a medical first aid kit. Always check the contents of the first aid kit before each tour. Anything else related to safety, like life jackets and radios, should be well maintained and in working order.

- Pre-existing medical conditions - Your guests may have medical issues that can cause problems for them on the tour. You need to know this beforehand. Many tour companies require their guests to fill in a form to declare any pre-existing medical conditions, such as food allergies, medications, recent surgeries or chronic diseases. If your employer doesn’t use a medical declaration form you can ask the guests before the trip if they are fit and healthy.

- Emergency Plan - Have a plan for what to do in case there is an accident. Think of every possible worst-case scenario and what you would do. Talk it through with your colleagues about how you would handle different situations. If something does happens, you have already thought about it. Many tour companies have written emergency plans so that staff are aware of them.

\section{- RISK MANAGEMENT}

Risk management deals with hazards in a way that minimises possible issues. Dealing with the problem before it becomes a problem. To manage risk, tour guides need to have good situational awareness. This means bbeing aware at all times of what is going on around you. Even if you are busy doing something you should keep an eye out for things that might be dangerous or cause problems. You need to simultaneously assess several things at once: the weather, the condition of the track, the people you meet, etc. Risk assessment should be an ongoing process that you subconsciously do all the time while on tour.

It is easy to forget that Solomon Islands is a new and unfamiliar environment for most tourists. They may not have the local knowledge to recognise dangerous situations. 
Many people on holiday also relax and enjoy themselves to a point where they became careless. A common joke is that tourists sometimes leave their brain at home when they go on holidays. Don't treat your guests like children, but at the same time don't underestimate their ability to get lost or injured.

\section{- SAFETY PRECAUTIONS DURING THE TOUR (RISK MANAGEMENT)}

- Give a helping hand - At any point where there is a risk that the guests might slip and fall, offer a helping hand. This includes getting in and out of boats, crossing rivers, and on slippery trails. If a guest becomes tired and unsteady on their feet, offer to carry their pack. Some guides also cut sticks for the guest to use as support. This is useful during river crossings.

- Warn about hazards - If you see anything that can cause harm, point it out and warn the guests to avoid it. See a list of common hazards in Solomon Islands in the next section.

- Clear the track - In the forest use your bush knife to clear the path of anything that can cause people to stumble, get scratched or become entangled. If a track hasn't been used for a while it's best to send someone ahead to clear a path, especially on overnight treks when you are carrying big packs. While clearing bush, be careful that the guests are not too close behind you, as they might get cut by your bush knife.

- Swimmer safety - Before allowing guests to swim make sure there are no dangers in the area. In lakes, rivers and coastal areas the main risk is crocodiles, and at sea strong ocean currents. Even young and fit guests who are good swimmers can get into trouble while free diving (shallow water black-out). When guests are swimming or snorkeling you should stay alert and monitor them at all times.

- Boat safety - A lot of tour travel takes place in small boats. Make sure to only use reliable drivers and boats, which are equipped with life jackets for all passengers. Don't compromise safety by overloading boats to save money. Even though the boat is the driver's responsibility, you should make sure that there is enough fuel, and that the boat has an anchor and oars on board. If you are going snorkeling from the boat you need a ladder. Never travel with a driver who appears drunk.

- Annoying people - If your guests are bothered by drunks or conmen, you should step in and diffuse the situation. Protect female guests from unwanted attention and harassment. Don't allow your guests to be taken advantage of, for example, by being overcharged for services, or pressured into giving donations. If you think a guest is feeling uncomfortable or threatened in any way, you need to do something about it, either by dealing with the person or by removing the group from the location.

- War remains - Unexploded Ordinance (UXO) or Explosive Remnants of War (ERW) are weapons like bombs, shells, grenades and mines that did not explode when they were deployed, or were left behind on the battle field. There is a lot of UXO left behind from WWII. Locals are well aware of this, as people are regularly injured and killed. The risk of tourists stepping on a UXO is minimal so many years after the war, but cannot be totally discounted. Do not allow tourists to handle anything that looks like an explosive weapon if you don't know for sure that it has been properly decommissioned.

\section{- HAZARDS IN SOLOMON ISLANDS}

Solomon Islands is no more dangerous than other destinations in the region, and injuries can be prevented by telling tourists how to avoid local hazards. Hazards are similar throughout the country, but vary a bit depending on where you work. Many resorts have a welcome briefing which includes an explanation of local hazards. Some

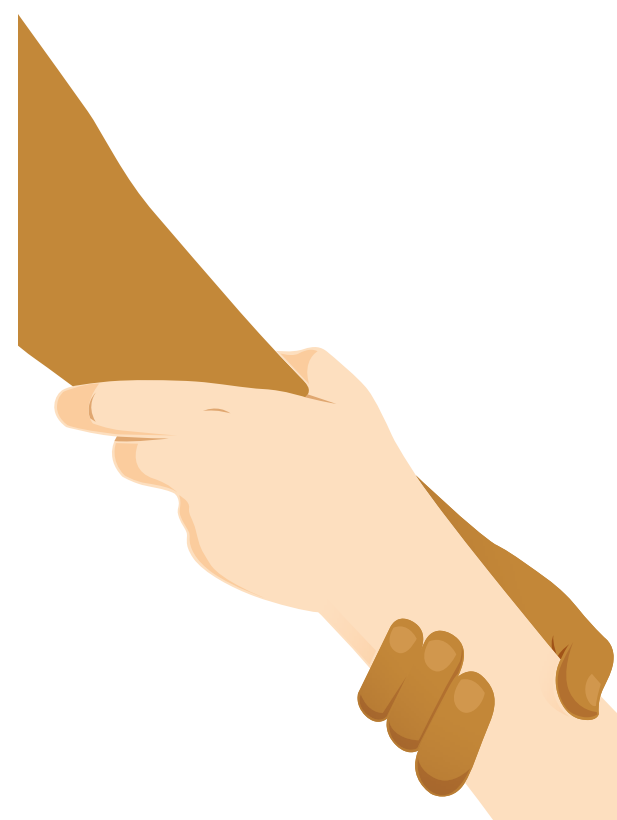

\section{Caught in a current}

"Once a tourist nearly drowned because he got stuck in the current and swept out to sea. We managed to pick him up with a boat before it was too late. We always tell the guest to let us know when they go snorkeling but this guy went alone anyway, without telling anyone. Luckily, we had a guide on the beach looking out for him. If the guide hadn't been there, he would have drowned." 
use posters that list things to avoid. For a short half-day tour, it's not necessary to talk about all the local hazards, but focus on the ones relevant to that specific tour. This list of hazards was compiled by professional tour guides in Solomon Islands.

\section{- IN THE BUSH}

- Poisonous or stinging leaves cause a burning sensation or severe itchiness. Some people have an allergic reaction. Stinging leaves exists in all provinces, with different local names. The sap of some plants can also sting.

- Vines or leaves with spikes. Needle-like spikes can puncture the skin and cause pain and infections. They can get stuck to the legs of walkers and cause them to trip.

- Low hanging branches. When walking in single file it's hard to see what's ahead, especially when wearing a hat. Tall people often walk into overhanging branches.

- Poisonous or stinging insects. Centipedes, ants, wasps and scorpions can bite or sting and cause intense pain and sometimes inflammation and allergic reactions. As a precaution always look inside your shoes and shake out your clothes before putting them back on, especially when camping in the bush.

+ Centipedes: Don't leave damp clothes on the floor or ground, as this attracts centipedes. When bush camping, wash your hands and face after eating, to avoid any smell of food that attracts centipedes.

+ Ants: Certain species (e.g., little fire ant) have a painful bite. Use your hand or a towel to sweep any surface before sitting down. Also sweep your bed before lying down.

- Snakes. Rarely seen and mostly harmless, but some are venomous. Local clinics do not stock anti-venoms. Avoid all snakes to be on the safe side.

- Wild pigs. Rarely seen, but can be dangerous if encountered on a narrow bush track.

- Flash floods. Steep ravines or river valleys should be avoided after heavy down pours.

\section{- IN THE SEA OR ON THE BEACH}

- Underwater hazards. While snorkeling, swimming or wading in the ocean you must be careful what you touch or step on.

+ Stings/burns: fire coral, crown of thorns

+ Toxic/venomous: Conch shells, stone fish, scorpion fish, sea snake

+ Painful/deep gashes: Stingrays, Titan trigger-fish, sea urchins

- Saltwater crocodiles. Rarely seen but must be taken seriously as attacks can be fatal. Crocodiles can be encountered anywhere, but are seen around dusk and dawn, near rivers and mangrove areas.

- Sharks. Most are not dangerous in Solomon Islands, but might become aggressive if their normal behaviour is disrupted by feeding.

- Broken glass. Mostly around Honiara, on popular beaches there is broken glass.

- Thieves. Never leave belongings unattended while swimming. Cars regularly gets broken into on beaches around Honiara. While staying at beach accommodation don't leave snorkeling gear outside overnight.

\section{- IN URBAN AREAS}

- Pickpockets. Be aware in crowded public spaces, in particular Honiara's Central Market. Tell guests to leave valuables in the tour vehicles and make sure a trusted driver or assistant remains in the vehicle.

- Drunkards. Can be harmless but sometimes annoying and aggressive. Unfortunately, it is not uncommon to encounter drunks in Solomon Islands. 


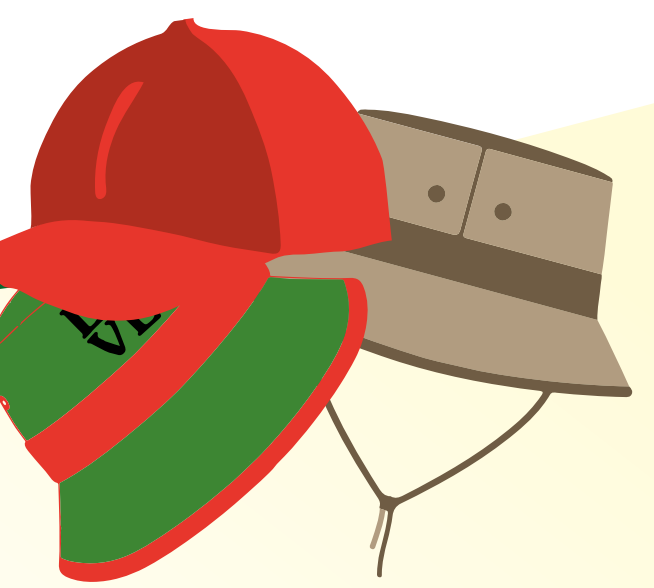

- Wild dogs. Sometimes packs of feral dogs attack people, after dark and if people walk alone.

A global cause of accidents (not unique to Solomon Islands) is alcohol. Many tourists are injured from slips and falls when drinking. The tendency to do stupid things like swim at night or try to climb a coconut palm also increase when drunk.

\section{- GUIDE KIT}

The equipment a guide needs in town, is different than in the bush. For city guides a small bag and a phone, some cash and a first aid kit in the bus might do. Guides in remote areas need a lot more. A typical guide kit includes:

- Backpack - All guides should carry a backpack, rather than just holding things in their hands. Guides should have a large pack, even if it's not full, in case extra gear is needed or you need to lighten the load for a guest.

- Bush knife - For any land-based activities in the bush.

- First aid - Mandatory in remote areas.

- Extra water - In the boat, vehicle and in the guide's backpack.

- Toilet kit - Essentials are toilet paper, shovel and hand sanitiser.

- Phone - Charged and with enough credit. Enter all the numbers you might need before the tour (police, hospital, hotels, drivers, etc.).

- Extra cash - Don't ask guests for cash to pay for incidental costs, this should be covered by the guide unless explained beforehand.

- Torch - In case the tour gets delayed until after dark. Make sure the torch works and has fresh batteries inside.

- Watch - Guides must carry a watch to be able to keep track of break times and general progress.

- Duct tape - To repair almost anything.

Optional

- Radios/satellite phone for areas without network coverage.

- Sun protection and mosquito repellent for the guests.

- Snacks in case the tour gets delayed past meal times.

- Pocket knife or Swiss army knife/multi tool has many different uses.

- ID guides for wildlife and plants.

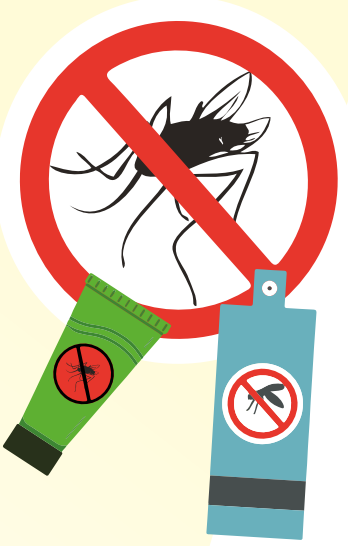




\section{COMMON INJURIES}

\section{AND HEALTH ISSUES ON TOUR}

A guide may only have basic first aid training, but it is important to understand the causes and signs of some common injuries and health issues experienced by tourists. The heat and humidity in Solomon Islands is challenging for many tourists and can trigger several health issues.

- Dehydration - During strenuous activities tourists sweat a lot. They lose a lot of fluid. Early signs of dehydration are headache, dry mouth, and dark urine. The solution is to rest in the shade and drink until the symptoms go away. If a dehydrated person doesn't rest, it can lead to heatstroke which is very serious. Prevent dehydration by making sure your guests drink enough. During the briefing remind everyone to bring enough water for the day, or provide it for them. Always bring extra water in case someone needs it. On a hot, full day walk with a pack, it's recommended to drink at least 4 litres.

- Heatstroke - Monitor how your guests cope with the heat. If they push themselves too hard their bodies can overheat. The symptoms of heatstroke are similar to dehydration. If it's really bad the person might faint, in which case you need to lower their body temperature as soon as possible. Bring the person in to shade and use water to cool the body down. Prevent heatstroke by observing if anyone looks particularly hot and flustered. Whenever you stop do not leave your group standing in the sun, find shade whenever possible. It's always good to break up hot walks with a swim to cool off.

- Sunburn - Some people with pale skin get sunburnt easily. While not that serious it can be painful. If you see anyone starting to turn pink or red, you should remind them to cover up, or put on more sun protection. Severe cases of sunburn can be very painful and cause blisters, similar to lighter burns. It can also cause fever and headache. Sometimes on long boat trips tourists forget about sun protection, because the wind is cooling them off. Remind them that the sun still burns, even if they don't feel hot. People with sensitive skin should wear a long-sleeved shirt and pants on boat trips.

- Bruises, scratches and sprains - During activities it's common that people slip or fall and get hurt. This can mean sprained ankles, broken bones, cuts or bruises. While most slip and fall injuries are not that serious it can ruin a holiday. On a bushwalk a twisted ankle can be a big problem. Helping an injured person back on a narrow bush trail is hard work and takes a long time. On an overnight trek a serious injury might require a full evacuation involving many people, or even a helicopter.

- Medical emergencies - Tourists sometimes get sick due to pre-existing medical conditions. Medical issues can get triggered by strenuous activities. This is why many tour operators ask tourists to fill out a medical form before the tour. A tourist with a heart problem shouldn't go on a 3-day trek. Someone with a bad back should avoid bumpy boat rides. For those on medication, it's important to remember to keep taking their medication during their travels. Food allergies are common and can be serious. The tourists should declare their food requirements when booking the tour, but the guide can ask as well to be on the safe side.

- Infections - Tourists can get small skin abrasions, like coral cuts while snorkeling. These cuts are not serious, but due to the humidity the wounds don't have a chance to dry out. Flies are attracted to open wounds which can causes infection. For tour- 
ists who stay 2-3 weeks this can be a problem. The infected wounds start to grow and the area around it becomes painful and inflamed. The infection can travel through the blood to other parts of the body. Once the infection spreads, it can result in a fever. In that case, you need to bring them to the nearest hospital, where they can get a prescription for antibiotics. This is effective, if it's the right kind. Infected cuts can ruin an expensive holiday. It is important to clean a cut immediately and cover it up. You should carry antiseptic swabs and band aids of different sizes in your first aid kit. If those are not available, warm water and soap is better than nothing, and duct tape and plastic bags can be used to cover an open wound temporarily.

\section{- FIRST AID AND CPR}

First aid is the help given to an injured person until more qualified help is available. This means until the person reaches a clinic, or if in a city, until an ambulance arrives. In remote areas in Solomon Islands there are no ambulances and it can be a long way to the nearest clinic. This is why all guides needs basic first aid skills.

A first aid certification is a legal requirement for guides in most countries. It is particularly important for nature-based tours in remote areas. First aid training is different from tour guide training, because it requires qualified first aid instructors. First aid courses are regularly conducted by the Solomon Islands Red Cross Society (SIRCS). The course includes basic first aid and cardiopulmonary resuscitation (CPR). CPR is a lifesaving technique used in life threatening emergencies, such as a heart attack or near drowning. CPR can restart a heart that has stopped or get someone breathing again.

During the first aid training you will learn how to use the supplies found in a typical first aid kit. Even if you haven't attended training, you should carry a basic first aid kit with you on every tour. Many tourists have first aid training and might be able to assist, in case someone is injured.

Some items commonly found in a first aid kit are:

- Rubber gloves so you don't touch open wounds with your bare hands, as this can cause infections.

- Antiseptic or alcohol wipes to clean fresh cuts and wounds.

- Plasters in several different sizes for different cuts.

- Butterfly stitches to be used temporarily to close deep cuts.

- Tweezers to remove foreign objects from wounds.

- Scissors to cut plasters, tape and bandages.

- Dressing/gauze for larger wounds.

- Elastic bandages to cover dressed wound or stabilize limbs.

- Triangular bandages for slings or padding of broken limbs.

- Medical tape to keep dressings in place for large wounds.

- Hydro-cortisone cream for skin inflammation and rashes.

- Rehydration solution sachet for people suffering from dehydration.

- Pain relief tablets to relieve pain for a wide number of issues and injuries.

These items are the basic supplies found in a typical first aid kit. A first aid kit can be adapted to the local area and for common injuries. There is no need to know how to treat frostbite in Solomon Islands, but it's important to be able to treat dehydration. For multi-day tours and overnight treks, you need to bring more than just the bare necessities.

\section{Hot walk}

"I once had an old lady collapse during a walk. We were far into the bush and I was very worried because I didn't know what was wrong with her. I thought it was something to do with the heat. me and the other guests put her under a tree and fanned her to cool her down. After a long time, she got better and we were able to slowly walk back. Later I found out that she had some medical problems from before, but she didn't tell me. If I knew, would not have taken on such a long walk."

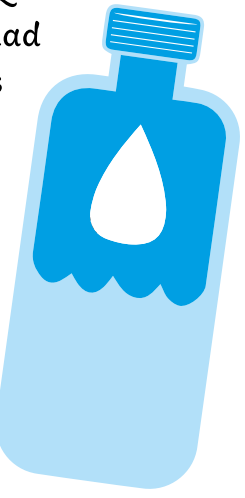


For a serious injury where the person's life is in danger, the evacuation must take place as soon as possible. For some injuries it might not be enough to bring the victim to the local hospital. They might need to be immediately evacuated to Honiara, or even overseas. This is when you need a manifest of participant's names, nationalities and passport numbers, because police and consular staff will get involved eventually. Evacuation by plane or helicopter is costly and usually only available on payment or guarantee of payment from an insurance company.

If the injured person requires helicopter evacuation, you need to provide the following details:

- Current location of casualty - name of location (and preferably GPS coordinates).

- Number of injured people - e.g., one adult male.

- Nature of injuries or symptoms - e.g., broken leg or severe fever and vomiting.

- Time of injury - when injury happened or illness was discovered.

- Action to be taken - group will carry injured person to evacuation point.

- Suggested evacuation point, and requested time of evacuation - name of location (and preferably GPS coordinates).

\section{- INCIDENT REPORT}

For any serious incident there will be a follow up. Your employer, the police, insurance companies and government tourism officials will want to know what happened. You should write down details of the incident, as soon as possible, while it's fresh in your memory. Tour companies use special forms for incidents and injuries. These are kept on file, because a legal claim for compensation can come long after the incident. Even for minor incidents, it's best to fill out an incident report, just in case. When writing the report make sure all the essential details (what, where, when, why, and how) are included.

- Date, time and location of the incident.

- People involved, including witnesses. Note full names and contact details (passport numbers and nationality for foreigners).

- Type of incident/injury. e.g., theft, sprained ankle, traffic accident.

- A detailed description of what happened.

- How was the incident managed - who got involved and who did what?

- Description of injuries or damages.

The incident report should be accurate and factual. Don't exaggerate or write anything that can't be supported by facts.

\section{Broken back}

"When I worked on a tourist ship, I saw several slips and falls. It can be dangerous because the boat moves a lot when the weather is rough, and there are a lot of old people onboard. Sometimes in the evening they have too much to drink as well. The worst thing that happened was one guy who fell down the stairs and broke his back. He had to be evacuated by helicopter."

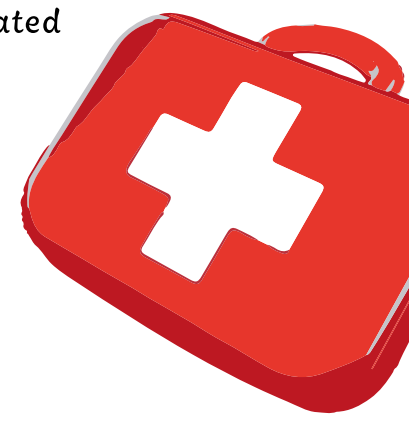


Congratulations on completing your tour guiding training. Once you start working as a guide, use this as a reference book. If you need to remind yourself of something you can go back to the relevant chapter and look for the information you need. This manual has outlined how to work as a guide and how to structure tours and activities. With this knowledge, you should develop your own style. It would be boring for tourists if all tours were similar and the guides more or less the same. Use your personality, your passion and strength to be unique. The tourists remember a good tour guide more than the actual tour.

While tourism numbers are low, tour guiding will be mainly a part-time job in Solomon Islands. But when tourist arrivals pickup there is a real chance that more local people can make a living from guiding, just like in other tourism destinations around the world.

As tourism increases there will be more job opportunities at new resorts, on liveaboard boats, yachts and cruise ships. In the future, there might be tour operators based in the provinces as well. We also don't know what kind of tourists will visit Solomon Islands in the future. There might be new activities developed. As a tour guide, you should keep an eye on new developments in tourism and try to adapt to the needs of the tourism sector.

Most tour guides in Solomon Islands start working out of tourist accommodation, or with a conservation project. But there are other possibilities for guide work. Guides working in Honiara usually work for an inbound tour operator. Other guides work as independent freelance guides. As a freelance guide you don't need to stick to one employer, you can work for whomever needs your services. This gives you more flexibility, but it also means you need to find your own work directly from tourists or by collaborating with accommodations and tour operators. It's a lot of work for new freelance guides, but if you establish a good reputation, it can be an interesting and well-paid job.

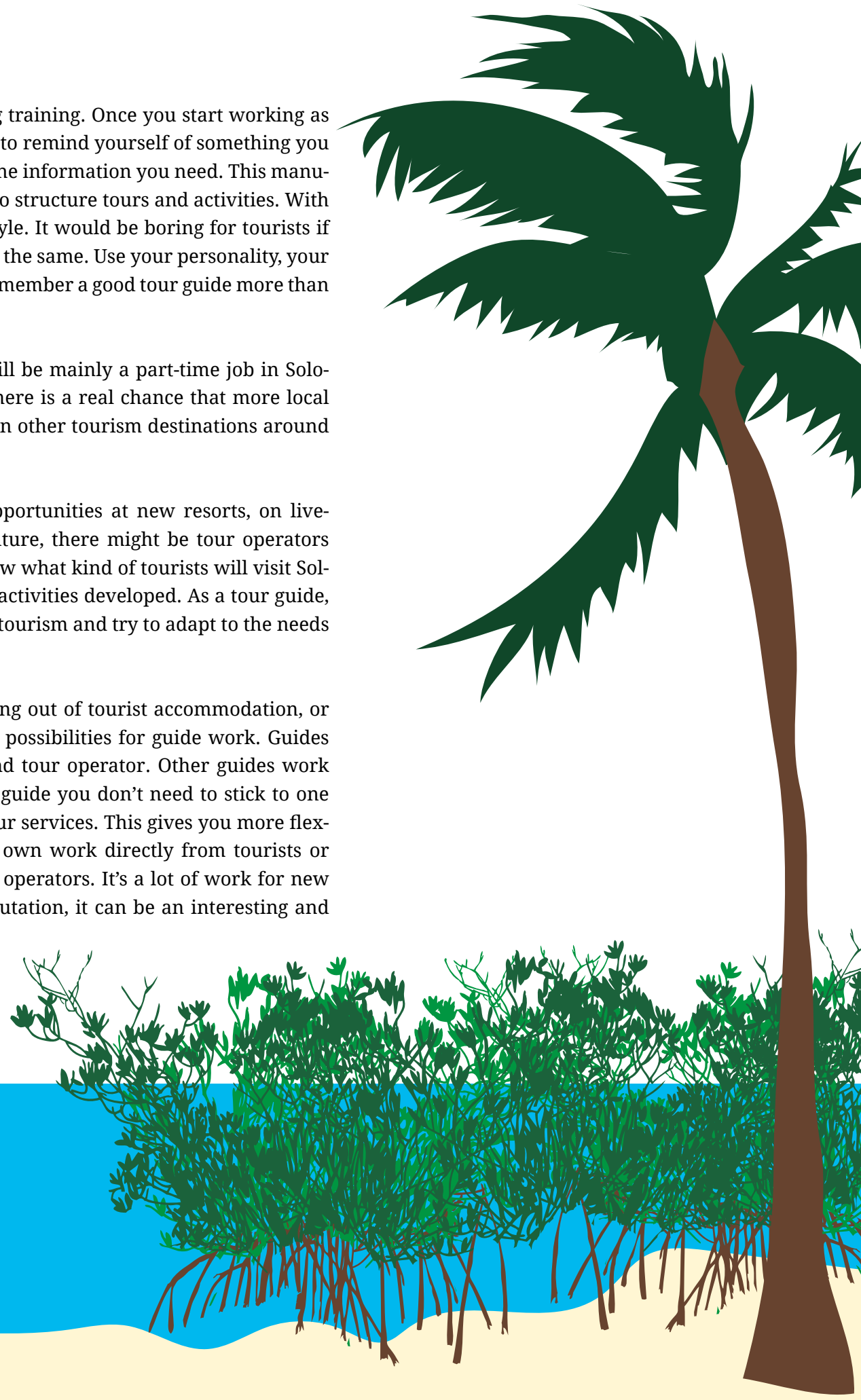




\section{Right attitude}

"If you want to be a tour guide, you need to have the right attitude and be willing to learn new things. Some things will be challenging in the beginning, but with each tour you gain more experience and confidence. To be a guide is a really interesting job!"
Word-of-mouth is an important promotional tool in Solomon Islands, especially for the domestic expatriate market. If you provide good services, local tourists will tell their friends which will lead to more work for you. Some guides create social media pages for their guiding activities. Keep it professional and don't mix up private posts with your tour guiding stories. Potential tourists should also be able to contact you, and get a reply back within a reasonable time. Keep your phone charged, credits topped up and check your messages daily. Many local guides miss out on jobs because they are not contactable.

Record your guiding experiences in a logbook. This is useful when applying for guide work. A guide logbook should record tour, activity, number of participants and nationality. In the future if a national tour guide registration is introduced you can use your logbook to obtain your professional tour guiding licence.

If you offer the same tour over and over again it becomes a routine. Guests notice if you are becoming complacent. Always strive to improve your tours and think of new ways to make them more interesting. What is a good tour? Simply put, it's when the tourists come back from the tour happy, having enjoyed themselves and experienced something new and interesting. If they also consider their money well spent and would recommend your tours to others, you have done a great job. Always strive to make every tour as good as it can be. Your effort is an important part of the success of the tourism in this country. Tour guides serve on the front-line of tourism and act as ambassadors of Solomon Islands. Hopefully you will become one of them.

Good luck on your future guiding career!
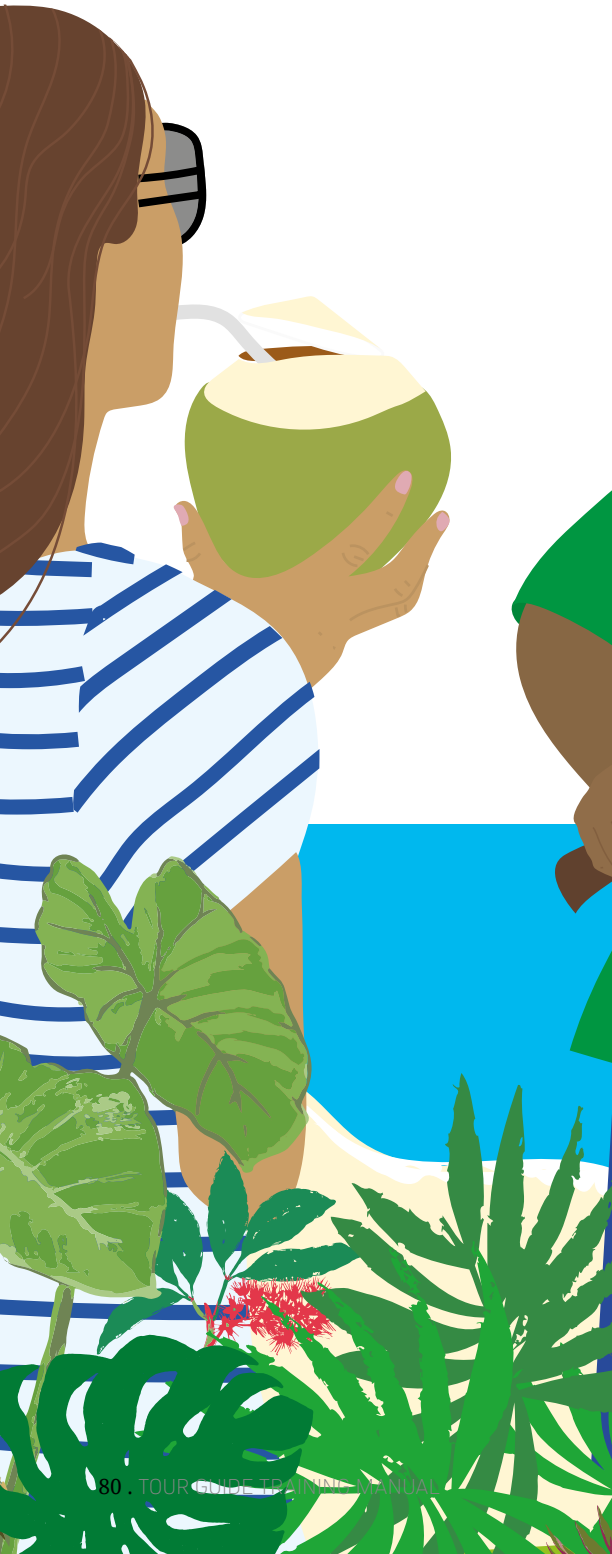

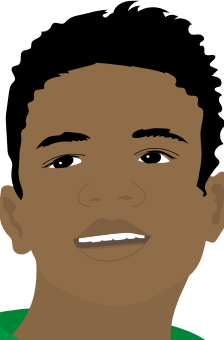

.

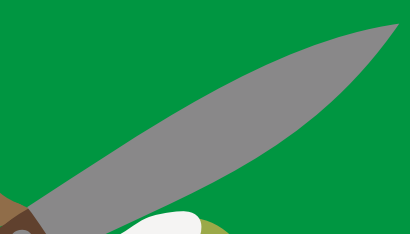

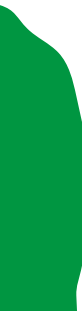




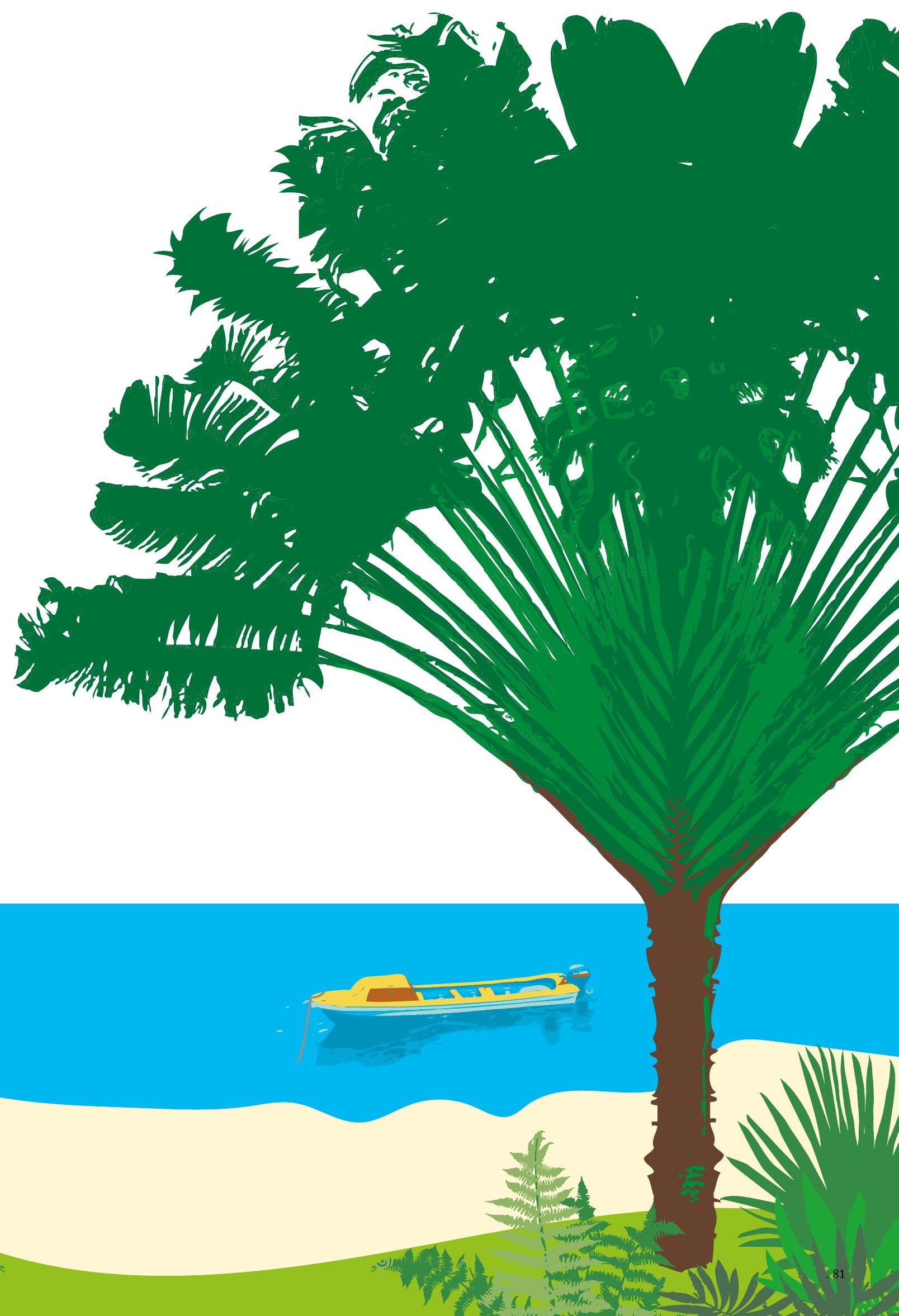


$x+4$

$+\quad 1 \quad 4 \quad 4 \quad+3$

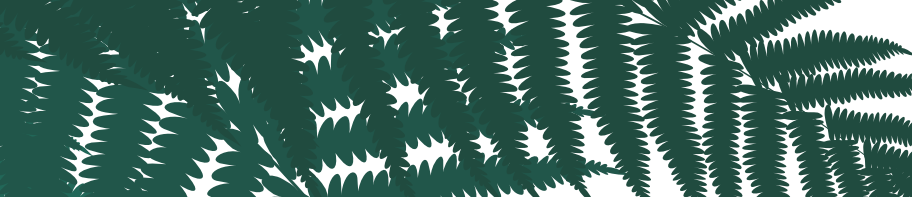

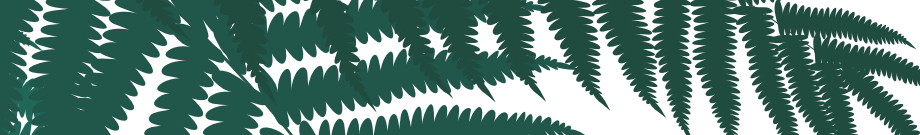

* *

$y$,

(y) Hommmina

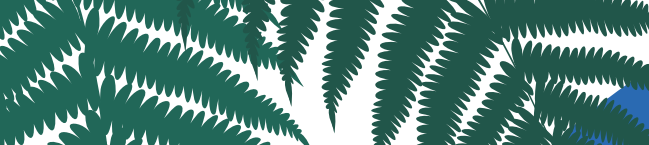
年 $\frac{4}{4}$ Appendix 


\section{- CODE OF PRACTICE FOR THE TOURISM SECTOR IN SOLOMON}

ISLANDS (MCT 2018)

- Provide consistent and efficient services to every guest.

- Be honest and fair with guests at all times.

- Marketing materials should be accurate and truthful about prices and services provided.

- Complaints are dealt with courteously and issues are attended to promptly.

- Staff are treated fairly and given proper training and instruction in their area of work.

- Support free and fair competition and promote cooperation within the tourism sector.

- The business and its staff comply with all local laws and regulations.

- High standards of cleanliness and hygiene are observed in all aspects of the business.

- Maintain facilities, equipment and transport used by guest to the highest standards.

- Care is taken in the operation and maintenance of facilities to ensure a safe environment for guests and staff.

- Staff and management are trained and equipped to deal with potential emergencies.

- Appropriate security is provided for customers and their possessions, including secure accommodation and storage.

- Tourism activities must not harm the environment or wildlife of Solomon Islands.

- Tourism businesses are respectful of local cultural protocol and where necessary tourists are informed about local customs.

- Efforts are made to increase the efficiency of resource and utility usage.

- Care is taken to reduce waste to a minimum, and dispose of it responsibly.

The Code of Practice for the Tourism sector in Solomon Islands is an adaptation of a version developed by the South Pacific Tourism Organisation. 


\section{TOUR AND ACTIVITY PLANNER}

Copy this format when planning your own tours and activities

\begin{tabular}{|l|l|}
\hline TITLE: Name of the tour/activity & $\begin{array}{l}\text { TYPE: What kind of tour/activity is it (e.g., cultural tour, bush } \\
\text { walk)? }\end{array}$ \\
\hline TOPIC: What is the tour/activity about?
\end{tabular}

TOPIC: What is the tour/activity about?

THEME/MESSAGE: What do you want participants to remember/understand?

PARTICIPANTS: Who is this tour aimed at? Is there a maximum number or any particular requirements for joining?

LOCATION(S): Describe ideal, or specific places to conduct this tour/activity.

OBJECTIVES: What do you want to achieve with this activity?

TIME LENGTH: How long will the tour/activity take?

TIME OF DAY: Is there an ideal time of day for this tour/activity?

RESEARCH: Do you need to research or learn anything before the

PREPARATIONS: Do you need to prepare anything before the tour tour? Sources?

(e.g., access to sites)?

TOUR COMMENTARY: Plan what stories you will talk about: including contact, main body and conclusion. Also think of what stories and anecdotes to include.

PROPS: Will you use any visual aids?

SENSES ENGAGED: Think of ways to engage all five senses.

DEMONSTRATIONS: Will you or anyone else demonstrate something?

EQUIPMENT: What equipment do you need to bring?

PARTICIPANTS PREP: What do the participants need to bring?

TRANSPORT: Will you need any transport during, before or after this tour/activity?

ITINERARY: Write a detailed itinerary for this tour/activity.

RISK MANAGEMENT: What are the main hazards of this tour/activity? How do you plan to avoid them and what is your plan if something goes wrong?

COSTS: What are the costs of this tour/activity?

PRICE: How much do you plan to charge the tourists?

PROMOTION: How will you promote this tour? Write a short promotional paragraph that describes the tour/activity 


\section{RESOURCES FOR TOUR GUIDE SUBJECT KNOWLEDGE}

\section{- ENVIRONMENT \& SPECIES IDENTIFICATION:}

- Birds of Melanesia; Bismarck's, Solomons, Vanuatu and New Caledonia. Guy Dutson, 2012.

- Reef Fish Identification: Tropical Pacific. Gerald R, Roger C Steene, Paul Humann, Ned DeLoach, 2015.

- Reptiles of the Solomon Islands. Michael McCoy, 2006.

- Butterflies of the Solomon Islands Systematics and Biogeography. John Tennent, 2002.

- World of Water Wildlife Guide: Solomon Islands. Neville Coleman, 2005.

- Shore to shore: wildlife and landscapes of Solomon Islands. Patrick Pikacha, 2018.

\section{- ART \& CULTURE:}

- Varilaku: Pacific Arts from the Solomon Islands. Crispin Howarth, 2011.

- Handcrafts of the Solomon Islands. Robert Austin, 2011.

- The Things We Value: Culture and History in Solomon Islands. Ben Hurt and Lissant Bolton, 2014.

\section{- HISTORY:}

- The Discovery of the Solomon Islands by Alvaro de Mendana in 1568. Basil Thomson \& Hernan Gallegos Lamero, 2014.

- The Naturalist and his 'Beautiful Islands': Charles Morris Woodford in the Western Pacific. David Russell Lawrence, 2014.

- Wealth of the Solomons: a history of a Pacific archipelago, 1800-1978. Judith A. Bennett, 1987.

\section{- WWII:}

- Islands of Destiny: The Solomons Campaign and the Eclipse of the Rising Sun. John Prados, 2012.

- The Solomons Campaigns, 1942-1943: From Guadalcanal to Bougainville, Pacific War Turning Point. William L. McGee, 2002.

- Into the Shadows Furious: the brutal battle for New Georgia. Brian Altobello, 2000.

- Solomon Islanders in World War II: An Indigenous Perspective. Anna Annie Kwai, 2017.

- Lonely Vigil: Coast Watchers of the Solomons. Walter Lord, 2012.

\section{- SOURCES}

This training manual is based on established guide training overseas, primarily competency units included in the Australian Certificate III in Guiding, which is a nationally recognised qualification. Many other organisations have also developed excellent guide training materials that were used as inspiration during the development of this manual:

- Tourist Guiding techniques (PNG). Papua New Guinea Tourism Promotion Authority, 2009.

- Practical Advice for New Tourist Guides (Uganda). Johnnie Kamugisha and Alfred Twinomujuni for the International Institute of For Environment and Development, 2019.

- Tetepare Island Tour Guide Manual (Solomon Islands). Katherine Moseby and John Read for Tetepare Descendants Association, 2012.

- Eco guide Australia Certified Guide Workbook (Australia). John Pastorelli and Stephen Pahl for Ecotourism Australia, 2007.

- National Tour guide Training Program Manual (Belize). Belize Tourism Board, 2007.

- Towards professionalism in Tour Guiding; a manual for trainers (Nicaragua). Thomas W. O’Brein and Sam H. Ham for United States Agency for International Development, 2012.

- Best Recipes for Interpreting our heritage; activities for eco tour guides and others (Australia). Gil Field for Department of Conservation and Land Management, Western Australia, 1998.

- Trekking Guide Handbook (Nepal). Usha Bandari for The Great Himalayan Trail Project, 2010.

- Tour Guide Training: Trainer Manual (Laos). Swiss contact, 2015. 



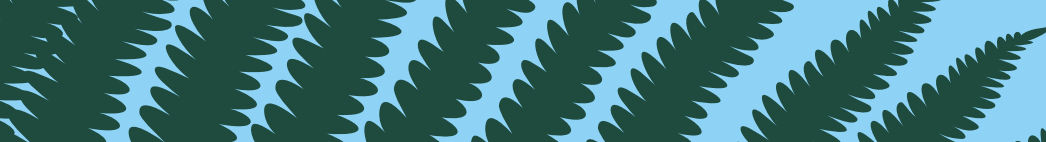

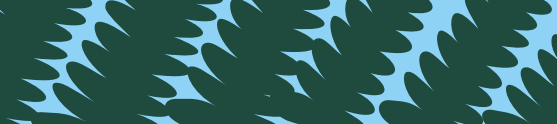

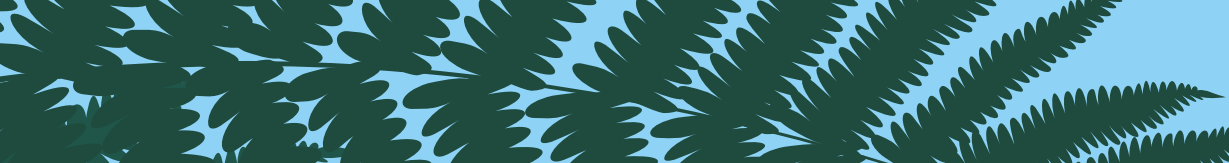

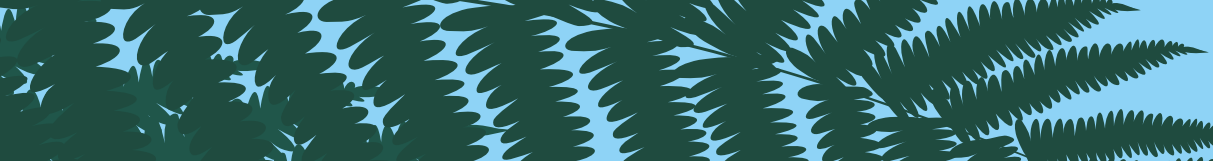

i. $\rightarrow$ ir 3 ह

1)

2
3
3

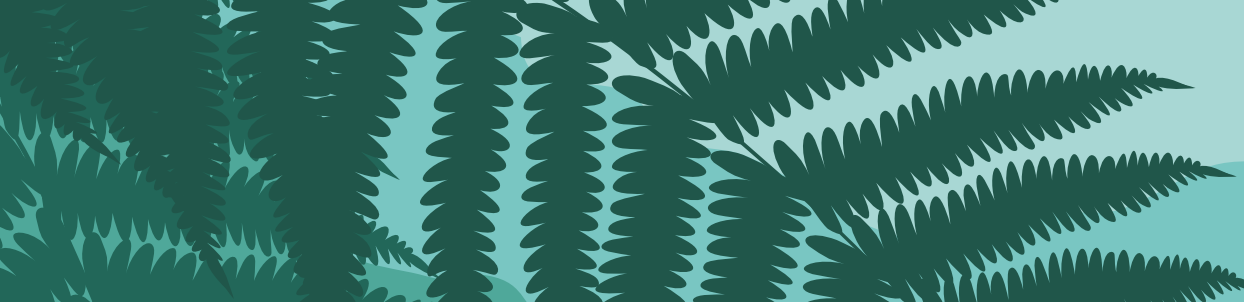

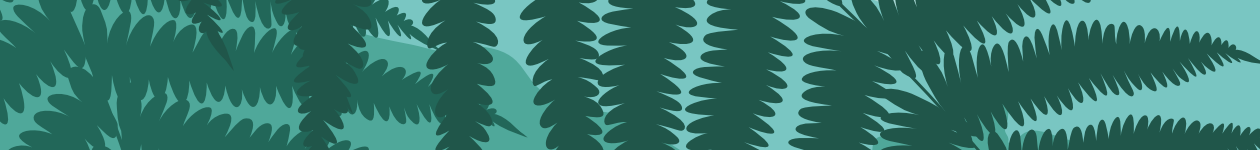
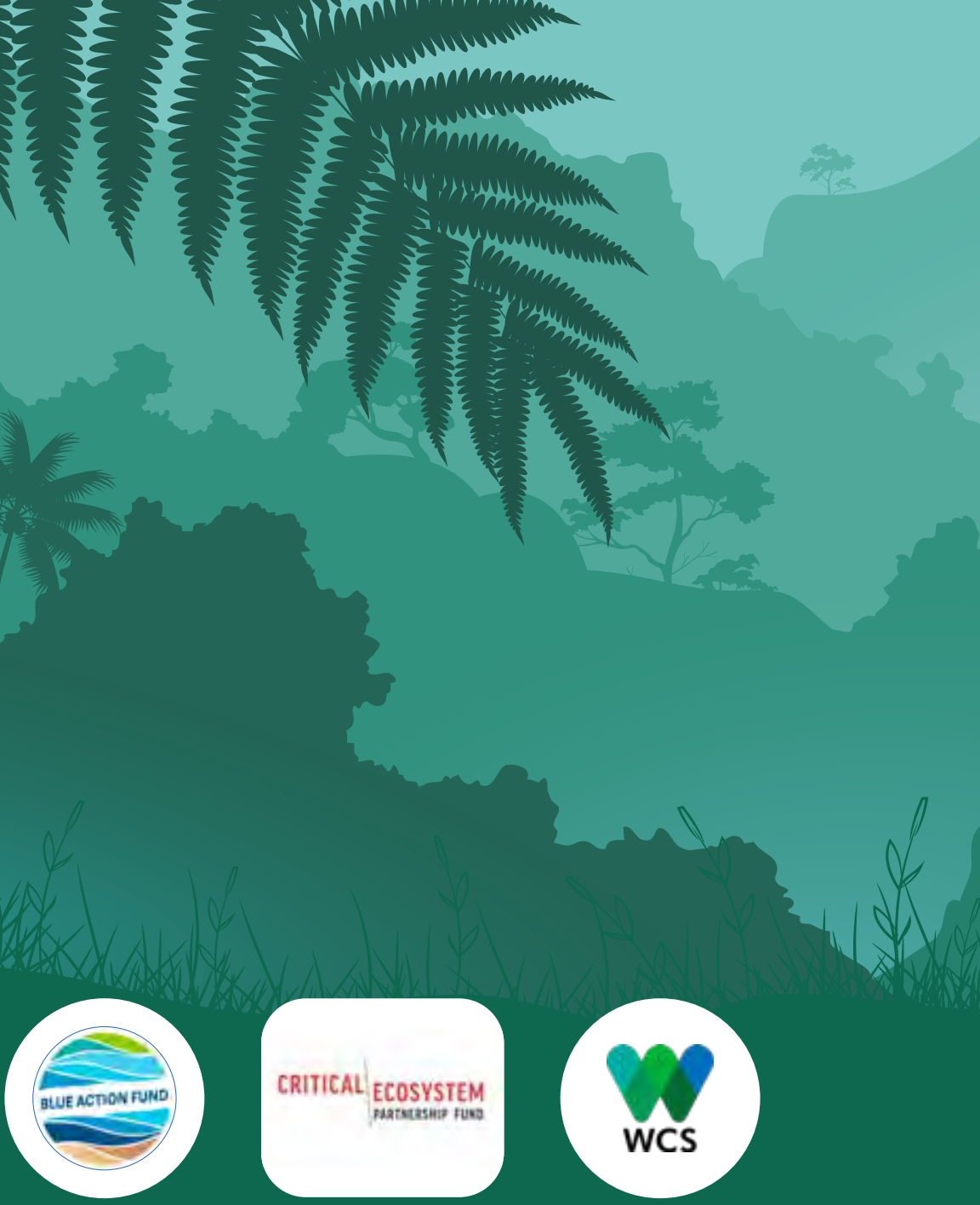

CRITICAL ECOSYSTEM

parascasiag fues

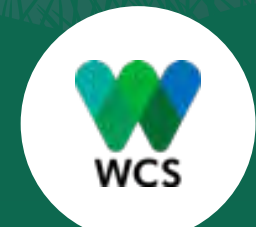

